\title{
A condition-based maintenance model for a single component in a system with scheduled and unscheduled downs
}

\section{Citation for published version (APA):}

Zhu, Q., Peng, H., Timmermans, B. L. R., \& van Houtum, G. J. J. A. N. (2016). A condition-based maintenance model for a single component in a system with scheduled and unscheduled downs. (BETA publicatie : working papers; Vol. 499). Technische Universiteit Eindhoven.

Document status and date:

Published: 01/04/2016

\section{Document Version:}

Publisher's PDF, also known as Version of Record (includes final page, issue and volume numbers)

\section{Please check the document version of this publication:}

- A submitted manuscript is the version of the article upon submission and before peer-review. There can be important differences between the submitted version and the official published version of record. People interested in the research are advised to contact the author for the final version of the publication, or visit the $\mathrm{DOI}$ to the publisher's website.

- The final author version and the galley proof are versions of the publication after peer review.

- The final published version features the final layout of the paper including the volume, issue and page numbers.

Link to publication

\section{General rights}

Copyright and moral rights for the publications made accessible in the public portal are retained by the authors and/or other copyright owners and it is a condition of accessing publications that users recognise and abide by the legal requirements associated with these rights.

- Users may download and print one copy of any publication from the public portal for the purpose of private study or research.

- You may not further distribute the material or use it for any profit-making activity or commercial gain

- You may freely distribute the URL identifying the publication in the public portal.

If the publication is distributed under the terms of Article 25fa of the Dutch Copyright Act, indicated by the "Taverne" license above, please follow below link for the End User Agreement:

www.tue.nl/taverne

Take down policy

If you believe that this document breaches copyright please contact us at:

openaccess@tue.nl

providing details and we will investigate your claim. 


\section{Beta}

Research School for Operations

Management and Logistics

A Condition-Based Maintenance Model for a Single Component in a System with Scheduled and Unscheduled Downs

Qiushi Zhu, Hao Peng, Bas Timmermans, and Geert-Jan van Houtum

Beta Working Paper series 499

\begin{tabular}{|rl|}
\hline BETA publicatie & WP 499 (working \\
paper) \\
ISBN & \\
ISSN & \\
NUR & 804 \\
Eindhoven & March 2016 \\
\hline
\end{tabular}




\title{
A Condition-Based Maintenance Model for a Single Component in a System with Scheduled and Unscheduled Downs
}

\author{
Qiushi Zhu ${ }^{a, b}$, Hao Peng ${ }^{c}$, Bas Timmermans ${ }^{d}$, and Geert-Jan van Houtum ${ }^{a, *}$ \\ ${ }^{a}$ School of Industrial Engineering, Eindhoven University of Technology, Eindhoven, The Netherlands \\ ${ }^{b}$ Vanderlande Industries, Veghel, The Netherlands \\ ${ }^{c}$ Academy of Mathematics and Systems Science, Chinese Academy of Sciences, Beijing, China \\ ${ }^{d}$ Gordian Logistic Experts, Maarssen, The Netherlands
}

March 28, 2016

\begin{abstract}
We introduce a maintenance model for a single component that is part of a complex engineering system and has a monotic, stochastic degradation process. For this component, a hard failure level is given and we use a condition-based maintenance (CBM) policy. The other components in the system are assumed to follow failure-based and periodic maintenance policies and their maintenance actions lead to unscheduled and scheduled downs of the system. These downs constitute opportunities for the single CBM component. If the degradation is at or above a control limit at an unscheduled or scheduled down, the component is replaced preventively and one saves on downtime and setup costs. We derive an efficient and accurate approximate evaluation procedure. Further, we show that this approximate evaluation leads to a close-to-optimal control limit policy when used within the optimization procedure and we show the potential savings when both unscheduled and scheduled downs are used as opportunities for the CBM component. Finally, we demonstrate that our model can be well used as a building block to solve multi-component CBM problems with many components.
\end{abstract}

Key words: Condition-based maintenance, complex systems, opportunistic maintenance, scheduled downs, unscheduled downs

\section{Introduction}

Nowadays, the development of advanced sensor and ICT technology makes the remote acquisition of condition monitoring data (e.g., temperature of an engine, wearing of a brake) less costly. Based on the condition of a component/system, one can improve the diagnostics and prognostics of failures in order to reduce the maintenance related costs (e.g., downtime costs, set-up costs), which is the main idea behind condition-based maintenance (CBM); see Jardine et al. [13] and Peng et al. [24]. Considerable attention from researchers has been attracted to study CBM for complex engineering systems. These occur in many industries (aviation, oilgas refinery, energy, automotive, semiconductor industry, and so on). It is usually not feasible to implement

${ }^{*}$ Corresponding author: P.O. Box 513, 5600 MB, Eindhoven, The Netherlands, T: +31 534895163 , Email: g.j.v.houtum@tue.nl; Other email addresses: q.zhu@tue.nl, penghao@amss.ac.cn, b.timmermans@gordian.nl 
CBM for all components in a complex engineering system. Instead, there may be only a limited number of critical components that is under continuous condition monitoring. For the rest of the components, corrective maintenance and periodic preventive maintenance policies may be in place (see also [1], Section 2.2.1). Hence, it is a challenging problem to coordinate the maintenance actions of the different policies for the various components in a complex system.

The existing studies about CBM for multi-component systems often focus on proposing models to coordinate the maintenance activities among the components under a CBM policy. Relatively speaking, little research about CBM has been done to coordinate the maintenance activities of a mixture of different maintenance policies.

In this paper, we introduce a CBM model for a single component that is part of a complex system. The component follows a monotonic, stochastic degradation process, which is monitored continuously and has a pre-set, hard failure level (in calculations, we assume a random coefficient model and a Gamma process for the degradation process). Maintenance for this component can be initiated at any moment, but if it is executed at a moment that one has already another maintenance action for another component, then one saves downtime costs of the complex system and maintenance setup costs. The setup costs occur because an engineer has to go to the system or because the system has to go to a maintenance location. The downtime costs occur because complex engineering systems are generally used in primary processes of their users and those processes are stopped/disturbed when the complex system is down. These downtime costs are very high in many cases. We assume that the other components are subject to failure-based policies or to periodic maintenance policies (inspections, cleaning, lubrication). This leads to unscheduled downs and scheduled downs, respectively, for the complex system. The unscheduled downs follow a Poisson process and the scheduled downs occur according to a fixed maintenance interval. We analyse a control limit policy: If the degradation process is at or above the control limit at an unscheduled or a scheduled down, then a preventive maintenance action is executed. We derive an approximate evaluation procedure and optimize the control limit. We also show how our single-component model can be used for a multi-component CBM model.

The related literature consists of single-component and multi-component CBM models. Within the stream of single-component CBM models, there is literature in which the control limit and/or inspection interval is optimized, based on the stochastic degradation processes estimated from the condition monitoring data; see the reviews of Wang [33], Jardine et al. [13], and Peng et al. [24]. Wang [33] proposed a CBM model based on the general random coefficient model (cf. Lu and Meeker [19]) to determine the optimal control limit and the monitored interval in terms of cost, downtime and reliability. Gebraeel et al. [9, 10] extended the general degradation model to estimate the RUL distribution from sensor signals by a Wiener process and Bayesian updating. Using this technique, a single-unit replacement problem is formulated as a Markov decision process to develop a structured replacement policy in Elwany et al. [8]. There are also multiple models where a Gamma process is used for the degradation process. Dieulle et al. [7] and Park $[22,23]$ developed such models with a single-level control limit and Grall et al. [11] developed such a model with a multi-level control limit. Here, we distinguish scenarios with periodic inspection ([22]), aperiodic inspection $([7,11])$ and continuous monitoring $([17,23])$. The degradation process is also often modelled as a Markov process with discrete states. Optimal replacement policies were derived for observable Markov processes by Makis and Jiang [20] and Kharoufeh et al. [14] and from the evolution of the hidden states by Bunks et al. [4] and Lin and Makis [18]. Further, proportional hazards models are often used to relate the system's condition variables to the hazard function of a system, so that the maintenance policies can be 
optimized with respect to the optimal risk value of the hazard function; see Jardine et al. [12] and Vlok et al. [32]. Another type of model is the filtering model; see e.g. Wang et al. [34], who apply such a model to marine diesel engines. Motivated by the maintenance services practice at an OEM in the compressed air and generator industry, a recent contribution has been made by Poppe et al. [25]. They consider the same model as our model and look at the effect of using a second threshold level just below the hard failure level that initiates a maintenance action with a separate setup. This maintenance action is executed after a short preparation period. They show that the average cost can be reduced significantly if this extra type of maintenance action is much cheaper than the normal corrective maintenance action. Their calculations are based on a different approximate evaluation procedure and a different degradation process.

The stream of multi-component CBM models consists of only a limited number of papers. Bouvard et al. [3] converted a condition-based maintenance problem into a similar age-based maintenance clustering problem (cf. [36]), which yielded an optimal schedule with a dynamic maintenance interval. Wijnmalen and Hontelez [35] used a heuristic algorithm for computing control limits for components in systems under different discounted scenarios, which is formulated within a Markov decision framework. Castanier et al. [5] introduced a model to coordinate inspection/replacement of a two-component system via a Markov renewal process and minimize the long-run maintenance cost. However, this model becomes intractable when it would be extended to systems with many components. For systems with many components subject to soft failures, Zhu et al. [38] proposed a model with a control limit policy per component and a the joint maintenance interval of the system (in this system all maintenance actions are executed at the scheduled downs). Moreover, for larger scale problems, there is research based on Monte Carlo simulation and genetic algorithms; see Marseguerra et al. [21] and Barata et al. [2]. Alternatively, Tian et al. [28] proposed two maintenance policies for multi-component systems using the proportional hazard model, and Tian and Liao [29] propose the use of an artificial neural network. To compare age/time-based and condition-based maintenance policies, Koochaki et al. [15] evaluated the cost effectiveness of a three-component series system in the context of opportunistic maintenance via simulation. In their model, only unscheduled opportunities are considered, while our model includes both scheduled and unscheduled opportunities. De Jonge et al. [6] consider policies for a system with identical components for which the degradation is modelled by a so-called P-F curve.

The contribution of this paper is as follows. First, we introduce a new single-component CBM model with both scheduled and unscheduled opportunities for executing a maintenance action without separate downtime and setup costs. Second, we derive an efficient and accurate approximate evaluation procedure for a given control policy. Third, we show that the approximate evaluation can be well used to optimize the control limit, and we show the savings when both unscheduled and scheduled downs are used as opportunities by the CBM component. Fourth, we demonstrate that our model can be well used as a building block for multi-component CBM problems with many components. Hence, we also contribute to the literature in multi-component CBM models. For the use of our model as a building block for a multi-component system with a mix of condition-based, age-based, and failure-based components, we refer to [37].

The outline of this paper is as follows. The description of the system and the assumptions are given in Section 2. The approximate evaluation procedure is described in Section 3. In Section 4, we describe a case for lithography machines used within the semiconductor industry, and we apply our evaluation and optimization procedures. In Section 5, numerical experiments are performed to investigate the accuracy of our approximate evaluation and the optimization based on the approximate evaluation. Further, we show the potential savings that can be obtained by using both unscheduled and scheduled downs as opportunities 
for relatively cheap maintenance of the CBM component. Next, in Section 6, we demonstrate how our model can be used as a building block for large-scale, multi-component CBM problems. Finally, the conclusions are given in Section 7.

\section{System Description}

Consider a complex engineering system consisting of multiple components. One critical component is monitored continuously and maintained according to a condition-based maintenance policy. We call such a component a "CBM component". The degradation state of the CBM component $X(t)$ can be monitored continuously over time $t, t \in[0, \infty)$. We assume that the degradation process $X(t)$ is monotonic. When the degradation state $X(t)$ exceeds a predetermined warning limit $H$, the system operates under an unsatisfied condition. Hence, a maintenance action will be triggered immediately to restore the degradation level of the CBM component to its initial level. Such a system down due to the maintenance of the CBM component is called "CBMD" (a down due to the CBM component, see Figure 1). In this model, the warning limit $H$ is a given parameter from technical experts, who have the knowledge on the physics of failures.

Apart from this CBM component, all other components in the system are subject to either a failure-based or a periodic maintenance policy:

- Failure-based maintenance policy: For the components that are under a failure-based maintenance policy, the maintenance or replacement will be conducted immediately after the failure of the component. This will lead to unscheduled downs (USDs) of the system (see Figure 1). We assume that the interarrival times of the failures follow an exponential distribution with rate $\lambda$, so that the corrective maintenance actions cause USDs according to a homogeneous Poisson process. According to the Palm-Khintchine theorem (see e.g. [26]), even if the failure times of some components do not follow exponential distributions, the combination of a large amount of non-Poisson renewal processes will still have Poisson properties. Hence, this assumption about corrective maintenance is realistic if a failure-based maintenance policy is used for a sufficiently large amount of components in the system.

- Periodic maintenance policy: In many industries (aviation, oil-gas refinery, energy, automotive, semiconductor industry, and so on), periodic maintenance actions (inspection, cleaning, lubrication) for the system are taken every fixed interval (see e.g. [30]. This is a common practice because it facilitates the planning and coordination of maintenance resources (service engineers, maintenance equipments, spare parts) and users of complex engineering systems can take them into account in their production schedules. Let $\tau$ be the length of this fixed interval. When determining the fixed interval length, one can also take other factors than periodic maintenance into account, such as industrial regulations (e.g., a requirement that each system has to have an annual inspections like for cars in many countries) or commercial aspects (maintenance may be outsourced and the service company may want to show its presence sufficiently often). The periodic maintenance is planned and hence leads to scheduled downs (SDs) of the system (see Figure 1).

When a system down occurs (USD, SD, or CBMD), the system operation will be interrupted and it will cause high downtime costs for the system. Also, setup costs for maintenance will be incurred, either for sending a maintenance crew to the field or for bringing the system to a maintenance location. Downtime and setup costs for the multi-component system can be reduced by combining maintenance actions. In our model, we use the system downs caused by failure-based maintenance (at USDs) and periodic maintenance 


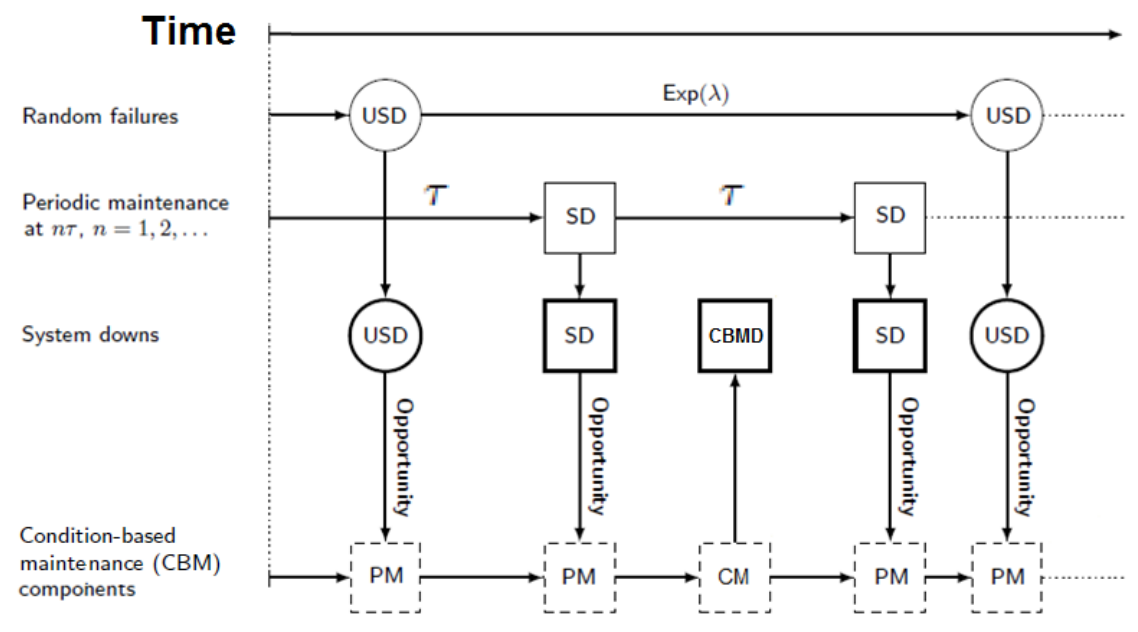

Figure 1: The maintenance policy of one CBM component

(at SDs) for other components as opportunities for the CBM component that we consider. We can do that by executing preventive maintenance before $X(t)$ reaches the warning limit $H$ (see Figure 2). Obviously, we then loose a fraction of the useful lifetime of the CBM component.

In this paper, we distinguish three types of maintenance actions for the CBM component:

1. Corrective Maintenance at a CBMD (CM): When the system stops due to a CBMD, namely, at a time point where $X(t)$ crosses $H$ (see Figure 2), a corrective maintenance (CM) action is taken with a cost $c^{C M}$, which includes the downtime and setup costs and the costs for replacing the failed CBM component by a spare part (which may be a new or a ready-for-use component).

2. Preventive Maintenance at an USD (PM-USD): When the system has an USD at a time instant $t$, it provides an opportunity for the CBM component to be maintained together with the component that failed and caused the USD. If the degradation $X(t)$ exceeds a control limit $C(X(t) \geq C$, see Figure 2), a preventive maintenance $(\mathrm{PM})$ action will be taken with a cost $c^{P M-U S D}$. This cost factor consists of the costs for replacing the CBM component by a spare part. In this case, no downtime and setup costs have to included. Hence, we assume that $c^{P M-U S D}<c^{C M}$ (and generally $c^{P M-U S D}$ will be much smaller than $\left.c^{C M}\right)$.

3. Preventive Maintenance at a SD (PM-SD): When the system has an SD at time $n \tau, n \in \mathbb{N}$, it provides an opportunity for the CBM component to be maintained together with the components for which periodic maintenance takes place at this SD. If the degradation $X(t)$ exceeds the control limit $C$ $\left(X(t) \geq C\right.$, see Figure 2), a preventive maintenance (PM) action will be taken with a cost $c^{P M-S D}$. As for the previous action, this cost factor consists of the costs for replacing the CBM component by a spare part, and no downtime and setup costs have to be included. Hence, we assume that $c^{P M-S D}<c^{C M}$. Further, we assume that the cost factors $c^{P M-S D}$ and $c^{P M-U S D}$ are almost equal. Under that assumption, it is reasonable to use the same control limit $C$. (In practice, it is possible that $c^{P M-S D}$ is somewhat smaller than $c^{P M-U S D}$ because a spare part for a replacement at a SD may be provided from a central warehouse instead of a local warehouse and thus one avoid the charged costs for keeping spare parts available in local warehouses at close distance of installed systems.)

The interval $\tau$ for periodic maintenance is in terms of weeks or months and is small in comparison to the 


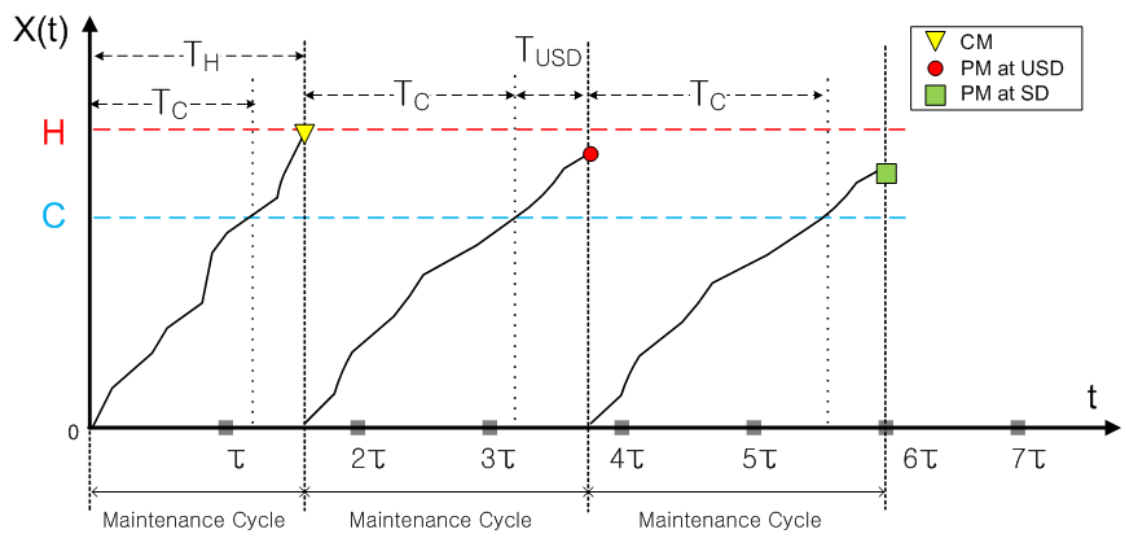

Figure 2: The degradation of the CBM component with three types of maintenance actions

long life cycles (10-40 years) of complex engineering systems. Hence, an infinite time horizon is assumed. Moreover, we assume that the CBM component is restored as good as new by any maintenance action (CM, PM-USD, or PM-SD), as shown in Figure 2.

The average costs per time unit under a given control limit are denoted by $Z(C)$. The objective is to minimize $Z(C)$ over all possible control limits $0<C \leq H$.

An exact evaluation of the average $\operatorname{costs} Z(C)$ can be done via simulation, and the optimization can be based on this evaluation by simulation. Because we have no proof that $Z(C)$ has a unique local minimum, we use enumeration for the optimization. However, simulation requires relatively large computation times. Hence, we develop an approximate evaluation procedure and that procedure can also be used within the optimization procedure.

\section{Approximate Evaluation}

The approximate evaluation starts with the definition of so-called maintenance cycles. We define a maintenance cycle as the time interval between two consecutive maintenance actions for the CBM component. We may distinguish two types of maintenance cycles. When the previous maintenance cycle ended with a PM-SD action, the next maintenance cycle starts at a SD. When the previous maintenance cycle ended with a CM or PM-USD action, the next maintenance cycle does not start at a SD. Hence, the time points at the beginning of the maintenance cycles do not constitute renewal points. Nevertheless, we pretend that these points are renewal points and we pretend that all cycles start at a SD. That are the only two approximate steps that we make. We denote the expected costs and the expected length per maintenance cycle by $K(C)$ and $L(C)$, respectively. By the renewal reward theorem, the average costs per time unit $Z(C)$ are equal to

$$
Z(C)=\frac{K(C)}{L(C)}
$$

Below, we derive formulas for $K(C)$ and $L(C)$. They both follow from the analysis of a single maintenance cycle.

For each maintenance cycle, we denote the time since the start of the cycle by $\hat{t}$, and we pretend that the start of the cycle coincides with a SD; see also Figure 3.

Let $X(\hat{t})$ denote the degradation of the CBM component at time $\hat{t} \in[0, \infty)$ in one given maintenance 


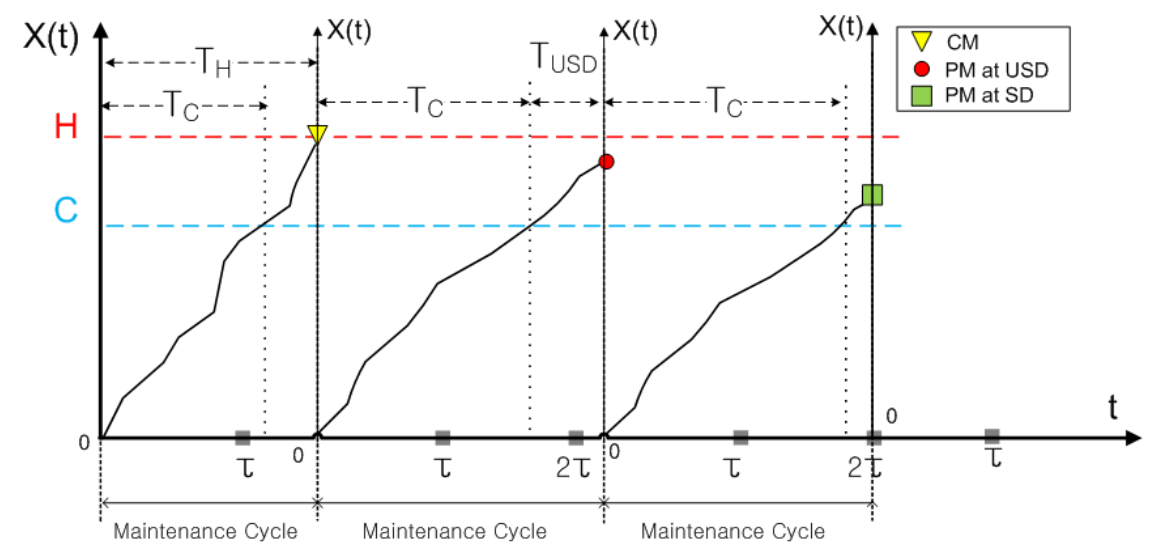

Figure 3: The degradation of the CBM component with three maintenance actions in renewal theory

cycle. Notice that the degradation process can be described by many different kinds of stochastic processes, e.g., a random coefficient model, a Gamma process, or a monotonic Markov Process. Because the degradation process is assumed to be monotonic, the probability that the degradation at time $\hat{t}$ exceeds a threshold $\chi$ is equal to the probability that the passage time $T_{\chi}$ of the threshold $\chi$ is less than time $\hat{t}$ :

$$
\operatorname{Pr}\left\{T_{\chi} \leq \hat{t}\right\}=\operatorname{Pr}\{X(\hat{t}) \geq \chi\} .
$$

Let $F_{T_{\chi}}(\hat{t})$ and $f_{T_{\chi}}(\hat{t})$ be the cumulative density function (c.d.f.) and the probability density function (p.d.f.) of the passage time $T_{\chi}$. Hence, the c.d.f. and p.d.f. of the passage time $T_{C}$ and $T_{H}$ can also be derived based on the degradation process $X(\hat{t})$. Because $X(\hat{t})$ will first cross the control limit $C$ before reaching $H$, it holds that $T_{C}<T_{H}$ in each maintenance cycle. The CBM component will be replaced preventively if there are opportunities between $T_{C}$ and $T_{H}$, and the first opportunity in the interval $\left[T_{C}, T_{H}\right)$ will be used. If no opportunity appears between $T_{C}$ and $T_{H}$, the CBM component will fail at time $T_{H}$ and then a CM action is executed.

To describe the possible events in a maintenance cycle, we distinguish two scenarios:

- Scenario 1: $(n-1) \tau \leq T_{C}<n \tau$ for some $n \in \mathbb{N}$ and $T_{H}<n \tau$

In this case, no SD occurs between $T_{C}$ and $T_{H}$. The first USD after $T_{C}$ will appear at $T_{C}+T_{U S D}$, where $T_{U S D}$ has an exponential distribution with rate $\lambda$. If $T_{C}+T_{U S D}<T_{H}$, then the maintenance cycle will end with a PM-USD action at time $T_{C}+T_{U S D}$. This happens with probability

$$
\int_{(n-1) \tau}^{n \tau} \int_{u}^{n \tau}\left(1-e^{-\lambda(v-u)}\right) f_{T_{H} \mid T_{C}}(v \mid u) d v f_{T_{C}}(u) d u
$$

where $f_{T_{H} \mid T_{C}}(v \mid u)$ is the p.d.f. of $T_{H}$ given that $T_{C}=u$. If $T_{C}+T_{U S D} \geq T_{H}$, then the maintenance cycle will end with a CM action at time $T_{H}$. This happens with probability

$$
\int_{(n-1) \tau}^{n \tau} \int_{u}^{n \tau} e^{-\lambda(v-u)} f_{T_{H} \mid T_{C}}(v \mid u) d v f_{T_{C}}(u) d u
$$

- Scenario 2: $(n-1) \tau \leq T_{C}<n \tau$ for some $n \in \mathbb{N}$ and $T_{H} \geq n \tau$

In this case, a SD occurs before $T_{H}$, and thus the maintenance cycle ends either with a PM-USD action or a PM-SD action. As in Scenario 1, The first USD after $T_{C}$ appears at $T_{C}+T_{U S D}$, where $T_{U S D}$ has 
an exponential distribution with rate $\lambda$. If $T_{C}+T_{U S D}<n \tau$, then the maintenance cycle will end with a PM-USD action at time $T_{C}+T_{U S D}$. This happens with probability

$$
\int_{(n-1) \tau}^{n \tau} \int_{n \tau}^{\infty}\left(1-e^{-\lambda(n \tau-u)}\right) f_{T_{H} \mid T_{C}}(v \mid u) d v f_{T_{C}}(u) d u
$$

If $T_{C}+T_{U S D} \geq n \tau$, a PM-SD action will be taken at time $n \tau$. This happens with a probability

$$
\int_{(n-1) \tau}^{n \tau} \int_{n \tau}^{\infty} e^{-\lambda(n \tau-u)} f_{T_{H} \mid T_{C}}(v \mid u) d v f_{T_{C}}(u) d u .
$$

Define $P_{1}, P_{2}$, and $P_{3}$ as the probabilities that a maintenance cycle ends with a PM-USD action, a PM-SD action, and a CM action, respectively. From the descriptions of the two scenarions, it follows that:

$$
\begin{aligned}
P_{1}= & \sum_{n=1}^{\infty}\left\{\int_{(n-1) \tau}^{n \tau} \int_{u}^{n \tau}\left(1-e^{-\lambda(v-u)}\right) f_{T_{H} \mid T_{C}}(v \mid u) d v f_{T_{C}}(u) d u\right. \\
& \left.\quad+\int_{(n-1) \tau}^{n \tau} \int_{n \tau}^{\infty}\left(1-e^{-\lambda(n \tau-u)}\right) f_{T_{H} \mid T_{C}}(v \mid u) d v f_{T_{C}}(u) d u\right\} \\
P_{2}= & \sum_{n=1}^{\infty} \int_{(n-1) \tau}^{n \tau} \int_{n \tau}^{\infty} e^{-\lambda(n \tau-u)} f_{T_{H} \mid T_{C}}(v \mid u) d v f_{T_{C}}(u) d u \\
P_{3}= & \sum_{n=1}^{\infty} \int_{(n-1) \tau}^{n \tau} \int_{u}^{n \tau} e^{-\lambda(v-u)} f_{T_{H} \mid T_{C}}(v \mid u) d v f_{T_{C}}(u) d u .
\end{aligned}
$$

This leads to the following formula for the expected costs $K(C)$ per maintenance cycle:

$$
K(C)=P_{1} c^{P M-U S D}+P_{2} c^{P M-S D}+P_{3} c^{C M} .
$$

From the above scenarios, we find the following formula for the expected length $L(C)$ of a maintenance cycle:

$$
\begin{aligned}
L(C)=\sum_{n=1}^{\infty}\{ & \int_{(n-1) \tau}^{n \tau} \int_{u}^{n \tau} \int_{0}^{v-u}(u+s) \lambda e^{-\lambda s} d s f_{T_{H} \mid T_{C}}(v \mid u) d v f_{T_{C}}(u) d u \\
& +\int_{(n-1) \tau}^{n \tau} \int_{u}^{n \tau} v e^{-\lambda(v-u)} f_{T_{H} \mid T_{C}}(v \mid u) d v f_{T_{C}}(u) d u \\
& +\int_{(n-1) \tau}^{n \tau} \int_{n \tau}^{\infty} \int_{0}^{n \tau-u}(u+s) \lambda e^{-\lambda s} d s f_{T_{H} \mid T_{C}}(v \mid u) d v f_{T_{C}}(u) d u \\
& \left.+\int_{(n-1) \tau}^{n \tau} \int_{n \tau}^{\infty} n \tau e^{-\lambda(n \tau-u)} f_{T_{H} \mid T_{C}}(v \mid u) d v f_{T_{C}}(u) d u\right\} \\
=\sum_{n=1}^{\infty} & \int_{(n-1) \tau}^{n \tau}\left\{\int_{u}^{n \tau}\left(\int_{0}^{v-u}(u+s) \lambda e^{-\lambda s} d s+v e^{-\lambda(v-u)}\right) f_{T_{H} \mid T_{C}}(v \mid u) d v\right. \\
& \left.+\int_{n \tau}^{\infty}\left(\int_{0}^{n \tau-u}(u+s) \lambda e^{-\lambda s} d s+n \tau e^{-\lambda(n \tau-u)}\right) f_{T_{H} \mid T_{C}}(v \mid u) d v\right\} f_{T_{C}}(u) d u
\end{aligned}
$$

Using integration by parts, we obtain

$$
\begin{aligned}
& \int_{0}^{v-u}(u+s) \lambda e^{-\lambda s} d s+v e^{-\lambda(v-u)}=u+\frac{1}{\lambda}\left(1-e^{-\lambda(v-u)}\right), \\
& \int_{0}^{n \tau-u}(u+s) \lambda e^{-\lambda s} d s+n \tau e^{-\lambda(n \tau-u)}=u+\frac{1}{\lambda}\left(1-e^{-\lambda(n \tau-u)}\right) .
\end{aligned}
$$


Hence, the formula $L(C)$ can be rewritten as

$$
\begin{aligned}
L(C)= & \sum_{n=1}^{\infty} \int_{(n-1) \tau}^{n \tau}\left\{\int_{u}^{n \tau}\left(u+\frac{1}{\lambda}\left(1-e^{-\lambda(v-u)}\right)\right) f_{T_{H} \mid T_{C}}(v \mid u) d v\right. \\
& \left.\quad+\int_{n \tau}^{\infty}\left(u+\frac{1}{\lambda}\left(1-e^{-\lambda(n \tau-u)}\right)\right) f_{T_{H} \mid T_{C}}(v \mid u) d v\right\} f_{T_{C}}(u) d u \\
= & \mathbb{E}\left\{T_{C}\right\}+\sum_{n=1}^{\infty} \int_{(n-1) \tau}^{n \tau}\left\{\int_{u}^{n \tau} \frac{1}{\lambda}\left(1-e^{-\lambda(v-u)}\right) f_{T_{H} \mid T_{C}}(v \mid u) d v\right. \\
& \left.+\frac{1}{\lambda}\left(1-e^{-\lambda(n \tau-u)}\right) \int_{n \tau}^{\infty} f_{T_{H} \mid T_{C}}(v \mid u) d v\right\} f_{T_{C}}(u) d u .
\end{aligned}
$$

The formulas (3)-(5) for $P_{1}, P_{2}, P_{3}$ and formula (7) for $L(C)$ can be evaluated numerically once explicit expressions are given for $f_{T_{C}}$ and $f_{T_{H} \mid T_{C}}(v \mid u)$; and $K(C)$ and $Z(C)$ are obtained by (6) and (1). Such explicit expressions are obtained when a specific degradation process is assumed; see Section 4 . The integrals in formulas (3)-(5) and (7) can be evaluated by numerical integration, and the infinite sums in these formulas require an appropriate truncation (notice that the probability $\operatorname{Pr}\left\{(n-1) \tau \leq T_{C}<n \tau\right\} \rightarrow 0$ for $n \rightarrow \infty$ and similarly for the $n$-th term in each of these infinite sums; this can be used for the truncation of these infinite sums).

\section{Case Study}

As a demonstration of our model, we provide a case of lithography machines used in the semiconductor industry. What we describe below is based on a study that we did at a manufacturer of lithography machines; see [30]. Because of their confidentiality, we are not allowed to give the real-life data for cost factors and parameters of degradation processes. Instead, we give modified data, which are still somewhat representative. More importantly, the description below shows how our model could be used in practice.

The lithography machines are complex engineering systems processing the pure-silicon-made wafers to semiconductor integrated circuits, also known as micro-chips. The laser unit in the machine is considered as one of the most important components, whose degradation is continuously monitored. The measurement of its physical condition is the output power in Watts. When the degradation of output power exceeds a certain limit, bad chips are produced and a maintenance action is needed. Considering the laser unit as the CBM component, the degradation of output power over time is obtained from the historical data of multiple laser units.

As mentioned in the literature review in Section 1, there are several approaches to model the stochastic degradation paths of a component. In this case, we model the degradation process $X(\hat{t})$ per maintenance cycle by the following two approaches: (i) the Random coefficient model (cf. [19]), because it is relatively flexible and convenient for describing the degradation paths derived from the physics of failures; (ii) the Gamma process (cf. [31]), which is a process that is often used in the literature.

Fitting Option 1 - Random coefficient model: $X(\hat{t} ; \Phi, \Theta)$ is a random variable with a given set of constant parameters $\Phi=\left\{\phi_{1}, \ldots, \phi_{Q}\right\}, Q \in \mathbb{N}_{0}$, and a set of random parameters, $\Theta=\left\{\theta_{1}, \ldots, \theta_{V}\right\}, V \in \mathbb{N}_{0}$, with given probability distributions. For example, based on the physics of failures, it may be known that the degradation behavior is described by a simple polynomial function: $X(\hat{t} ; \Phi, \Theta)=\phi_{1}+\theta_{1} \hat{t}^{\phi_{2}}$ (so, $\Phi=\left\{\phi_{1}, \phi_{2}\right\}$ and $\left.\Theta=\left\{\theta_{1}\right\}\right)$. For the laser unit, the behavior is well described by the following linear function: $X(\hat{t})=\theta_{1} \hat{t}$, 


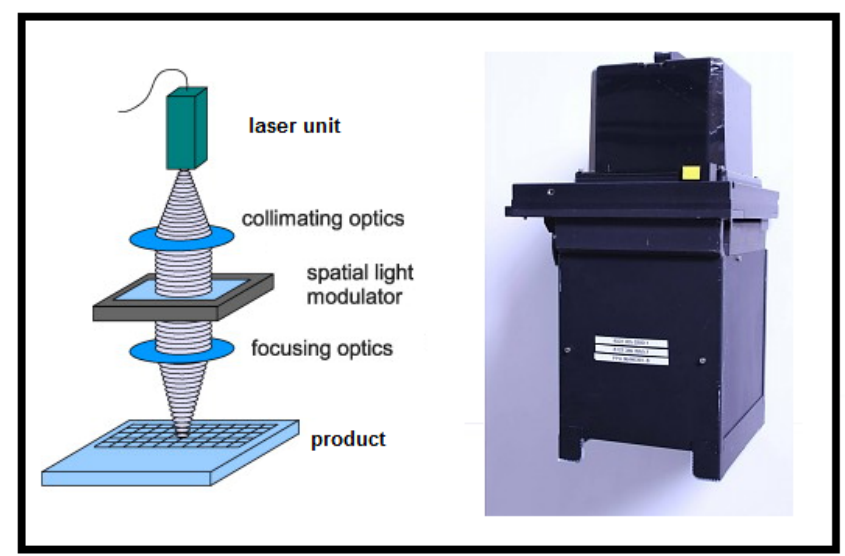

Laser unit

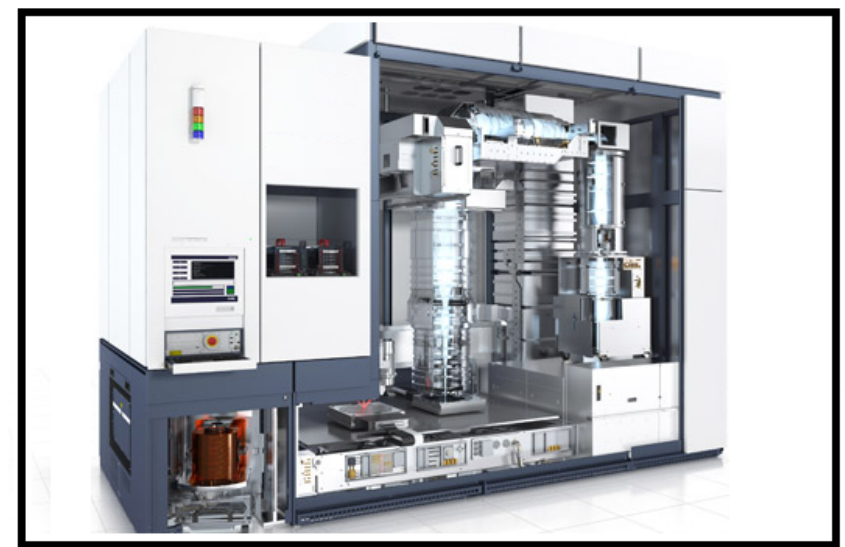

Lithography machine

Figure 4: A laser unit in a lithography machine

where $\theta_{1}$ is a random variable. Under this modelling, the speed of degradation is constant over time for each laser unit, but this speed varies for the various laser units in installed systems. Then equation (2) can be written in terms of $F_{\theta_{1}}$ (the c.d.f. of $\theta_{1} \geq 0$ ):

$$
\operatorname{Pr}\left\{T_{\chi} \leq \hat{t}\right\}=\operatorname{Pr}\left\{\theta_{1} \hat{t} \geq \chi\right\}=\operatorname{Pr}\left\{\theta_{1} \geq \frac{\chi}{\hat{t}}\right\}=1-F_{\theta_{1}}\left(\frac{\chi}{\hat{t}}\right) .
$$

The p.d.f. of the passage time $T_{\chi}$ is equal to $\left(\chi / \hat{t}^{2}\right) f_{\theta_{1}}(\chi / \hat{t})$, where $f_{\theta_{1}}$ is the p.d.f. of $\theta_{1}$. This expression can be further rewritten when a distribution is given for $\theta_{1}$. For the laser unit, it is reasonable to assume that $\theta_{1}$ follows a Weibull distribution with shape parameter $\beta$ and scale parameter $\alpha$. Then the p.d.f. of the passage time $T_{\chi}$ can be written as

$$
\begin{aligned}
f_{T_{\chi}}(\hat{t}) & =\frac{\chi}{\hat{t}^{2}} f_{\theta_{1}}(\chi / \hat{t})=\frac{\chi}{\hat{t}^{2}} \frac{\beta}{\alpha}\left(\frac{\chi}{\alpha \hat{t}}\right)^{\beta-1} \exp \left\{-\left(\frac{\chi}{\alpha \hat{t}}\right)^{\beta}\right\} \\
& =\frac{\beta \alpha}{\chi}\left(\frac{\chi}{\alpha \hat{t}}\right)^{\beta+1} \exp \left\{-\left(\frac{\chi}{\alpha \hat{t}}\right)^{\beta}\right\}, \hat{t}>0 .
\end{aligned}
$$

Taking $\chi=C$ in equation (9) gives the formula for the p.d.f. of $T_{C}, f_{T_{C}}$, which is needed in the formulas 
Table 1: Input parameters (because of confidentiality, these input parameters are modified data and not the real-life data)

\begin{tabular}{c|l}
\hline Parameter & Explanation \\
\hline$c^{P M-S D}=26.5$ & Costs of preventive maintenance at a scheduled down [thousand Euro] \\
$c^{P M-U S D}=28.8$ & Costs of preventive maintenance at an unscheduled downs [thousand Euro] \\
$c^{C M}=44.5$ & Costs of corrective maintenance [thousand Euro] \\
$\tau=91$ & Fixed time interval for the scheduled downs [day] \\
$\lambda=8.86 * 10^{-3}$ & Poisson arrival rate of unscheduled downs [per day] \\
$H=88$ & Failure threshold [Watt] \\
$\beta=3.73$ & Shape parameter of the Weibull distribution for $\theta_{1}$ under Fitting Option 1 \\
$\alpha=0.159$ & Scale parameter of the Weibull distribution for $\theta_{1}$ under Fitting Option 1 \\
$\gamma=0.221$ & Shape parameter of the Gamma process under Fitting Option 2 \\
$\eta=1.85$ & Scale parameter of the Gamma process under Fitting Option 2 \\
\hline
\end{tabular}

(3)-(5) and (7) to compute $P_{1}, P_{2}, P_{3}$ and $L(C)$. Because of the RCM that we assumed, the value of $T_{H}$ is directly coupled to the value of $T_{C}$. If $T_{C}=u$, then $T_{H}=(H / C) \cdot u$, i.e., $\left(T_{H} \mid T_{C}=u\right)$ is deterministic and this property can be used to first simplify the formulas for $P_{1}, P_{2}, P_{3}$ and $L(C)$ (see also [38], where this is shown for a different CBM model).

Fitting Option 2 - Gamma process: $X(\hat{t})$ is a Gamma process with shape parameter $\gamma$, scale parameter $\eta$, and initial degradation level 0 at $\hat{t}=0$. The random increments throughout the process are independently and identically distributed. This implies that the degradation increment $X\left(\hat{t}_{2}\right)-X\left(\hat{t}_{1}\right)$ between two time points $\hat{t}_{1}$ and $\hat{t}_{2}, 0 \leq \hat{t}_{1}<\hat{t}_{2}$, is Gamma distributed with shape parameter $\gamma\left(t_{2}-t_{1}\right)$ and scale parameter $\eta$ (the corresponding p.d.f. is $\eta^{\gamma\left(t_{2}-t_{1}\right)} x^{\gamma\left(t_{2}-t_{1}\right)-1} e^{-\eta x} / \Gamma\left(\gamma\left(t_{2}-t_{1}\right)\right)$ ), and this increment is independent of the degradation process until time point $\hat{t}_{1}$. Then, for each $\chi>0$, equation (2) can be rewritten as (use that $X(\hat{t})$ is Gamma distributed with shape parameter $\gamma \hat{t}$ and scale parameter $\eta)$ :

$$
\operatorname{Pr}\left\{T_{\chi} \leq \hat{t}\right\}=\operatorname{Pr}\{X(\hat{t}) \geq \chi\}=1-F_{X(\hat{t})}(\chi)=\frac{\Gamma(\gamma \hat{t}, \eta \chi)}{\Gamma(\gamma \hat{t})}, \hat{t}>0
$$

where

$$
\begin{aligned}
\Gamma(\gamma \hat{t}) & =\int_{0}^{\infty} y^{\gamma \hat{t}-1} e^{-y} d y \\
\Gamma(\gamma \hat{t}, \eta \chi) & =\int_{\eta \chi}^{\infty} y^{\gamma \hat{t}-1} e^{-y} d y
\end{aligned}
$$

(see also [27]).

The degradation parameters (i.e., $\alpha, \beta, \gamma$ and $\eta$ ) can be estimated from real-life data. For this estimation, one can follow the standard methods in the literature (see [27]). In Table 1, we give modified input data for the laser units (as stated above, because of their confidentiality, we are not allowed to give the real-life data). We apply both the random coefficient model (Fitting Option 1) and the Gamma process (Fitting Option 2) for the degradation process.

The optimal control limit $C^{*}$ in terms of a percentage of $H$ can be found by minimizing the average costs $Z(C)$ via enumeration, where the evaluations are done via the approximate evaluation procedure of Section 3. As a comparison, we also simulate the average costs $\hat{Z}\left(C^{*}\right)$ under control limit $C^{*}$ (see Appendix A for a description of the simulation procedure). Figure 5 shows the behavior of the average costs $Z(C)$ as a function of the control limit $C$ (as percentage of $H$ ) for both degradation processes. In this figure, we also 

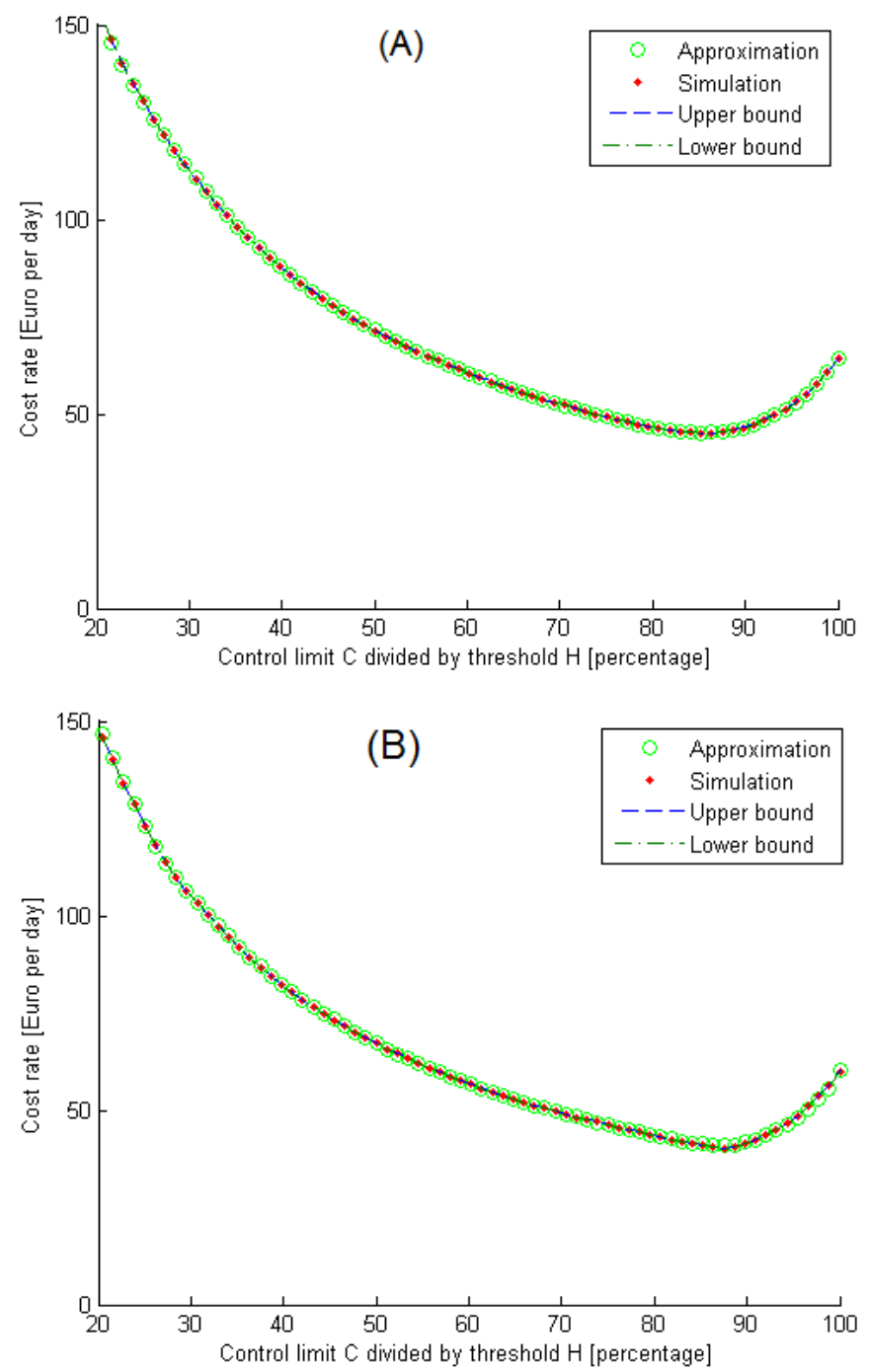

Figure 5: Average cost rate [Euro per day] as a function of the control limit $C$ (denoted as percentage of $H$ ) for two fitting options: (A) the random coefficient model; (B) the Gamma process

give the simulated costs, together with the lower bound and upper bound of the $95 \%$ confidence interval. We can observe that the approximate costs are within the confidence intervals for all values of the control limit $C$.

The most important numerical results are also given in Table 2. Under the use of the random coefficient model, the optimal maintenance policy obtained via the approximate evaluation has a control limit that is $85.71 \%$ of the threshold $\left(C^{*} / H=85.71 \%\right)$ and a minimum cost rate of 45.09 Euro per day (see also Figure 5-A). In the case of the Gamma process, the optimal maintenance policy obtained via the approximate evaluation has a control limit that is $87.18 \%$ of $H$ with a minimum cost rate around 40.99 Euro per day (see also Figure 5-B).

To further investigate the differences between our approximate results and the simulation results, Table 2 shows: (i) the results obtained via the approximate evaluation, being $C^{*}$, its minimum cost rate $Z\left(C^{*}\right)$, its probabilities $P_{1}, P_{2}, P_{3}$, and its expected cycle length $L\left(C^{*}\right)$; (ii) the simulation results under the optimal control limit $C^{*}$ obtained via approximate evaluation, where $\hat{Z}\left(C^{*}\right)$ denotes the simulated average costs, 
Table 2: The optimal maintenance policies under the parameter setting given in Table 1 Fitting Option 1: the random coefficient model (RCM)

\begin{tabular}{|c|c|}
\hline Approximation Result & Simulation Result 1 \\
\hline$Z\left(C^{*}\right)=45.09$ [Euro per day] & $\hat{Z}\left(C^{*}\right)=45.16 \pm 0.024$ [Euro per day] \\
$C^{*} / H=85.71 \%$ & $C^{*} / H=85.71 \%$ \\
$\left\{P_{1}, P_{2}, P_{3}\right\}=\{0.3075,0.6350,0.0576\}$ & $\left\{\hat{P}_{1}, \hat{P}_{2}, \hat{P}_{3}\right\}=\{0.3062,0.6333,0.0605\}$ \\
$L\left(C^{*}\right)=627.4$ [day] & $\hat{L}\left(C^{*}\right)=627.6$ [day] \\
\hline Simulation Result 2 & \\
\hline$\hat{Z}\left(\hat{C}^{*}\right)=45.14 \pm 0.021$ [Euro per day] & Gap $1:\left|\frac{\left(\hat{Z}\left(C^{*}\right)-Z\left(C^{*}\right)\right)}{\hat{Z}\left(C^{*}\right)}\right|=0.16 \%$ \\
$\hat{C}^{*} / H=85.23 \%$ & Gap $2:\left|\frac{\left(\hat{Z}\left(\hat{C}^{*}\right)-\hat{Z}\left(C^{*}\right)\right)}{\hat{Z}\left(\hat{C}^{*}\right)}\right|=0.04 \%$ \\
$\left\{\hat{P}_{1}, \hat{P}_{2}, \hat{P}_{3}\right\}=\{0.3086,0.6412,0.0502\}$ & \\
$\hat{L}\left(\hat{C}^{*}\right)=623.8$ [day] & \\
\hline
\end{tabular}

Fitting Option 2: the Gamma process (GP)

\begin{tabular}{|c|c|}
\hline Approximation Result & Simulation Result 1 \\
\hline$Z\left(C^{*}\right)=40.99$ [Euro per day] & $\hat{Z}\left(C^{*}\right)=41.01 \pm 0.051$ [Euro per day] \\
$C^{*} / H=87.18 \%$ & $C^{*} / H=87.18 \%$ \\
$\left\{P_{1}, P_{2}, P_{3}\right\}=\{0.3102,0.6563,0.0335\}$ & $\left\{\hat{P}_{1}, \hat{P}_{2}, \hat{P}_{3}\right\}=\{0.3096,0.6512,0.0392\}$ \\
$L\left(C^{*}\right)=679.76$ [day] & $\hat{L}\left(C^{*}\right)=681.98$ [day] \\
\hline Simulation Result 2 & \\
\hline$\hat{Z}\left(\hat{C}^{*}\right)=40.57 \pm 0.038$ [Euro per day] & Gap $1:\left|\frac{\left(\hat{Z}\left(C^{*}\right)-Z\left(C^{*}\right)\right)}{\hat{Z}\left(C^{*}\right)}\right|=0.05 \%$ \\
$\hat{C}^{*} / H=85.75 \%$ & Gap $2:\left|\frac{\left(\hat{Z}\left(\hat{C}^{*}\right)-\hat{Z}\left(C^{*}\right)\right)}{\hat{Z}\left(\hat{C}^{*}\right)}\right|=1.06 \%$ \\
$\left\{\hat{P}_{1}, \hat{P}_{2}, \hat{P}_{3}\right\}=\{0.3122,0.6635,0.0243\}$ & \\
$\hat{L}\left(\hat{C}^{*}\right)=682.79$ [day] & \\
\hline
\end{tabular}

$\hat{P}_{1}, \hat{P}_{2}, \hat{P}_{3}$ denote the simulated probabilities for the three maintenance actions at the end of a maintenance cycle, and $\hat{L}\left(C^{*}\right)$ denotes the simulated mean cycle length; (iii) the optimal control limit $\hat{C}^{*}$ obtained via simulation-based optimization with its minimum cost rate $\hat{Z}\left(\hat{C}^{*}\right)$, its probabilities $\hat{P}_{1}, \hat{P}_{2}, \hat{P}_{3}$ for the three maintenance actions, and its mean cycle length $\hat{L}\left(\hat{C}^{*}\right)$.

Based on the results in Table 2, we observe that the absolute value $\left|\left(\hat{Z}\left(C^{*}\right)-Z\left(C^{*}\right)\right) / \hat{Z}\left(C^{*}\right)\right|$, denoted as Gap 1, is only $0.16 \%$ in the RCM case and $0.05 \%$ in the GP case, which shows that our approximate evaluation is very close to the true costs under the same control limit $C^{*}$. The absolute value $\left|\left(\hat{Z}\left(\hat{C}^{*}\right)-\hat{Z}\left(C^{*}\right)\right) / \hat{Z}\left(\hat{C}^{*}\right)\right|$, denoted as Gap 2, is only $0.04 \%$ in the RCM case and $1.06 \%$ in the GP case. This implies that the deviation of $C^{*}$ from $\hat{C}^{*}$ does not lead to a large deviation for the simulated optimal costs, which is due to the fact that the average costs function $\hat{Z}(C)$ is flat in the neighborhood of its minimum. Hence, in practice, the optimal maintenance policy obtained via our approximate evaluation results in average costs that are very close to the true minimum average costs. Also notice that the approximated values for $P_{1}, P_{2}, P_{3}$ and $L(C)$ are close to the simulated values $\hat{P}_{1}, \hat{P}_{2}, \hat{P}_{3}$ and $\hat{L}(C)$. Therefore, we can conclude that the gaps are small and our approximate evaluation is accurate in this case study.

\section{Numerical Experiments}

In this section, we conduct the following numerical experiments based on full factorial test beds. In Section 5.1 , we investigate the accuracy of the approximate evaluation. In Section 5.2, we optimize the control limit based on approximate evaluations and we investigate the gap with the true optimal control limit. In 
Table 3: Parameter setting for Test bed 1

\begin{tabular}{c|l}
\hline Parameter & Explanation \\
\hline$E\left[T_{H}\right]=1$ & Mean lifetime \\
$H=100 \%$ & Hard failure threshold \\
$C=\{30 \%, 50 \%, 70 \%\}$ & Control limit \\
$\sigma=1 / 2 *\{50 \%, 100 \%, 150 \%\}$ & Standard deviation of component lifetime \\
$\lambda=2 *\{50 \%, 100 \%, 150 \%\}$ & Poisson arrival rate for unscheduled downs \\
$\tau=0.2 *\{50 \%, 100 \%, 150 \%\}$ & Fixed time interval for scheduled downs \\
\hline
\end{tabular}

Section 5.3, we evaluate the cost reduction potential of our proposed policy under various parameter settings. Throughout this section, we follow the same notation as in Section 4 to distinguish results obtained via the approximate evaluation and simulated results.

\subsection{Accuracy of the approximate evaluation}

The accuracy of our approximate evaluation can be assessed based on the gap between the approximation result $Z(C)$ and the simulation result $\hat{Z}(C)$. W.l.o.g., we take the mean life time $E\left[T_{H}\right]$ of the CBM component equal to 1 time unit. This normalizes the time unit. Similarly, we can take the hard failure level $H$ equal to 1 which normalizes the degradation level. By fitting the two moments of the component life time, the shape and scale parameters of the Weibull distribution for the RCM case (see Fitting Option 1 in Section 4) and the Gamma distribution for the GP case (see Fitting Option 2 in Section 4) can be determined. The standard deviation $\sigma$ is varied in our experiment. The larger $\sigma$, the larger the stochasticity of the degradation process. Next, $\tau$ and $\lambda$ are varied, because they determine the frequency of the opportunities for PM-SD and PM-USD maintenance actions (see Section 2). Finally, we vary the control limit $C$, which we express as percentage of $H$. We use the following three values for the control limit $C: 30 \%, 50 \%, 70 \%$. Each of the other three parameters has a basic value multiplied by a set of factors, $\{50 \%, 100 \%, 150 \%\}$. The basic values are found back in Table 3. For each parameter, the chosen values are ordered in increasing order and denoted with subindices $1,2,3$. Hence, we have a full factorial test bed $\Lambda$ with instances $\left(C_{j}, \sigma_{l}, \lambda_{k}, \tau_{m}\right)$, where $j, l, k, m=\{1,2,3\}$. This test bed, denoted as Test Bed 1, consists of $|\Lambda|=81$ instances.

Notice that no cost parameters are chosen as factors in this test bed, since the average costs $Z(C)$ are fully determined by the probabilities of the three maintenance actions and the expected cycle length. This also helps to reduce the size of the test bed. To compare the approximate and simulation results, we compare the obtained values for the probabilities $P_{1}, P_{2}, P_{3}$ and the mean cycle length $L(C)$. To see how much the approximate and simulation results differ, we define a deviation vector $\left[\delta_{1}, \delta_{2}, \delta_{3}, \delta_{4}\right]=\left[\hat{P}_{1}-P_{1}, \hat{P}_{2}-P_{2}, \hat{P}_{3}-\right.$ $\left.P_{3},(\hat{L}(C)-L(C)) / \hat{L}(C)\right]$. The deviation vectors of 81 instances are shown in Tables 9-12 of Appendix B. There are three levels for each parameter $C, \sigma, \lambda, \tau$. We categorize the instances containing a specific level of a certain parameter into a subset. For example, the subset of instances containing level $C_{1}$ for $C$ is defined as $\Lambda_{C_{1}}=\left\{\left(C_{1}, \sigma_{l}, \lambda_{k}, \tau_{m}\right) \mid l, k, m \in\{1,2,3\}\right\}$. For each of these subsets, the average of the absolute deviation vectors (denoted by AAD) and the maximum of the absolute deviation vectors (denoted by MAD) are summarized in Table 4. The computation time of the approximate evaluation was in the order of a few seconds per instance.

The first insight from Table 4 is that the AAD and MAD of $\delta_{1}, \delta_{2}, \delta_{3}$ and $\delta_{4}$ are small for the RCM case. For this case, the approximate evaluation is accurate under all parameter settings. For the GP case, the $\mathrm{AAD}$ and MAD values for $\delta_{1}$ and $\delta_{4}$ are equally small as in the RCM case. For $\delta_{2}$ and $\delta_{3}$, the AAD and 
Table 4: The average absolute difference (AAD) and maximum absolute difference (MAD) between the approximate results and simulation results under two fitting options for the degradation process

Fitting Option 1: the random coefficient model (RCM)

\begin{tabular}{|c|cccc|}
\hline & $\left|\delta_{1}\right|$ & $\left|\delta_{2}\right|$ & $\left|\delta_{3}\right|$ & $\left|\delta_{4}\right|$ \\
& $\{A A D, M A D\}$ & $\{A A D, M A D\}$ & $\{A A D, M A D\}$ & $\{A A D, M A D\}$ \\
\hline$\Lambda_{C_{1}}$ & $\{0.0047,0.0156\}$ & $\{0.0048,0.0160\}$ & $\{0.0003,0.0004\}$ & $\{0.52 \%, 1.48 \%\}$ \\
$\Lambda_{C_{2}}$ & $\{0.0030,0.0143\}$ & $\{0.0031,0.0149\}$ & $\{0.0005,0.0007\}$ & $\{0.21 \%, 1.01 \%\}$ \\
$\Lambda_{C_{3}}$ & $\{0.0020,0.0168\}$ & $\{0.0039,0.0295\}$ & $\{0.0023,0.0127\}$ & $\{0.12 \%, 0.62 \%\}$ \\
$\Lambda_{\sigma_{1}}$ & $\{0.0043,0.0168\}$ & $\{0.0057,0.0295\}$ & $\{0.0017,0.0127\}$ & $\{0.33 \%, 1.40 \%\}$ \\
$\Lambda_{\sigma_{2}}$ & $\{0.0028,0.0148\}$ & $\{0.0034,0.0151\}$ & $\{0.0009,0.0053\}$ & $\{0.26 \%, 1.30 \%\}$ \\
$\Lambda_{\sigma_{3}}$ & $\{0.0026,0.0150\}$ & $\{0.0028,0.0154\}$ & $\{0.0005,0.0014\}$ & $\{0.26 \%, 1.48 \%\}$ \\
$\Lambda_{\lambda_{1}}$ & $\{0.0012,0.0048\}$ & $\{0.0019,0.0143\}$ & $\{0.0010,0.0095\}$ & $\{0.17 \%, 0.58 \%\}$ \\
$\Lambda_{\lambda_{2}}$ & $\{0.0031,0.0109\}$ & $\{0.0038,0.0209\}$ & $\{0.0011,0.0122\}$ & $\{0.29 \%, 1.06 \%\}$ \\
$\Lambda_{\lambda_{3}}$ & $\{0.0054,0.0168\}$ & $\{0.0061,0.0295\}$ & $\{0.0011,0.0127\}$ & $\{0.39 \%, 1.48 \%\}$ \\
$\Lambda_{\tau_{1}}$ & $\{0.0005,0.0014\}$ & $\{0.0007,0.0019\}$ & $\{0.0005,0.0007\}$ & $\{0.07 \%, 0.19 \%\}$ \\
$\Lambda_{\tau_{2}}$ & $\{0.0031,0.0140\}$ & $\{0.0031,0.0138\}$ & $\{0.0004,0.0007\}$ & $\{0.25 \%, 0.95 \%\}$ \\
$\Lambda_{\tau_{3}}$ & $\{0.0060,0.0168\}$ & $\{0.0081,0.0295\}$ & $\{0.0022,0.0127\}$ & $\{0.53 \%, 1.48 \%\}$ \\
$\Lambda$ & $\{0.0032,0.0168\}$ & $\{0.0039,0.0295\}$ & $\{0.0010,0.0127\}$ & $\{0.28 \%, 1.48 \%\}$ \\
\hline
\end{tabular}

Fitting Option 2: the Gamma process (GP)

\begin{tabular}{|c|cccc|}
\hline & $\left|\delta_{1}\right|$ & $\left|\delta_{2}\right|$ & $\left|\delta_{3}\right|$ & $\left|\delta_{4}\right|$ \\
& $\{A A D, M A D\}$ & $\{A A D, M A D\}$ & $\{A A D, M A D\}$ & $\{A A D, M A D\}$ \\
\hline$\Lambda_{C_{1}}$ & $\{0.0017,0.0055\}$ & $\{0.0016,0.0040\}$ & $\{0.0008,0.0040\}$ & $\{0.16 \%, 0.50 \%\}$ \\
$\Lambda_{C_{2}}$ & $\{0.0017,0.0078\}$ & $\{0.0069,0.0314\}$ & $\{0.0066,0.0294\}$ & $\{0.20 \%, 0.44 \%\}$ \\
$\Lambda_{C_{3}}$ & $\{0.0052,0.0186\}$ & $\{0.0298,0.0600\}$ & $\{0.0339,0.0635\}$ & $\{0.37 \%, 1.12 \%\}$ \\
$\Lambda_{\sigma_{1}}$ & $\{0.0021,0.0078\}$ & $\{0.0080,0.0504\}$ & $\{0.0073,0.0511\}$ & $\{0.19 \%, 0.43 \%\}$ \\
$\Lambda_{\sigma_{2}}$ & $\{0.0034,0.0186\}$ & $\{0.0125,0.0516\}$ & $\{0.0141,0.0598\}$ & $\{0.26 \%, 0.88 \%\}$ \\
$\Lambda_{\sigma_{3}}$ & $\{0.0032,0.0154\}$ & $\{0.0177,0.0600\}$ & $\{0.0198,0.0635\}$ & $\{0.29 \%, 1.12 \%\}$ \\
$\Lambda_{\lambda_{1}}$ & $\{0.0019,0.0077\}$ & $\{0.0148,0.0600\}$ & $\{0.0150,0.0635\}$ & $\{0.24 \%, 0.70 \%\}$ \\
$\Lambda_{\lambda_{2}}$ & $\{0.0030,0.0186\}$ & $\{0.0119,0.0509\}$ & $\{0.0137,0.0598\}$ & $\{0.26 \%, 1.12 \%\}$ \\
$\Lambda_{\lambda_{3}}$ & $\{0.0038,0.0184\}$ & $\{0.0115,0.0479\}$ & $\{0.0125,0.0575\}$ & $\{0.24 \%, 0.88 \%\}$ \\
$\Lambda_{\tau_{1}}$ & $\{0.0013,0.0030\}$ & $\{0.0041,0.0207\}$ & $\{0.0033,0.0191\}$ & $\{0.18 \%, 0.50 \%\}$ \\
$\Lambda_{\tau_{2}}$ & $\{0.0026,0.0097\}$ & $\{0.0144,0.0600\}$ & $\{0.0148,0.0635\}$ & $\{0.22 \%, 0.55 \%\}$ \\
$\Lambda_{\tau_{3}}$ & $\{0.0048,0.0186\}$ & $\{0.0197,0.0535\}$ & $\{0.0231,0.0607\}$ & $\{0.34 \%, 1.12 \%\}$ \\
$\Lambda$ & $\{0.0029,0.0186\}$ & $\{0.0127,0.0600\}$ & $\{0.0137,0.0635\}$ & $\{0.25 \%, 1.12 \%\}$ \\
\hline
\end{tabular}

MAD values are larger than in the RCM case. The AAD values are still sufficiently small, but the MAD values show that the deviations for $P_{2}$ and $P_{3}$ go up to $6 \%$.

\subsection{Quality of the heuristic policy obtained via approximate evaluation}

The results for the case of Section 4 show that the optimal policy obtained via our approximate evaluation was close to optimal. In this section, we verify the quality of the optimal control limit policy $C^{*}$ which is obtained when the approximate evaluation is used in the optimization procedure. This policy may deviate from the true optimal policy $\hat{C}^{*}$ and thus is a heuristic. We consider the same gaps as in Section 4: (i) Gap $1,\left(\hat{Z}\left(C^{*}\right)-Z\left(C^{*}\right)\right) / \hat{Z}\left(C^{*}\right)$, shows the accuracy in average costs of the approximate evaluation for control limit policy $C^{*}$; (ii) Gap $2,\left(\hat{Z}\left(\hat{C}^{*}\right)-\hat{Z}\left(C^{*}\right)\right) / \hat{Z}\left(\hat{C}^{*}\right)$, shows how much the heuristic policy $C^{*}$ deviates in true average costs from the true optimal policy $\hat{C}^{*}$.

In this experiment, we take the same instances as in Test Bed 1 in Section 5.1. However, the control limit is no longer an input variable since the control limit is optimized in this experiment. The resulting test bed 
Table 5: The average absolute difference (AAD) and the maximum absolute difference (MAD) for $\left(\hat{C}^{*}-C^{*}\right) / H$, Gap 1 , and Gap 2 under two fitting options for the degradation process

Fitting Option 1: the random coefficient model (RCM)

\begin{tabular}{|c|ccc|}
\hline & $\left(\hat{C}^{*}-C^{*}\right) / H$ & Gap 1 & Gap 2 \\
& $\{A A D, M A D\}$ & $\{A A D, M A D\}$ & $\{A A D, M A D\}$ \\
\hline$\Omega_{\sigma_{1}}$ & $\{0.97 \%, 6.57 \%\}$ & $\{0.20 \%, 0.30 \%\}$ & $\{0.12 \%, 0.41 \%\}$ \\
$\Omega_{\sigma_{2}}$ & $\{0.55 \%, 1.36 \%\}$ & $\{0.20 \%, 0.64 \%\}$ & $\{0.10 \%, 0.19 \%\}$ \\
$\Omega_{\sigma_{3}}$ & $\{0.90 \%, 3.72 \%\}$ & $\{0.17 \%, 0.35 \%\}$ & $\{0.14 \%, 0.33 \%\}$ \\
$\Omega_{\lambda_{1}}$ & $\{0.83 \%, 3.72 \%\}$ & $\{0.14 \%, 0.30 \%\}$ & $\{0.12 \%, 0.33 \%\}$ \\
$\Omega_{\lambda_{2}}$ & $\{1.13 \%, 6.57 \%\}$ & $\{0.21 \%, 0.63 \%\}$ & $\{0.15 \%, 0.41 \%\}$ \\
$\Omega_{\lambda_{3}}$ & $\{0.45 \%, 1.36 \%\}$ & $\{0.22 \%, 0.64 \%\}$ & $\{0.10 \%, 0.17 \%\}$ \\
$\Omega_{\tau_{1}}$ & $\{0.31 \%, 1.36 \%\}$ & $\{0.11 \%, 0.35 \%\}$ & $\{0.10 \%, 0.21 \%\}$ \\
$\Omega_{\tau_{2}}$ & $\{0.73 \%, 3.72 \%\}$ & $\{0.15 \%, 0.26 \%\}$ & $\{0.15 \%, 0.33 \%\}$ \\
$\Omega_{\tau_{3}}$ & $\{1.37 \%, 6.57 \%\}$ & $\{0.32 \%, 0.64 \%\}$ & $\{0.11 \%, 0.41 \%\}$ \\
$\Omega$ & $\{0.81 \%, 6.57 \%\}$ & $\{0.19 \%, 0.64 \%\}$ & $\{0.12 \%, 0.41 \%\}$ \\
\hline
\end{tabular}

Fitting Option 2: the Gamma process (GP)

\begin{tabular}{|c|ccc|}
\hline & $\left(\hat{C}^{*}-C^{*}\right) / H$ & Gap 1 & Gap 2 \\
& $\{A A D, M A D\}$ & $\{A A D, M A D\}$ & $\{A A D, M A D\}$ \\
\hline$\Omega_{\sigma_{1}}$ & $\{1.76 \%, 3.82 \%\}$ & $\{3.61 \%, 4.93 \%\}$ & $\{0.68 \%, 1.69 \%\}$ \\
$\Omega_{\sigma_{2}}$ & $\{2.67 \%, 5.45 \%\}$ & $\{3.98 \%, 6.76 \%\}$ & $\{1.03 \%, 1.74 \%\}$ \\
$\Omega_{\sigma_{3}}$ & $\{3.71 \%, 7.33 \%\}$ & $\{3.18 \%, 7.13 \%\}$ & $\{1.92 \%, 3.93 \%\}$ \\
$\Omega_{\lambda_{1}}$ & $\{2.72 \%, 6.65 \%\}$ & $\{3.98 \%, 7.13 \%\}$ & $\{1.44 \%, 3.93 \%\}$ \\
$\Omega_{\lambda_{2}}$ & $\{2.53 \%, 5.14 \%\}$ & $\{3.56 \%, 6.90 \%\}$ & $\{1.11 \%, 2.79 \%\}$ \\
$\Omega_{\lambda_{3}}$ & $\{2.89 \%, 7.33 \%\}$ & $\{3.23 \%, 6.52 \%\}$ & $\{1.08 \%, 2.58 \%\}$ \\
$\Omega_{\tau_{1}}$ & $\{1.21 \%, 1.79 \%\}$ & $\{1.11 \%, 2.36 \%\}$ & $\{0.68 \%, 1.69 \%\}$ \\
$\Omega_{\tau_{2}}$ & $\{2.17 \%, 4.30 \%\}$ & $\{3.59 \%, 4.70 \%\}$ & $\{1.33 \%, 2.73 \%\}$ \\
$\Omega_{\tau_{3}}$ & $\{4.77 \%, 7.33 \%\}$ & $\{6.06 \%, 7.13 \%\}$ & $\{1.62 \%, 3.93 \%\}$ \\
$\Omega$ & $\{2.72 \%, 7.33 \%\}$ & $\{3.59 \%, 7.13 \%\}$ & $\{1.21 \%, 3.93 \%\}$ \\
\hline
\end{tabular}

is denoted by $\Omega$ and consists of instances $\left(\sigma_{l}, \lambda_{k}, \tau_{m}\right), l, k, m=\{1,2,3\}$. This test bed is denoted as test bed 2 and consist of $|\Omega|=27$ instances. For the cost factors, we use the same factors as in Section 4; see Table 1 for their values. The deviation $\left(\hat{C}^{*}-C^{*}\right) / H$, Gap 1, and Gap 2 for all 27 instances are listed in Table 13 of Appendix B. For each factor, we categorize the instances containing a specific level into a subset. For example, the subset of all instances containing $\sigma_{1}$ is defined as $\Omega_{\sigma_{1}}=\left\{\left(\sigma_{1}, \lambda_{k}, \tau_{m}\right) \mid k, m \in\{1,2,3\}\right\}$. For each of these subsets, the average and maximum absolute deviation, denoted by AAD and MAD are listed in Table 5 for both fitting options for the degradation process. The computation times of the results obtained via approximate evaluation were in the order of a few minutes per instance.

The first insight from Table 5 is that the AAD and MAD values are almost all small for the RCM case. The MAD value for $\left(\hat{C}^{*}-C^{*}\right) / H$ in the whole test bed is $6.57 \%$, which is significant. This MAD value is obtained for the instance $\left(\sigma_{1}, \lambda_{2}, \tau_{3}\right)$ (see Table 13). The value for Gap 1 for this instance is only $0.09 \%$, which is again low, and the value for Gap 2 is $0.41 \%$. The latter value is the highest value for Gap 2 among all instances, but is still low. In general, even if the absolute value for $\left(\hat{C}^{*}-C^{*}\right) / H$ is somewhat larger, the values for Gap 1 and Gap 2 are very low. This is due to the accuracy of the approximate evaluation and the flatness of the average costs $\hat{Z}(C)$ in the neighbourhood of the optimum. We can conclude that the quality of our heuristic is excellent for the RCM case.

For the GP case, the AAD and MAD value for $\left(\hat{C}^{*}-C^{*}\right) / H$ in the whole test bed is $2.72 \%$ and $7.33 \%$, respectively. This is reasonable, but less good than in the RCM case. The AAD and MAD value for Gap 1 
is $3.59 \%$ and $7.13 \%$, respectively. This is relatively high, and shows that the approximate evaluation for the control limit policy $C^{*}$ is much less accurate than in the RCM case. Fortunately, the AAD and MAD value for Gap 2 is $1.21 \%$ and $3.93 \%$, respectively. This is less good than in the RCM case, but it shows that the average costs of the heuristic policy $C^{*}$ are close to the optimal costs. We may conclude that the quality of our heuristic is good for the GP case.

\subsection{Cost reduction potential}

As stated in the introduction, our model for a single CBM component with USDs and SDs as opportunities for preventive maintenance is new. Hence, in this section, we compare the optimal control limit policy within our model to three other policies. This shows the value of using both USDs and SDs and thus also the value of our new model. The three other policies that we consider are: 1) an only-SD-opportunistic policy, which means that only SDs are considered as opportunities; 2) an only-USD-opportunistic policy, which means that only USDs are considered as opportunities; 3) a failure-based policy, which means that neither USDs or SDs are considered as opportunities for preventive maintenance. For the only-SD-opportunistic policy and the only-USD-opportunistic policy, we use a control limit policy with an optimized control limit. This optimization can be done via special cases of our model with $\lambda=0$ and $\tau=\infty$, respectively. For the failure-based policy, the average costs are equal to $c^{C M} / E\left[T_{H}\right]=44.5 / 1=44.5$ thousand Euro per time unit. They are constant over all combinations of instances and the two fitting options for the degradation process, because they only depend on the factors $c^{C M}$ and $E\left[T_{H}\right]$ and these factors are the same in all instances and under both fitting options.

For this experiment, we can use the same test bed as in Section 5.2, i.e., Test bed 2. The average costs of the optimal control limit policy that uses USDs and SDs are denoted by $Z$. The average costs of the optimal only-SD-opportunistic policy and the optimal only-USD-opportunistic policy are denoted by $\tilde{Z}_{1}$ and $\tilde{Z}_{2}$, respectively. The average costs under the failure-based policy are denoted by $\tilde{Z}_{3}$. Because $\tilde{Z}_{3}$ is the same in all instances and under both fitting options, we use $\tilde{Z}_{3}$ as the basis for three comparisons that we make: A) the cost savings percentage of including opportunities at both USDs and SDs, denoted by $\triangle_{0}=\left(\tilde{Z}_{3}-Z\right) / \tilde{Z}_{3}$; B) the cost savings percentage of using only opportunities at SDs, denoted by $\triangle_{1}=\left(\tilde{Z}_{3}-\tilde{Z}_{1}\right) / \tilde{Z}_{3}$; C) the cost savings percentage of using only opportunities at USDs, denoted by $\triangle_{2}=\left(\tilde{Z}_{3}-\tilde{Z}_{2}\right) / \tilde{Z}_{3}$. The mean cost savings, and their minimum and maximum over subsets of instances and the whole test bed are given in Table 6. The results per instance are listed in Table 14 in Appendix B. All results in this experiment are based on the approximate evaluation procedure.

Let us first consider the results for the RCM case in Table 6 . We see that the cost savings are on average equal to $8.4 \%$ when only USDs are used as opportunities for preventive maintenance; see the mean value for $\triangle_{2}$ over the whole test bed. This percentage increases strongly as a function of the rate with which these USDs occur. For the subset $\Omega_{\lambda_{3}}$, the mean time between two successive USDs is $1 / \lambda_{3}=1 / 3=0.33$ time units (recall that the mean lifetime $E\left[T_{H}\right]=1$ time unit) and the average value of $\triangle_{2}$ is $11.5 \%$. The average costs savings when only SDs are used are equal to $22.6 \%$, and these savings decrease strongly as a function of the maintenance interval length. For the subset $\Omega_{\tau_{3}}$, the maintenance interval length $\tau_{3}=0.3$ time units and the average value of $\triangle_{1}$ is $14.1 \%$. This percentage may be compared to the $11.5 \%$ for $\triangle_{2}$ in subset $\Omega_{\lambda_{3}}$, and shows that it is slightly better to have SDs with deterministic interarrival times than an (almost) equal amount of USDs with exponential interarrival times (notice that this includes the effect of slightly cheaper preventive maintenance costs at SDs than at USDs). The cost savings when both USDs and SDs are used are equal to $28.9 \%$; see the mean value for $\triangle_{2}$ over the whole test bed. This is significantly more than when 
Table 6: The cost savings percentages $\triangle_{0}, \triangle_{1}, \triangle_{2}$ under two fitting options for the degradation process Fitting Option 1: the random coefficient model (RCM)

\begin{tabular}{|c|ccc|ccc|ccc|}
\hline & \multicolumn{3}{|c|}{$\triangle_{0}$} & & \multicolumn{3}{|c|}{$\triangle_{1}$} & \multicolumn{3}{c|}{$\triangle_{2}$} \\
& mean & $\min$ & $\max$ & $\operatorname{mean}$ & $\min$ & $\max$ & $\operatorname{mean}$ & $\min$ & $\max$ \\
\hline$\Omega_{\sigma_{1}}$ & $29.7 \%$ & $23.0 \%$ & $35.3 \%$ & $23.4 \%$ & $11.6 \%$ & $31.6 \%$ & $8.6 \%$ & $5.1 \%$ & $11.7 \%$ \\
$\Omega_{\sigma_{2}}$ & $28.7 \%$ & $22.7 \%$ & $34.7 \%$ & $22.5 \%$ & $14.6 \%$ & $29.7 \%$ & $8.4 \%$ & $5.0 \%$ & $11.5 \%$ \\
$\Omega_{\sigma_{3}}$ & $28.5 \%$ & $23.0 \%$ & $34.3 \%$ & $21.9 \%$ & $16.2 \%$ & $29.5 \%$ & $8.2 \%$ & $4.8 \%$ & $11.3 \%$ \\
$\Omega_{\lambda_{1}}$ & $29.5 \%$ & $23.7 \%$ & $35.3 \%$ & $22.6 \%$ & $11.6 \%$ & $31.6 \%$ & $5.0 \%$ & $4.8 \%$ & $5.1 \%$ \\
$\Omega_{\lambda_{2}}$ & $28.8 \%$ & $22.7 \%$ & $35.0 \%$ & $22.6 \%$ & $11.6 \%$ & $31.6 \%$ & $8.7 \%$ & $8.5 \%$ & $8.9 \%$ \\
$\Omega_{\lambda_{3}}$ & $28.5 \%$ & $22.7 \%$ & $34.7 \%$ & $22.6 \%$ & $11.6 \%$ & $31.6 \%$ & $11.5 \%$ & $11.3 \%$ & $11.7 \%$ \\
$\Omega_{\tau_{1}}$ & $34.5 \%$ & $33.7 \%$ & $35.3 \%$ & $30.3 \%$ & $29.5 \%$ & $31.6 \%$ & $8.4 \%$ & $4.8 \%$ & $11.7 \%$ \\
$\Omega_{\tau_{2}}$ & $29.0 \%$ & $27.8 \%$ & $30.9 \%$ & $23.4 \%$ & $20.2 \%$ & $27.0 \%$ & $8.4 \%$ & $4.8 \%$ & $11.7 \%$ \\
$\Omega_{\tau_{3}}$ & $23.4 \%$ & $22.7 \%$ & $25.0 \%$ & $14.1 \%$ & $11.6 \%$ & $16.2 \%$ & $8.4 \%$ & $4.8 \%$ & $11.7 \%$ \\
$\Omega$ & $28.9 \%$ & $22.7 \%$ & $35.3 \%$ & $22.6 \%$ & $11.6 \%$ & $31.6 \%$ & $8.4 \%$ & $4.8 \%$ & $11.7 \%$ \\
\hline
\end{tabular}

Fitting Option 2: the Gamma process (GP)

\begin{tabular}{|c|ccc|ccc|ccc|}
\hline & \multicolumn{3}{|c|}{$\triangle_{0}$} & & \multicolumn{3}{|c|}{$\triangle_{1}$} & \multicolumn{3}{|c|}{$\triangle_{2}$} \\
& $\operatorname{mean}$ & $\min$ & $\max$ & $\operatorname{mean}$ & $\min$ & $\max$ & $\operatorname{mean}$ & $\min$ & $\max$ \\
\hline$\Omega_{\sigma_{1}}$ & $27.4 \%$ & $23.6 \%$ & $31.4 \%$ & $21.0 \%$ & $16.5 \%$ & $25.9 \%$ & $11.5 \%$ & $8.8 \%$ & $14.0 \%$ \\
$\Omega_{\sigma_{2}}$ & $26.3 \%$ & $23.0 \%$ & $30.1 \%$ & $20.8 \%$ & $15.4 \%$ & $26.4 \%$ & $10.5 \%$ & $7.5 \%$ & $13.1 \%$ \\
$\Omega_{\sigma_{3}}$ & $26.1 \%$ & $22.9 \%$ & $29.7 \%$ & $20.7 \%$ & $12.2 \%$ & $27.9 \%$ & $9.5 \%$ & $6.4 \%$ & $12.4 \%$ \\
$\Omega_{\lambda_{1}}$ & $26.7 \%$ & $22.9 \%$ & $31.4 \%$ & $20.8 \%$ & $12.2 \%$ & $27.9 \%$ & $7.6 \%$ & $6.4 \%$ & $8.8 \%$ \\
$\Omega_{\lambda_{2}}$ & $26.6 \%$ & $22.9 \%$ & $31.2 \%$ & $20.8 \%$ & $12.2 \%$ & $27.9 \%$ & $10.8 \%$ & $9.8 \%$ & $11.8 \%$ \\
$\Omega_{\lambda_{3}}$ & $26.5 \%$ & $23.0 \%$ & $31.0 \%$ & $20.8 \%$ & $12.2 \%$ & $27.9 \%$ & $13.2 \%$ & $12.4 \%$ & $14.0 \%$ \\
$\Omega_{\tau_{1}}$ & $30.2 \%$ & $29.5 \%$ & $31.4 \%$ & $26.7 \%$ & $25.9 \%$ & $27.9 \%$ & $10.5 \%$ & $6.4 \%$ & $14.0 \%$ \\
$\Omega_{\tau_{2}}$ & $26.3 \%$ & $25.6 \%$ & $27.4 \%$ & $21.1 \%$ & $20.6 \%$ & $21.9 \%$ & $10.5 \%$ & $6.4 \%$ & $14.0 \%$ \\
$\Omega_{\tau_{3}}$ & $23.2 \%$ & $22.9 \%$ & $24.0 \%$ & $14.7 \%$ & $12.2 \%$ & $16.5 \%$ & $10.5 \%$ & $6.4 \%$ & $14.0 \%$ \\
$\Omega$ & $26.6 \%$ & $22.9 \%$ & $31.4 \%$ & $20.8 \%$ & $12.2 \%$ & $27.9 \%$ & $10.5 \%$ & $6.4 \%$ & $14.0 \%$ \\
\hline
\end{tabular}

only SDs or only USDs are used. Hence, it is beneficial to use both SDs and USDs if possible. Finally, we observe that the average values of $\triangle_{0}, \triangle_{1}, \triangle_{2}$ decrease only slightly as a function of the standard deviation of the lifetime, or, equivalently, the stochasticity of the degradation process.

When we consider the results for the GP case, we see exactly the same effects as for the RCM case. In fact, the cost savings percentages are remarkably similar in both cases. On one hand, this is surprising because the degradation behavior under RCM is really different than under GP. On the other hand, we saw already that the stochasticity of the degradation process has a limited effect on the cost savings. This seems to be related to each other.

\section{Demonstration for a multi-component systems}

In this section, we demonstrate that our single component model can be used as a building block for the analysis of multi-component systems. Let us consider a system consisting of $20 \mathrm{CBM}$ components with degradation processes that are modeled by the random coefficient model described in Section 4 . The components are numbered from 1 to 20 . In Table 7, the following input parameters are given: 1) $\alpha_{i}$ and $\beta_{i}$ are the scale and shape parameters of the Weibull distribution for the factor $\theta_{1}$ used in the description of the degradation process for component $i$; 2) $C_{i}^{P M-U S D}, C_{i}^{P M-S D}$, and $C_{i}^{C M}$ are the costs for a PM-USD, PM-SD, and CM action, respectively. The rest of the parameter setting is the same as in the case described in Section 4 (see Table 1); for all components, $H=88, \tau=91$ days and $\lambda=8.86 * 10^{-3}$ USDs per time unit. 
Table 7: Input parameters for the multi-component system with 20 CBM components

\begin{tabular}{|c|ccccc|}
\hline Component & $\alpha_{i}$ & $\beta_{i}$ & $\begin{array}{c}C_{i}^{P M-U S D} \\
\left(\times 10^{3} \text { Euro }\right)\end{array}$ & $\begin{array}{c}C_{i}^{P M-S D} \\
\left(\times 10^{3} \text { Euro }\right)\end{array}$ & $\begin{array}{c}C_{c p m} \\
\left(\times 10^{3} \text { Euro }\right)\end{array}$ \\
\hline 1 & 0.159 & 3.37 & 28.8 & 26.5 & 44.5 \\
2 & 0.167 & 3.55 & 29.3 & 27.0 & 45.6 \\
3 & 0.176 & 3.72 & 29.9 & 27.6 & 46.7 \\
4 & 0.184 & 3.90 & 30.4 & 28.1 & 47.8 \\
5 & 0.192 & 4.08 & 30.9 & 28.6 & 48.9 \\
6 & 0.201 & 4.26 & 31.4 & 29.1 & 50.0 \\
7 & 0.209 & 4.43 & 32.0 & 29.7 & 51.1 \\
8 & 0.218 & 4.61 & 32.5 & 30.2 & 52.2 \\
9 & 0.226 & 4.79 & 33.0 & 30.7 & 53.3 \\
10 & 0.234 & 4.97 & 33.5 & 31.2 & 54.4 \\
11 & 0.243 & 5.14 & 34.1 & 31.8 & 55.6 \\
12 & 0.251 & 5.32 & 34.6 & 32.3 & 56.7 \\
13 & 0.259 & 5.50 & 35.1 & 32.8 & 57.8 \\
14 & 0.268 & 5.68 & 35.6 & 33.3 & 58.9 \\
15 & 0.276 & 5.85 & 36.2 & 33.9 & 60.0 \\
16 & 0.285 & 6.03 & 36.7 & 34.4 & 61.1 \\
17 & 0.293 & 6.21 & 37.2 & 34.9 & 62.2 \\
18 & 0.301 & 6.39 & 37.7 & 35.4 & 63.3 \\
19 & 0.310 & 6.56 & 38.3 & 36.0 & 64.4 \\
20 & 0.318 & 6.74 & 38.8 & 36.5 & 65.5 \\
\hline
\end{tabular}

The rate $\lambda$ denotes the rate for USDs that occur because of failures of other components than the 20 CBM components.

For each CBM component, we follow a control limit policy with control limit $C_{i}$. We optimize them via an iterative procedure. In an initial iteration, for each component $i$, we apply our single-component model with rate $\lambda$ for the USDs and interval length $\tau$ for the SDs. We use the approximate evaluation procedure and optimize the control limit $C_{i}$. This gives a first optimized level $C_{i}^{*}$ for component $i$. What we also get is an estimate $\lambda_{i}=P_{3} / L\left(C_{i}^{*}\right)$ that denotes the number of corrective maintenance actions for component $i$ per time unit. These are extra USDs that can be used by the other CBM components. This is used in the further iterations.

In each next iteration, for each CBM component $i$, we take the USDs caused by other CBM components into account, and we approximate their arrival process by a Poisson process. The total rate of the USDs then becomes equal to $\lambda+\sum_{j \in\{1, \ldots, 20\} \backslash\{i\}} \lambda_{j}$. Subsequently, we recalculate the optimal control limit $C_{i}^{*}$ for component $i$ and we recalculate the rate $\lambda_{i}$ with which USDs are caused. This iterative process is continued until we have convergence for the optimal control limits $C_{i}^{*}$. At the end of this procedure, we also obtain the average costs $Z_{i}\left(C_{i}^{*}\right)$ for each component $i$ and the total costs $\sum_{i \in\{1, \ldots, 20\}} Z_{i}\left(C_{i}^{*}\right)$. In addition, we apply simulation to obtain the true average $\operatorname{costs} \hat{Z}_{i}\left(C_{i}^{*}\right)$ for each component $i$ and the true total costs $\sum_{i \in\{1, \ldots, 20\}} \hat{Z}_{i}\left(C_{i}^{*}\right)$.

We have no guarantee for the convergence of the above procedure, but we obtained convergence for all instances to which this procedure was applied. This holds also for the generalized procedure of [37] for systems with a mix of CBM, age-based, and failure-based components.

For our problem, the above procedure leads to the results listed in Table 8 . In the last column, we list the relative gap $\left|\left(\hat{Z}_{i}\left(C_{i}^{*}\right)-Z_{i}\left(C_{i}^{*}\right)\right) / \hat{Z}_{i}\left(C_{i}^{*}\right)\right|$, and similarly for the total costs. The computation time was 30.2 minutes on a PC with a $2.5 \mathrm{GHz}$ processor and $4 \mathrm{G}$ RAM. This shows that a system with 20 
Table 8: Output for the multi-component system with $20 \mathrm{CBM}$ components

\begin{tabular}{|c|cccc|}
\hline Component & $C_{i}^{*}$ & $\begin{array}{c}Z_{i}\left(C_{i}^{*}\right) \\
\text { (Euro/day) }\end{array}$ & $\begin{array}{c}\hat{Z}_{i}\left(C_{i}^{*}\right) \\
(\text { Euro/day })\end{array}$ & Gap \\
\hline 1 & $86.41 \%$ & 43.84 & 44.01 & $0.4 \%$ \\
2 & $85.71 \%$ & 48.05 & 48.46 & $0.9 \%$ \\
3 & $85.60 \%$ & 52.43 & 52.54 & $0.2 \%$ \\
4 & $84.96 \%$ & 56.99 & 57.21 & $0.4 \%$ \\
5 & $83.85 \%$ & 61.68 & 61.47 & $0.3 \%$ \\
6 & $83.45 \%$ & 66.50 & 66.81 & $0.5 \%$ \\
7 & $83.33 \%$ & 71.51 & 71.84 & $0.5 \%$ \\
8 & $82.81 \%$ & 76.70 & 76.93 & $0.3 \%$ \\
9 & $81.54 \%$ & 81.96 & 82.08 & $0.1 \%$ \\
10 & $80.60 \%$ & 87.28 & 86.99 & $0.3 \%$ \\
11 & $80.00 \%$ & 92.69 & 92.01 & $0.7 \%$ \\
12 & $79.89 \%$ & 98.25 & 97.76 & $0.5 \%$ \\
13 & $79.89 \%$ & 104.02 & 104.38 & $0.4 \%$ \\
14 & $79.77 \%$ & 110.05 & 110.74 & $0.6 \%$ \\
15 & $79.66 \%$ & 116.43 & 117.97 & $1.3 \%$ \\
16 & $79.93 \%$ & 123.21 & 124.82 & $1.3 \%$ \\
17 & $79.35 \%$ & 130.45 & 131.55 & $0.8 \%$ \\
18 & $78.41 \%$ & 138.10 & 139.22 & $0.8 \%$ \\
19 & $76.58 \%$ & 146.01 & 146.36 & $0.2 \%$ \\
20 & $75.00 \%$ & 153.84 & 152.46 & $0.9 \%$ \\
\hline Total & & 1859.99 & 1865.61 & $0.0 \%$ \\
\hline
\end{tabular}

components can be solved within a reasonable computation time. This calculation time seems to be linear in the number of components (with more components, the number of iterations is about the same, and the calculation time per component is linear as a function of the number of components). The results in Table 8 also show that components with the shortest lifetimes (the components with the highest indices) and highest costs for maintenance actions get the lowest control limits $C_{i}^{*}$. Further, we observe that the gaps $\left|\left(\hat{Z}_{i}\left(C_{i}^{*}\right)-Z_{i}\left(C_{i}^{*}\right)\right) / \hat{Z}_{i}\left(C_{i}^{*}\right)\right|$ are small and the gap for the total costs is almost zero.

\section{Conclusions}

In this paper, we introduced a new model for a single CBM component that is part of a complex engineering system and has both USDs and SDs as opportunities for preventive maintenance. For the degradation process, we applied both a random coefficient model and a Gamma process. We developed an efficient approximate evaluation procedure for control limit policies and showed that this procedure leads to good heuristic solutions when used for the optimization of the control limit. We also showed that the average costs can be reduced significantly when using both USDs and SDs instead of only SDs, only USDs, or no opportunities at all. Finally, we demonstrated that our model can also be used for solving multi-component systems within a reasonable computation time.

\section{Acknowledgments}

The authors thank TKI Dinalog for funding this research. 


\section{Appendices}

\section{A: Simulation procedure}

In this appendix, we described the setup of the simulations to evaluate given maintenance policies.

A maintenance policy is described by the control limit $C$. Suppose that this control limit $C$ is given. We simulate the unscheduled downs by a Poisson process with a rate $\lambda$ and we take a given model with given parameters for the degradation of the CBM component. The simulation consists of $m=100$ subruns, which are numbered as $1, \ldots, m$. Per subrun we simulate over a time horizon $T_{\max }$ that is sufficiently large to obtain accurate simulated results (e.g., $10^{6}$ times larger than $L(C)$ ). In each subrun $i$, we have a finite number of maintenance cycles that we number as $1, \ldots, k_{i}$, and we keep track of the following variables:

$$
\begin{aligned}
I_{i, k}^{P M-U S D} & = \begin{cases}1 & \text { if a PM-USD action is taken at the end of the } k \text {-th cycle; } \\
0 & \text { otherwise }\end{cases} \\
I_{i, k}^{P M-S D} & = \begin{cases}1 & \text { if a PM-SD action is taken at the end of the } k \text {-th cycle; } \\
0 & \text { otherwise, }\end{cases} \\
I_{i, k}^{C M} & = \begin{cases}1 & \text { if a CM action is taken at the end of the } k \text {-th cycle; } \\
0 & \text { otherwise }\end{cases} \\
L_{i} & =\text { total length of the } k_{i} \text { cycles of subrun } i .
\end{aligned}
$$

The average costs in subrun $i$ are then given by

$$
\hat{Z}_{i}=\frac{1}{L_{i}} \sum_{k=1}^{k_{i}}\left(I_{i, k}^{P M-U S D} c^{P M-U S D}+I_{i, k}^{P M-S D} c^{P M-S D}+I_{i, k}^{C M} c^{C M}\right), \quad i=1, \ldots, m .
$$

Next, the average costs are estimated at $\hat{Z}=\frac{1}{m} \sum_{i=1}^{m} \hat{Z}_{i}$ with a $100(1-\alpha) \%$ confidence interval given by (cf. $[16]$ ):

$$
\hat{Z} \pm t(1-\alpha / 2, m-1) \sqrt{\frac{S^{2}}{m}}
$$

where $S^{2}=\frac{1}{m-1} \sum_{i=1}^{m}\left(\hat{Z}_{i}-\hat{Z}\right)^{2}$ and $t(1-\alpha / 2, m-1)$ is the upper $1-\alpha / 2$ critical point for the t-distribution with $m-1$ degrees of freedom ( $\alpha=0.05$ for all reported results in this paper). The probabilities $\hat{P}_{1}, \hat{P}_{2}$, and $\hat{P}_{3}$ that an arbitrary cycle ends with a PM-USD, PM-SD, and CM action, respectively, are determined by

$$
\begin{aligned}
& \hat{P}_{1}=\frac{1}{m} \sum_{i=1}^{m} \frac{1}{k_{i}} \sum_{k=1}^{k_{i}} I_{i, k}^{P M-U S D}, \\
& \hat{P}_{2}=\frac{1}{m} \sum_{i=1}^{m} \frac{1}{k_{i}} \sum_{k=1}^{k_{i}} I_{i, k}^{P M-S D}, \\
& \hat{P}_{3}=\frac{1}{m} \sum_{i=1}^{m} \frac{1}{k_{i}} \sum_{k=1}^{k_{i}} I_{i, k}^{C M} .
\end{aligned}
$$

Finally, the expected cycle length $\hat{L}(C)$ is determined by $\hat{L}=\frac{1}{m} \sum_{i=1}^{m}\left(L_{i} / k_{i}\right)$.

\section{B: Detail results for the Test beds 1 and 2}

In this appendix, we give detailed results for the test beds 1 and 2. Tables 9 and 9 contain the detailed results for test bed 1 under the use of the random coefficient model. Tables 11 and 12 contain the detailed results for test bed 1 under the use of the Gamma process. Tables 13 and 14 contain detailed results for Test bed 2 . 


\section{References}

[1] I. Alsyouf. Maintenance practices in Swedish industries: Survey results. International Journal of Production Economics, 121:212-223, 2009.

[2] J. Barata, C.G. Soares, M. Marseguerra, and E. Zio. Simulation modelling of repairable multi-component deteriorating systems for 'on condition' maintenance optimisation. Reliability Engineering and System Safety, $76: 255-264,2002$.

[3] K. Bouvard, S. Artus, C. Berenguer, and V. Cocquempot. Condition-based dynamic maintenance operations planning \& grouping: Application to commercial heavy vehicles. Reliability Engineering and System Safety, 96:601-610, 2011.

[4] C. Bunks, D. McCarthy, and T. Al-Ani. Condition-based maintenance of machines using Hidden Markov Models. Mechanical Systems \& Signal Processing, 14:597-612, 2000.

[5] B. Castanier, A. Grall, and C. Berenguer. A condition-based maintenance policy with non-periodic inspections for a two-unit series system. Reliability Engineering and System Safety, 87:109-120, 2005.

[6] B. de Jonge, W. Klingenberg, R. Teunter, and T. Tinga. Reducing costs by clustering maintenance activities for multiple critical units. Reliability Engineering and System Safety, 145:93-103, 2016.

[7] L. Dieulle, C. Berenguer, A. Grall, and M. Roussignol. Sequential condition-based maintenance scheduling for a deteriorating system. European Journal of Operational Research, 150:451-461, 2003.

[8] A. H. Elwany, N. Z. Gebraeel, and L. M. Maillart. Structured replacement policies for components with complex degradation processes and dedicated sensors. Operations Research, 59:684-695, 2011.

[9] N.Z. Gebraeel. Sensory-updated residual life distributions for components with exponential degradation patterns. IEEE Transactions on Automation Science and Engineering, 3:382-393, 2006.

[10] N.Z. Gebraeel, M.A. Lawley, R. Li, and J.K. Ryan. Residual-life distributions from component degradation signals: A Bayesian approach. IIE Transactions 37:543-557, 2005.

[11] A. Grall, C. Berenguer, and L. Dieulle. A condition-based maintenance policy for stochastically deteriorating systems. Reliability Engineering and System Safety, 76:167-180, 2002.

[12] A.K.S. Jardine, P. M. Anderson, and D. S. Mann. Application of the weibull proportional hazards model to aircraft and marine engine failure data. Quality and Reliability Engineering International, 3:77-82, 1987.

[13] A.K.S. Jardine, D. Lin, and D. Banjevic. A review on machinery diagnostics and prognostics implementing condition-based maintenance. Mechanical Systems and Signal Processing, 20:1483-1510, 2006.

[14] J.P. Kharoufeh, C.J. Solo, and M. Ulukus. Semi-markov models for degradation-based reliability. IIE Transactions, 42:599-612, 2010.

[15] J. Koochaki, J. Bokhorst, H. Wortmann, and W. Klingenberg. Condition based maintenance in the context of opportunistic maintenance. International Journal of Production Research, 50:6918-6929, 2012.

[16] A.M. Law and W.D. Kelton. Simulation modeling and analysis, 3rd edition. McGraw-Hill, 2000.

[17] H.T. Liao, A. Elsayed, and L.Y. Chan. Maintenance of continuously monitored degrading systems. European Journal of Operational Research, 175:821-835, 2006. 
[18] D.M. Lin and V. Makis. Recursive filters for a partially observable system subject to random failure. Advances in Applied Probability, 35:207-227, 2003.

[19] C.J. Lu and W.Q. Meeker. Using degradation measures to estimate a time-to-failure distribution. Technometrics, 35:161-174, 1993.

[20] V. Makis and X. Jiang. Optimal replacement under partial observations. Mathematics of Operations Research, 28:382-394, 2003.

[21] M. Marseguerra, E. Zio, and L. Podofillini. Condition-based maintenance optimization by means of genetic algorithms and Monte Carlo simulation. Reliability Engineering and System Safety, 77:151-165, 2002.

[22] K.S. Park. Optimal continuous-wear limit replacement under periodic inspections. IEEE Transactions on Reliability, 37:97-102, 1988.

[23] K.S. Park. Optimal wear-limit replacement with wear-dependent failures. IEEE Transactions on Reliability, $37: 293-294,1988$

[24] Y. Peng, M. Dong, and M.J. Zuo. Current status of machine prognostics in condition-based maintenance: A review. International Journal of Advanced Manufacturing Technology, 50:297-313, 2010.

[25] J. Poppe, R.N. Boute, and M.R. Lambrecht. A hybrid condition-based maintenance policy for continuously monitored components with two degradation thresholds. Working paper, KU Leuven, 2016.

[26] S.M. Ross. Stochastic Processes, Second Edition. John Wiley \& Sons, 1996.

[27] M. Roussignol. Gamma stochastic process and application to maintenance. Lecture notes, Université Paris-Est, 2009 .

[28] Z.G. Tian, T.D. Jin, B.R Wu, and F.F Ding. Condition based maintenance optimization for wind power generation systems under continuous monitoring. Renewable Energy, 36:1502-1509, 2011.

[29] Z.G. Tian and H.T. Liao. Condition based maintenance optimization for multi-component systems using proportional hazards model. Reliability Engineering and System Safety, 96:581-589, 2011.

[30] B. Timmermans. Development and application of decision model for synchronizing condition-based maintenance. MSc thesis, Eindhoven University of Technology, 2012.

[31] J.M. van Noortwijk. A survey of the application of Gamma processes in maintenance. Reliability Engineering and System Safety, 94:2-21, 2009.

[32] P.J. Vlok, J.L. Coetzee, D. Banjevic, A.K.S. Jardine, and V. Makis. Optimal component replacement decisions using vibration monitoring and the proportional-hazards model. Journal of The Operational Research Society, $53: 193-202,2002$.

[33] H.Z. Wang. A survey of maintenance policies of deteriorating systems. European Journal of Operational Research, 139:469-489, 2002.

[34] W. Wang, B. Hussin, and T. Jefferis. A case study of condition based maintenance modelling based upon the oil analysis data of marine diesel engines using stochastic filtering. International Journal of Production Economics, 136:84-92, 2012.

[35] D.J.D Wijnmalen and J.A.M Hontelez. Coordinated condition-based repair strategies for components of a multicomponent maintenance system with discounts. European Journal of Operational Research, 98:52-63, 1997. 
[36] R.E. Wildeman, R. Dekker, and A.C.J.M. Smit. A dynamic policy for grouping maintenance activities. European Journal of Operational Research, 99:530-551, 1997.

[37] Q. Zhu, H. Peng, and G.J. Houtum. Remote monitoring and condition-based maintenance for high-tech capital goods. In Pombo, J., editor, Proceedings of the Second International Conference on Railway Technology: Research, Development and Maintenance, Civil-Comp Press, Stirlingshire, United Kingdom, paper 302, 2014.

[38] Q. Zhu, H. Peng, and G.J. Houtum. A condition-based maintenance policy for multi-component systems with a high maintenance setup cost. OR Spectrum, 37:1007-1035, 2015. 
Table 9: Detailed results for the first 40 of the 81 instances of Test bed 1 under the use of the random coefficient model

\begin{tabular}{|c|c|c|}
\hline Instance & $\begin{array}{c}\text { Simulation } \\
\left\{\hat{P}_{1}, \hat{P}_{2}, \hat{P}_{3}, \hat{L}(C)\right\}\end{array}$ & $\begin{array}{c}\text { Deviation } \\
\left\{\delta_{1}, \delta_{2}, \delta_{3}, \delta_{4}\right\}\end{array}$ \\
\hline$\left(C_{1}, \sigma_{1}, \lambda_{1}, \tau_{1}\right)$ & $\{0.044,0.956,0.000,0.344\}$ & $\{0.000,0.000,0.000,0.1 \%\}$ \\
\hline$\left(C_{1}, \sigma_{1}, \lambda_{1}, \tau_{2}\right)$ & $\{0.104,0.896,0.000,0.403\}$ & $\{0.000,-0.001,0.000,0.0 \%\}$ \\
\hline$\left(C_{1}, \sigma_{1}, \lambda_{1}, \tau_{3}\right)$ & $\{0.109,0.890,0.000,0.409\}$ & $\{0.003,-0.003,0.000,0.6 \%\}$ \\
\hline$\left(C_{1}, \sigma_{1}, \lambda_{2}, \tau_{1}\right)$ & $\{0.085,0.914,0.000,0.343\}$ & $\{0.000,0.000,0.000,0.2 \%\}$ \\
\hline$\left(C_{1}, \sigma_{1}, \lambda_{2}, \tau_{2}\right)$ & $\{0.193,0.807,0.000,0.397\}$ & $\{-0.002,0.002,0.000,-0.1 \%\}$ \\
\hline$\left(C_{1}, \sigma_{1}, \lambda_{2}, \tau_{3}\right)$ & $\{0.201,0.799,0.000,0.401\}$ & $\{0.008,-0.008,0.000,1.0 \%\}$ \\
\hline$\left(C_{1}, \sigma_{1}, \lambda_{3}, \tau_{1}\right)$ & $\{0.125,0.875,0.000,0.342\}$ & $\{0.001,-0.001,0.000,0.2 \%\}$ \\
\hline$\left(C_{1}, \sigma_{1}, \lambda_{3}, \tau_{2}\right)$ & $\{0.273,0.727,0.000,0.391\}$ & $\{-0.003,0.003,0.000,-0.3 \%\}$ \\
\hline$\left(C_{1}, \sigma_{1}, \lambda_{3}, \tau_{3}\right)$ & $\{0.278,0.722,0.000,0.393\}$ & $\{0.016,-0.016,0.000,1.4 \%\}$ \\
\hline$\left(C_{1}, \sigma_{2}, \lambda_{1}, \tau_{1}\right)$ & $\{0.048,0.951,0.000,0.348\}$ & $\{0.000,0.000,0.000,0.0 \%\}$ \\
\hline$\left(C_{1}, \sigma_{2}, \lambda_{1}, \tau_{2}\right)$ & $\{0.109,0.891,0.000,0.409\}$ & $\{-0.001,0.001,0.000,-0.3 \%\}$ \\
\hline$\left(C_{1}, \sigma_{2}, \lambda_{1}, \tau_{3}\right)$ & $\{0.108,0.891,0.000,0.408\}$ & $\{0.002,-0.003,0.000,0.5 \%\}$ \\
\hline$\left(C_{1}, \sigma_{2}, \lambda_{2}, \tau_{1}\right)$ & $\{0.092,0.907,0.000,0.347\}$ & $\{-0.001,0.001,0.000,0.1 \%\}$ \\
\hline$\left(C_{1}, \sigma_{2}, \lambda_{2}, \tau_{2}\right)$ & $\{0.201,0.799,0.000,0.400\}$ & $\{-0.005,0.005,0.000,-0.6 \%\}$ \\
\hline$\left(C_{1}, \sigma_{2}, \lambda_{2}, \tau_{3}\right)$ & $\{0.202,0.798,0.000,0.401\}$ & $\{0.009,-0.009,0.000,1.1 \%\}$ \\
\hline$\left(C_{1}, \sigma_{2}, \lambda_{3}, \tau_{1}\right)$ & $\{0.135,0.864,0.000,0.346\}$ & $\{0.000,0.000,0.000,0.1 \%\}$ \\
\hline$\left(C_{1}, \sigma_{2}, \lambda_{3}, \tau_{2}\right)$ & $\{0.279,0.721,0.000,0.393\}$ & $\{-0.011,0.011,0.000,-0.9 \%\}$ \\
\hline$\left(C_{1}, \sigma_{2}, \lambda_{3}, \tau_{3}\right)$ & $\{0.280,0.720,0.000,0.393\}$ & $\{0.015,-0.015,0.000,1.3 \%\}$ \\
\hline$\left(C_{1}, \sigma_{3}, \lambda_{1}, \tau_{1}\right)$ & $\{0.050,0.950,0.000,0.350\}$ & $\{0.000,0.000,0.000,0.0 \%\}$ \\
\hline$\left(C_{1}, \sigma_{3}, \lambda_{1}, \tau_{2}\right)$ & $\{0.109,0.891,0.000,0.410\}$ & $\{-0.002,0.002,0.000,-0.4 \%\}$ \\
\hline$\left(C_{1}, \sigma_{3}, \lambda_{1}, \tau_{3}\right)$ & $\{0.108,0.891,0.000,0.409\}$ & $\{0.002,-0.002,0.000,0.5 \%\}$ \\
\hline$\left(C_{1}, \sigma_{3}, \lambda_{2}, \tau_{1}\right)$ & $\{0.096,0.903,0.000,0.348\}$ & $\{0.000,0.000,0.000,0.1 \%\}$ \\
\hline$\left(C_{1}, \sigma_{3}, \lambda_{2}, \tau_{2}\right)$ & $\{0.201,0.799,0.000,0.401\}$ & $\{-0.008,0.007,0.000,-0.7 \%\}$ \\
\hline$\left(C_{1}, \sigma_{3}, \lambda_{2}, \tau_{3}\right)$ & $\{0.202,0.797,0.000,0.401\}$ & $\{0.008,-0.008,0.000,0.9 \%\}$ \\
\hline$\left(C_{1}, \sigma_{3}, \lambda_{3}, \tau_{1}\right)$ & $\{0.140,0.860,0.000,0.346\}$ & $\{0.000,0.000,0.000,-0.1 \%\}$ \\
\hline$\left(C_{1}, \sigma_{3}, \lambda_{3}, \tau_{2}\right)$ & $\{0.279,0.721,0.000,0.394\}$ & $\{-0.014,0.014,0.000,-1.0 \%\}$ \\
\hline$\left(C_{1}, \sigma_{3}, \lambda_{3}, \tau_{3}\right)$ & $\{0.282,0.717,0.000,0.395\}$ & $\{0.015,-0.015,0.000,1.5 \%\}$ \\
\hline$\left(C_{2}, \sigma_{1}, \lambda_{1}, \tau_{1}\right)$ & $\{0.049,0.950,0.000,0.549\}$ & $\{0.000,-0.001,0.000,0.0 \%\}$ \\
\hline$\left(C_{2}, \sigma_{1}, \lambda_{1}, \tau_{2}\right)$ & $\{0.107,0.892,0.000,0.606\}$ & $\{0.000,0.000,0.000,-0.2 \%\}$ \\
\hline$\left(C_{2}, \sigma_{1}, \lambda_{1}, \tau_{3}\right)$ & $\{0.128,0.871,0.001,0.627\}$ & $\{0.004,-0.005,0.001,0.5 \%\}$ \\
\hline$\left(C_{2}, \sigma_{1}, \lambda_{2}, \tau_{1}\right)$ & $\{0.096,0.904,0.000,0.548\}$ & $\{0.000,-0.001,0.000,0.1 \%\}$ \\
\hline$\left(C_{2}, \sigma_{1}, \lambda_{2}, \tau_{2}\right)$ & $\{0.196,0.803,0.000,0.598\}$ & $\{-0.005,0.004,0.000,-0.3 \%\}$ \\
\hline$\left(C_{2}, \sigma_{1}, \lambda_{2}, \tau_{3}\right)$ & $\{0.240,0.759,0.001,0.620\}$ & $\{0.011,-0.011,0.001,0.8 \%\}$ \\
\hline$\left(C_{2}, \sigma_{1}, \lambda_{3}, \tau_{1}\right)$ & $\{0.138,0.862,0.000,0.546\}$ & $\{-0.001,0.000,0.000,0.0 \%\}$ \\
\hline$\left(C_{2}, \sigma_{1}, \lambda_{3}, \tau_{2}\right)$ & $\{0.272,0.727,0.000,0.591\}$ & $\{-0.010,0.010,0.000,-0.5 \%\}$ \\
\hline$\left(C_{2}, \sigma_{1}, \lambda_{3}, \tau_{3}\right)$ & $\{0.334,0.666,0.001,0.613\}$ & $\{0.014,-0.015,0.001,1.0 \%\}$ \\
\hline$\left(C_{2}, \sigma_{2}, \lambda_{1}, \tau_{1}\right)$ & $\{0.050,0.950,0.000,0.548\}$ & $\{0.001,-0.002,0.000,0.0 \%\}$ \\
\hline$\left(C_{2}, \sigma_{2}, \lambda_{1}, \tau_{2}\right)$ & $\{0.097,0.902,0.000,0.599\}$ & $\{-0.002,0.001,0.000,-0.1 \%\}$ \\
\hline$\left(C_{2}, \sigma_{2}, \lambda_{1}, \tau_{3}\right)$ & $\{0.139,0.861,0.001,0.638\}$ & $\{0.001,-0.002,0.001,0.2 \%\}$ \\
\hline$\left(C_{2}, \sigma_{2}, \lambda_{2}, \tau_{1}\right)$ & $\{0.095,0.905,0.000,0.547\}$ & $\{0.001,-0.002,0.000,0.0 \%\}$ \\
\hline
\end{tabular}


Table 10: Detailed results for the last 41 of the 81 instances of Test bed 1 under the use of the random coefficient model

\begin{tabular}{|c|c|c|}
\hline Instance & $\begin{array}{c}\text { Simulation } \\
\left\{\hat{P}_{1}, \hat{P}_{2}, \hat{P}_{3}, \hat{L}(C)\right\}\end{array}$ & $\begin{array}{c}\text { Deviation } \\
\left\{\delta_{1}, \delta_{2}, \delta_{3}, \delta_{4}\right\}\end{array}$ \\
\hline$\left(C_{2}, \sigma_{2}, \lambda_{2}, \tau_{2}\right)$ & $\{0.184,0.816,0.000,0.592\}$ & $\{-0.002,0.001,0.000,-0.2 \%\}$ \\
\hline$\left(C_{2}, \sigma_{2}, \lambda_{2}, \tau_{3}\right)$ & $\{0.255,0.745,0.001,0.627\}$ & $\{0.003,-0.003,0.001,0.2 \%\}$ \\
\hline$\left(C_{2}, \sigma_{2}, \lambda_{3}, \tau_{1}\right)$ & $\{0.136,0.863,0.000,0.546\}$ & $\{0.001,-0.001,0.000,0.1 \%\}$ \\
\hline$\left(C_{2}, \sigma_{2}, \lambda_{3}, \tau_{2}\right)$ & $\{0.255,0.745,0.000,0.586\}$ & $\{-0.006,0.006,0.000,-0.1 \%\}$ \\
\hline$\left(C_{2}, \sigma_{2}, \lambda_{3}, \tau_{3}\right)$ & $\{0.351,0.648,0.001,0.618\}$ & $\{0.003,-0.004,0.001,0.2 \%\}$ \\
\hline$\left(C_{2}, \sigma_{3}, \lambda_{1}, \tau_{1}\right)$ & $\{0.049,0.951,0.000,0.549\}$ & $\{0.001,-0.001,0.000,0.2 \%\}$ \\
\hline$\left(C_{2}, \sigma_{3}, \lambda_{1}, \tau_{2}\right)$ & $\{0.094,0.906,0.000,0.595\}$ & $\{0.000,0.000,0.000,0.1 \%\}$ \\
\hline$\left(C_{2}, \sigma_{3}, \lambda_{1}, \tau_{3}\right)$ & $\{0.145,0.855,0.001,0.645\}$ & $\{-0.001,0.000,0.001,0.0 \%\}$ \\
\hline$\left(C_{2}, \sigma_{3}, \lambda_{2}, \tau_{1}\right)$ & $\{0.094,0.906,0.000,0.547\}$ & $\{0.001,-0.001,0.000,0.0 \%\}$ \\
\hline$\left(C_{2}, \sigma_{3}, \lambda_{2}, \tau_{2}\right)$ & $\{0.176,0.824,0.000,0.588\}$ & $\{-0.001,0.001,0.000,0.0 \%\}$ \\
\hline$\left(C_{2}, \sigma_{3}, \lambda_{2}, \tau_{3}\right)$ & $\{0.263,0.736,0.001,0.632\}$ & $\{-0.002,0.002,0.001,-0.2 \%\}$ \\
\hline$\left(C_{2}, \sigma_{3}, \lambda_{3}, \tau_{1}\right)$ & $\{0.136,0.863,0.000,0.546\}$ & $\{0.001,-0.001,0.000,0.1 \%\}$ \\
\hline$\left(C_{2}, \sigma_{3}, \lambda_{3}, \tau_{2}\right)$ & $\{0.245,0.754,0.000,0.583\}$ & $\{-0.003,0.003,0.000,0.1 \%\}$ \\
\hline$\left(C_{2}, \sigma_{3}, \lambda_{3}, \tau_{3}\right)$ & $\{0.360,0.640,0.001,0.620\}$ & $\{-0.005,0.005,0.001,-0.3 \%\}$ \\
\hline$\left(C_{3}, \sigma_{1}, \lambda_{1}, \tau_{1}\right)$ & $\{0.048,0.952,0.001,0.748\}$ & $\{0.000,0.000,0.001,0.0 \%\}$ \\
\hline$\left(C_{3}, \sigma_{1}, \lambda_{1}, \tau_{2}\right)$ & $\{0.098,0.902,0.001,0.797\}$ & $\{0.000,-0.001,0.001,0.0 \%\}$ \\
\hline$\left(C_{3}, \sigma_{1}, \lambda_{1}, \tau_{3}\right)$ & $\{0.145,0.762,0.093,0.847\}$ & $\{-0.005,0.014,-0.01,-0.3 \%\}$ \\
\hline$\left(C_{3}, \sigma_{1}, \lambda_{2}, \tau_{1}\right)$ & $\{0.093,0.907,0.001,0.747\}$ & $\{-0.001,0.000,0.001,0.0 \%\}$ \\
\hline$\left(C_{3}, \sigma_{1}, \lambda_{2}, \tau_{2}\right)$ & $\{0.181,0.819,0.001,0.791\}$ & $\{-0.001,0.001,0.001,0.0 \%\}$ \\
\hline$\left(C_{3}, \sigma_{1}, \lambda_{2}, \tau_{3}\right)$ & $\{0.263,0.670,0.067,0.832\}$ & $\{-0.009,0.021,-0.012,-0.5 \%\}$ \\
\hline$\left(C_{3}, \sigma_{1}, \lambda_{3}, \tau_{1}\right)$ & $\{0.137,0.863,0.001,0.745\}$ & $\{0.001,-0.002,0.001,0.0 \%\}$ \\
\hline$\left(C_{3}, \sigma_{1}, \lambda_{3}, \tau_{2}\right)$ & $\{0.254,0.746,0.001,0.785\}$ & $\{-0.003,0.002,0.001,-0.1 \%\}$ \\
\hline$\left(C_{3}, \sigma_{1}, \lambda_{3}, \tau_{3}\right)$ & $\{0.354,0.599,0.048,0.818\}$ & $\{-0.017,0.029,-0.013,-0.6 \%\}$ \\
\hline$\left(C_{3}, \sigma_{2}, \lambda_{1}, \tau_{1}\right)$ & $\{0.048,0.952,0.001,0.749\}$ & $\{-0.001,0.000,0.001,0.1 \%\}$ \\
\hline$\left(C_{3}, \sigma_{2}, \lambda_{1}, \tau_{2}\right)$ & $\{0.092,0.908,0.001,0.792\}$ & $\{0.000,-0.001,0.001,0.1 \%\}$ \\
\hline$\left(C_{3}, \sigma_{2}, \lambda_{1}, \tau_{3}\right)$ & $\{0.132,0.790,0.079,0.833\}$ & $\{-0.002,0.006,-0.004,-0.1 \%\}$ \\
\hline$\left(C_{3}, \sigma_{2}, \lambda_{2}, \tau_{1}\right)$ & $\{0.093,0.906,0.001,0.748\}$ & $\{0.000,0.000,0.001,0.2 \%\}$ \\
\hline$\left(C_{3}, \sigma_{2}, \lambda_{2}, \tau_{2}\right)$ & $\{0.172,0.827,0.001,0.786\}$ & $\{0.000,-0.001,0.001,0.0 \%\}$ \\
\hline$\left(C_{3}, \sigma_{2}, \lambda_{2}, \tau_{3}\right)$ & $\{0.240,0.702,0.058,0.822\}$ & $\{-0.003,0.008,-0.005,0.1 \%\}$ \\
\hline$\left(C_{3}, \sigma_{2}, \lambda_{3}, \tau_{1}\right)$ & $\{0.136,0.863,0.001,0.746\}$ & $\{0.000,0.000,0.001,0.0 \%\}$ \\
\hline$\left(C_{3}, \sigma_{2}, \lambda_{3}, \tau_{2}\right)$ & $\{0.244,0.755,0.001,0.782\}$ & $\{0.002,-0.002,0.001,0.2 \%\}$ \\
\hline$\left(C_{3}, \sigma_{2}, \lambda_{3}, \tau_{3}\right)$ & $\{0.332,0.623,0.045,0.811\}$ & $\{-0.001,0.005,-0.004,-0.1 \%\}$ \\
\hline$\left(C_{3}, \sigma_{3}, \lambda_{1}, \tau_{1}\right)$ & $\{0.048,0.951,0.001,0.749\}$ & $\{0.000,-0.001,0.001,0.1 \%\}$ \\
\hline$\left(C_{3}, \sigma_{3}, \lambda_{1}, \tau_{2}\right)$ & $\{0.092,0.906,0.002,0.792\}$ & $\{0.000,-0.001,0.001,0.1 \%\}$ \\
\hline$\left(C_{3}, \sigma_{3}, \lambda_{1}, \tau_{3}\right)$ & $\{0.128,0.802,0.070,0.829\}$ & $\{0.000,0.002,-0.001,0.0 \%\}$ \\
\hline$\left(C_{3}, \sigma_{3}, \lambda_{2}, \tau_{1}\right)$ & $\{0.094,0.906,0.001,0.747\}$ & $\{0.000,-0.001,0.001,0.0 \%\}$ \\
\hline$\left(C_{3}, \sigma_{3}, \lambda_{2}, \tau_{2}\right)$ & $\{0.172,0.826,0.002,0.787\}$ & $\{0.000,-0.001,0.001,0.2 \%\}$ \\
\hline$\left(C_{3}, \sigma_{3}, \lambda_{2}, \tau_{3}\right)$ & $\{0.237,0.708,0.055,0.818\}$ & $\{0.002,-0.002,0.000,0.1 \%\}$ \\
\hline$\left(C_{3}, \sigma_{3}, \lambda_{3}, \tau_{1}\right)$ & $\{0.135,0.864,0.001,0.745\}$ & $\{-0.001,0.000,0.001,0.0 \%\}$ \\
\hline$\left(C_{3}, \sigma_{3}, \lambda_{3}, \tau_{2}\right)$ & $\{0.243,0.755,0.001,0.782\}$ & $\{0.000,-0.001,0.001,0.1 \%\}$ \\
\hline$\left(C_{3}, \sigma_{3}, \lambda_{3}, \tau_{3}\right)$ & $\{0.325,0.632,0.043,0.809\}$ & $\{0.002,-0.003,0.001,0.2 \%\}$ \\
\hline
\end{tabular}


Table 11: Detailed results for the first 40 of the 81 instances of Test bed 1 under the use of the Gamma process

\begin{tabular}{|c|c|c|}
\hline Instance & $\begin{array}{c}\text { Simulation } \\
\left\{\hat{P}_{1}, \hat{P}_{2}, \hat{P}_{3}, \hat{L}(C)\right\}\end{array}$ & $\begin{array}{c}\text { Deviation } \\
\left\{\delta_{1}, \delta_{2}, \delta_{3}, \delta_{4}\right\}\end{array}$ \\
\hline$\left(C_{1}, \sigma_{1}, \lambda_{1}, \tau_{1}\right)$ & $\{0.047,0.953,0.000,0.360\}$ & $\{-0.001,0.001,0.000,0.0 \%\}$ \\
\hline$\left(C_{1}, \sigma_{1}, \lambda_{1}, \tau_{2}\right)$ & $\{0.095,0.905,0.000,0.406\}$ & $\{0.001,-0.001,0.000,0.0 \%\}$ \\
\hline$\left(C_{1}, \sigma_{1}, \lambda_{1}, \tau_{3}\right)$ & $\{0.132,0.868,0.000,0.446\}$ & $\{-0.001,0.001,0.000,0.3 \%\}$ \\
\hline$\left(C_{1}, \sigma_{1}, \lambda_{2}, \tau_{1}\right)$ & $\{0.092,0.908,0.000,0.358\}$ & $\{-0.002,0.001,0.000,-0.1 \%\}$ \\
\hline$\left(C_{1}, \sigma_{1}, \lambda_{2}, \tau_{2}\right)$ & $\{0.176,0.824,0.000,0.400\}$ & $\{-0.001,0.001,0.000,-0.1 \%\}$ \\
\hline$\left(C_{1}, \sigma_{1}, \lambda_{2}, \tau_{3}\right)$ & $\{0.241,0.759,0.000,0.432\}$ & $\{-0.001,0.001,0.000,-0.1 \%\}$ \\
\hline$\left(C_{1}, \sigma_{1}, \lambda_{3}, \tau_{1}\right)$ & $\{0.138,0.861,0.000,0.357\}$ & $\{0.002,-0.002,0.000,0.1 \%\}$ \\
\hline$\left(C_{1}, \sigma_{1}, \lambda_{3}, \tau_{2}\right)$ & $\{0.246,0.753,0.000,0.393\}$ & $\{-0.003,0.003,0.000,-0.4 \%\}$ \\
\hline$\left(C_{1}, \sigma_{1}, \lambda_{3}, \tau_{3}\right)$ & $\{0.330,0.669,0.000,0.421\}$ & $\{-0.001,0.001,0.000,-0.2 \%\}$ \\
\hline$\left(C_{1}, \sigma_{2}, \lambda_{1}, \tau_{1}\right)$ & $\{0.051,0.949,0.000,0.371\}$ & $\{0.002,-0.002,0.000,-0.1 \%\}$ \\
\hline$\left(C_{1}, \sigma_{2}, \lambda_{1}, \tau_{2}\right)$ & $\{0.092,0.907,0.000,0.416\}$ & $\{-0.001,0.001,0.000,0.0 \%\}$ \\
\hline$\left(C_{1}, \sigma_{2}, \lambda_{1}, \tau_{3}\right)$ & $\{0.131,0.868,0.001,0.457\}$ & $\{-0.002,0.003,-0.001,0.1 \%\}$ \\
\hline$\left(C_{1}, \sigma_{2}, \lambda_{2}, \tau_{1}\right)$ & $\{0.092,0.908,0.000,0.370\}$ & $\{-0.002,0.001,0.000,0.2 \%\}$ \\
\hline$\left(C_{1}, \sigma_{2}, \lambda_{2}, \tau_{2}\right)$ & $\{0.176,0.824,0.000,0.412\}$ & $\{0.000,0.000,0.000,0.4 \%\}$ \\
\hline$\left(C_{1}, \sigma_{2}, \lambda_{2}, \tau_{3}\right)$ & $\{0.244,0.755,0.001,0.446\}$ & $\{0.001,0.000,-0.001,0.3 \%\}$ \\
\hline$\left(C_{1}, \sigma_{2}, \lambda_{3}, \tau_{1}\right)$ & $\{0.137,0.863,0.000,0.368\}$ & $\{0.000,-0.001,0.000,0.1 \%\}$ \\
\hline$\left(C_{1}, \sigma_{2}, \lambda_{3}, \tau_{2}\right)$ & $\{0.244,0.756,0.000,0.406\}$ & $\{-0.004,0.004,0.000,0.1 \%\}$ \\
\hline$\left(C_{1}, \sigma_{2}, \lambda_{3}, \tau_{3}\right)$ & $\{0.338,0.661,0.001,0.435\}$ & $\{0.003,-0.003,0.000,0.2 \%\}$ \\
\hline$\left(C_{1}, \sigma_{3}, \lambda_{1}, \tau_{1}\right)$ & $\{0.049,0.951,0.000,0.385\}$ & $\{0.001,-0.001,0.000,0.5 \%\}$ \\
\hline$\left(C_{1}, \sigma_{3}, \lambda_{1}, \tau_{2}\right)$ & $\{0.094,0.905,0.001,0.430\}$ & $\{0.000,0.001,-0.001,0.4 \%\}$ \\
\hline$\left(C_{1}, \sigma_{3}, \lambda_{1}, \tau_{3}\right)$ & $\{0.136,0.861,0.003,0.469\}$ & $\{0.001,0.003,-0.004,-0.1 \%\}$ \\
\hline$\left(C_{1}, \sigma_{3}, \lambda_{2}, \tau_{1}\right)$ & $\{0.094,0.906,0.000,0.382\}$ & $\{0.000,0.000,0.000,0.1 \%\}$ \\
\hline$\left(C_{1}, \sigma_{3}, \lambda_{2}, \tau_{2}\right)$ & $\{0.177,0.822,0.001,0.423\}$ & $\{0.001,0.000,-0.001,0.0 \%\}$ \\
\hline$\left(C_{1}, \sigma_{3}, \lambda_{2}, \tau_{3}\right)$ & $\{0.251,0.747,0.003,0.457\}$ & $\{0.004,0.000,-0.004,-0.2 \%\}$ \\
\hline$\left(C_{1}, \sigma_{3}, \lambda_{3}, \tau_{1}\right)$ & $\{0.134,0.865,0.000,0.380\}$ & $\{-0.002,0.002,0.000,0.0 \%\}$ \\
\hline$\left(C_{1}, \sigma_{3}, \lambda_{3}, \tau_{2}\right)$ & $\{0.252,0.747,0.001,0.417\}$ & $\{0.003,-0.003,-0.001,-0.1 \%\}$ \\
\hline$\left(C_{1}, \sigma_{3}, \lambda_{3}, \tau_{3}\right)$ & $\{0.345,0.653,0.002,0.448\}$ & $\{0.005,-0.002,-0.003,0.1 \%\}$ \\
\hline$\left(C_{2}, \sigma_{1}, \lambda_{1}, \tau_{1}\right)$ & $\{0.045,0.954,0.000,0.555\}$ & $\{-0.003,0.003,0.000,-0.2 \%\}$ \\
\hline$\left(C_{2}, \sigma_{1}, \lambda_{1}, \tau_{2}\right)$ & $\{0.095,0.905,0.000,0.599\}$ & $\{0.001,-0.001,0.000,-0.4 \%\}$ \\
\hline$\left(C_{2}, \sigma_{1}, \lambda_{1}, \tau_{3}\right)$ & $\{0.131,0.868,0.001,0.643\}$ & $\{-0.003,0.007,-0.003,0.0 \%\}$ \\
\hline$\left(C_{2}, \sigma_{1}, \lambda_{2}, \tau_{1}\right)$ & $\{0.093,0.906,0.000,0.556\}$ & $\{0.000,0.000,0.000,0.2 \%\}$ \\
\hline$\left(C_{2}, \sigma_{1}, \lambda_{2}, \tau_{2}\right)$ & $\{0.178,0.821,0.001,0.595\}$ & $\{0.002,-0.003,0.000,-0.2 \%\}$ \\
\hline$\left(C_{2}, \sigma_{1}, \lambda_{2}, \tau_{3}\right)$ & $\{0.249,0.751,0.001,0.632\}$ & $\{0.003,0.000,-0.003,0.2 \%\}$ \\
\hline$\left(C_{2}, \sigma_{1}, \lambda_{3}, \tau_{1}\right)$ & $\{0.135,0.864,0.001,0.554\}$ & $\{-0.001,0.000,0.001,0.2 \%\}$ \\
\hline$\left(C_{2}, \sigma_{1}, \lambda_{3}, \tau_{2}\right)$ & $\{0.240,0.759,0.001,0.593\}$ & $\{-0.008,0.008,0.000,0.3 \%\}$ \\
\hline$\left(C_{2}, \sigma_{1}, \lambda_{3}, \tau_{3}\right)$ & $\{0.339,0.661,0.001,0.622\}$ & $\{0.001,0.001,-0.002,0.3 \%\}$ \\
\hline$\left(C_{2}, \sigma_{2}, \lambda_{1}, \tau_{1}\right)$ & $\{0.049,0.950,0.001,0.565\}$ & $\{0.001,-0.001,0.000,0.0 \%\}$ \\
\hline$\left(C_{2}, \sigma_{2}, \lambda_{1}, \tau_{2}\right)$ & $\{0.094,0.906,0.001,0.607\}$ & $\{0.000,0.004,-0.004,-0.4 \%\}$ \\
\hline$\left(C_{2}, \sigma_{2}, \lambda_{1}, \tau_{3}\right)$ & $\{0.134,0.865,0.001,0.653\}$ & $\{-0.002,0.019,-0.017,0.2 \%\}$ \\
\hline$\left(C_{2}, \sigma_{2}, \lambda_{2}, \tau_{1}\right)$ & $\{0.093,0.907,0.001,0.562\}$ & $\{-0.001,0.001,0.000,-0.2 \%\}$ \\
\hline
\end{tabular}


Table 12: Detailed results for the last 41 of the 81 instances of Test bed 1 under the use of the Gamma process

\begin{tabular}{|c|c|c|}
\hline Instance & $\begin{array}{c}\text { Simulation } \\
\left\{\hat{P}_{1}, \hat{P}_{2}, \hat{P}_{3}, \hat{L}(C)\right\}\end{array}$ & $\begin{array}{c}\text { Deviation } \\
\left\{\delta_{1}, \delta_{2}, \delta_{3}, \delta_{4}\right\}\end{array}$ \\
\hline$\left(C_{2}, \sigma_{2}, \lambda_{2}, \tau_{2}\right)$ & $\{0.176,0.824,0.001,0.605\}$ & $\{0.000,0.003,-0.003,0.2 \%\}$ \\
\hline$\left(C_{2}, \sigma_{2}, \lambda_{2}, \tau_{3}\right)$ & $\{0.246,0.753,0.001,0.641\}$ & $\{-0.001,0.015,-0.014,0.2 \%\}$ \\
\hline$\left(C_{2}, \sigma_{2}, \lambda_{3}, \tau_{1}\right)$ & $\{0.136,0.863,0.001,0.561\}$ & $\{0.000,0.000,0.000,-0.1 \%\}$ \\
\hline$\left(C_{2}, \sigma_{2}, \lambda_{3}, \tau_{2}\right)$ & $\{0.250,0.749,0.000,0.600\}$ & $\{0.003,0.000,-0.003,0.2 \%\}$ \\
\hline$\left(C_{2}, \sigma_{2}, \lambda_{3}, \tau_{3}\right)$ & $\{0.343,0.656,0.001,0.630\}$ & $\{0.004,0.008,-0.012,0.1 \%\}$ \\
\hline$\left(C_{2}, \sigma_{3}, \lambda_{1}, \tau_{1}\right)$ & $\{0.048,0.952,0.000,0.572\}$ & $\{-0.001,0.003,-0.002,-0.3 \%\}$ \\
\hline$\left(C_{2}, \sigma_{3}, \lambda_{1}, \tau_{2}\right)$ & $\{0.095,0.904,0.001,0.618\}$ & $\{0.002,0.010,-0.012,0.1 \%\}$ \\
\hline$\left(C_{2}, \sigma_{3}, \lambda_{1}, \tau_{3}\right)$ & $\{0.132,0.863,0.005,0.660\}$ & $\{-0.002,0.031,-0.029,0.1 \%\}$ \\
\hline$\left(C_{2}, \sigma_{3}, \lambda_{2}, \tau_{1}\right)$ & $\{0.094,0.906,0.001,0.571\}$ & $\{0.000,0.002,-0.002,-0.2 \%\}$ \\
\hline$\left(C_{2}, \sigma_{3}, \lambda_{2}, \tau_{2}\right)$ & $\{0.176,0.823,0.001,0.614\}$ & $\{0.001,0.009,-0.010,0.3 \%\}$ \\
\hline$\left(C_{2}, \sigma_{3}, \lambda_{2}, \tau_{3}\right)$ & $\{0.244,0.752,0.004,0.650\}$ & $\{0.000,0.025,-0.025,0.4 \%\}$ \\
\hline$\left(C_{2}, \sigma_{3}, \lambda_{3}, \tau_{1}\right)$ & $\{0.135,0.864,0.000,0.570\}$ & $\{-0.001,0.003,-0.002,-0.1 \%\}$ \\
\hline$\left(C_{2}, \sigma_{3}, \lambda_{3}, \tau_{2}\right)$ & $\{0.246,0.753,0.001,0.608\}$ & $\{-0.001,0.010,-0.009,0.1 \%\}$ \\
\hline$\left(C_{2}, \sigma_{3}, \lambda_{3}, \tau_{3}\right)$ & $\{0.339,0.658,0.003,0.635\}$ & $\{0.003,0.018,-0.022,-0.2 \%\}$ \\
\hline$\left(C_{3}, \sigma_{1}, \lambda_{1}, \tau_{1}\right)$ & $\{0.048,0.951,0.001,0.754\}$ & $\{0.000,0.001,0.000,0.1 \%\}$ \\
\hline$\left(C_{3}, \sigma_{1}, \lambda_{1}, \tau_{2}\right)$ & $\{0.091,0.908,0.000,0.797\}$ & $\{-0.002,0.022,-0.020,-0.1 \%\}$ \\
\hline$\left(C_{3}, \sigma_{1}, \lambda_{1}, \tau_{3}\right)$ & $\{0.133,0.826,0.041,0.840\}$ & $\{0.001,0.050,-0.051,0.4 \%\}$ \\
\hline$\left(C_{3}, \sigma_{1}, \lambda_{2}, \tau_{1}\right)$ & $\{0.091,0.908,0.00$ & $\{-0.003,0.003,0.000,0.3 \%\}$ \\
\hline$\left(C_{3}, \sigma_{1}, \lambda_{2}, \tau_{2}\right)$ & $\{0.176,0.823,0.001,0.791\}$ & $\{0.002,0.015,-0.017,-0.1 \%\}$ \\
\hline$\left(C_{3}, \sigma_{1}, \lambda_{2}, \tau_{3}\right)$ & $\{0.244,0.721,0.035,0.829\}$ & $\{0.002,0.039,-0.041,0.4 \%\}$ \\
\hline$\left(C_{3}, \sigma_{1}, \lambda_{3}, \tau_{1}\right)$ & $\{0.133,0.866,0.001,0.748\}$ & $\{-0.003,0.003,0.000,-0.3 \%\}$ \\
\hline$\left(C_{3}, \sigma_{1}, \lambda_{3}, \tau_{2}\right)$ & $\{0.247,0.752,0.001,0.787\}$ & $\{0.000,0.015,-0.015,0.1 \%\}$ \\
\hline$\left(C_{3}, \sigma_{1}, \lambda_{3}, \tau_{3}\right)$ & $\{0.340,0.637,0.023,0.816\}$ & $\{0.007,0.033,-0.040,0.1 \%\}$ \\
\hline$\left(C_{3}, \sigma_{2}, \lambda_{1}, \tau_{1}\right)$ & $\{0.048,0.951,0.001,0.761\}$ & $\{0.000,0.008,-0.009,0.4 \%\}$ \\
\hline$\left(C_{3}, \sigma_{2}, \lambda_{1}, \tau_{2}\right)$ & $\{0.095,0.904,0.001,0.805\}$ & $\{0.003,0.043,-0.047,0.5 \%\}$ \\
\hline$\left(C_{3}, \sigma_{2}, \lambda_{1}, \tau_{3}\right)$ & $\{0.136,0.802,0.063,0.843\}$ & $\{0.008,0.052,-0.059,0.7 \%\}$ \\
\hline$\left(C_{3}, \sigma_{2}, \lambda_{2}, \tau_{1}\right)$ & $\{0.091,0.908,0.001,0.757\}$ & $\{-0.002,0.010,-0.008,0.1 \%\}$ \\
\hline$\left(C_{3}, \sigma_{2}, \lambda_{2}, \tau_{2}\right)$ & $\{0.182,0.817,0.002,0.799\}$ & $\{0.010,0.032,-0.042,0.4 \%\}$ \\
\hline$\left(C_{3}, \sigma_{2}, \lambda_{2}, \tau_{3}\right)$ & $\{0.253,0.703,0.044,0.832\}$ & $\{0.019,0.041,-0.060,0.6 \%\}$ \\
\hline$\left(C_{3}, \sigma_{2}, \lambda_{3}, \tau_{1}\right)$ & $\{0.135,0.865,0.001,0.754\}$ & $\{-0.001,0.008,-0.008,-0.1 \%\}$ \\
\hline$\left(C_{3}, \sigma_{2}, \lambda_{3}, \tau_{2}\right)$ & $\{0.240,0.759,0.001,0.793\}$ & $\{-0.003,0.041,-0.037,0.2 \%\}$ \\
\hline$\left(C_{3}, \sigma_{2}, \lambda_{3}, \tau_{3}\right)$ & $\{0.342,0.621,0.037,0.825\}$ & $\{0.018,0.034,-0.052,0.9 \%\}$ \\
\hline$\left(C_{3}, \sigma_{3}, \lambda_{1}, \tau_{1}\right)$ & $\{0.050,0.949,0.001,0.764\}$ & $\{0.002,0.017,-0.019,0.2 \%\}$ \\
\hline$\left(C_{3}, \sigma_{3}, \lambda_{1}, \tau_{2}\right)$ & $\{0.094,0.901,0.006,0.806\}$ & $\{0.004,0.060,-0.064,0.2 \%\}$ \\
\hline$\left(C_{3}, \sigma_{3}, \lambda_{1}, \tau_{3}\right)$ & $\{0.133,0.786,0.081,0.846\}$ & $\{0.007,0.053,-0.061,0.7 \%\}$ \\
\hline$\left(C_{3}, \sigma_{3}, \lambda_{2}, \tau_{1}\right)$ & $\{0.090,0.909,0.001,0.763\}$ & $\{-0.002,0.021,-0.018,0.3 \%\}$ \\
\hline$\left(C_{3}, \sigma_{3}, \lambda_{2}, \tau_{2}\right)$ & $\{0.177,0.818,0.005,0.798\}$ & $\{0.007,0.051,-0.058,-0.2 \%\}$ \\
\hline$\left(C_{3}, \sigma_{3}, \lambda_{2}, \tau_{3}\right)$ & $\{0.243,0.693,0.064,0.839\}$ & $\{0.012,0.046,-0.059,1.1 \%\}$ \\
\hline$\left(C_{3}, \sigma_{3}, \lambda_{3}, \tau_{1}\right)$ & $\{0.136,0.864,0.001,0.762\}$ & $\{0.001,0.016,-0.018,0.3 \%\}$ \\
\hline$\left(C_{3}, \sigma_{3}, \lambda_{3}, \tau_{2}\right)$ & $\{0.245,0.751,0.004,0.799\}$ & $\{0.005,0.048,-0.053,0.5 \%\}$ \\
\hline$\left(C_{3}, \sigma_{3}, \lambda_{3}, \tau_{3}\right)$ & $\{0.333,0.616,0.050,0.828\}$ & $\{0.015,0.042,-0.057,0.8 \%\}$ \\
\hline
\end{tabular}


Table 13: Detailed results for the 27 instances of Test bed 2 under the use of the random coefficient model (RCM) and Gamma process (GP).

\begin{tabular}{|c|c|c|}
\hline Instance & $\begin{array}{c}\mathrm{RCM} \\
\left\{\left(\hat{C}^{*}-C^{*}\right) / H, \text { Gap } 1, \text { Gap } 2\right\}\end{array}$ & $\begin{array}{c}\text { GP } \\
\left\{\left(\hat{C}^{*}-C^{*}\right) / H, \text { Gap } 1, \text { Gap } 2\right\}\end{array}$ \\
\hline$\left(\sigma_{1}, \lambda_{1}, \tau_{1}\right)$ & $\{-0.03 \%, 0.06 \%, 0.01 \%\}$ & $\{1.79 \%, 2.36 \%, 1.69 \%\}$ \\
\hline$\left(\sigma_{1}, \lambda_{1}, \tau_{2}\right)$ & $\{0.28 \%, 0.25 \%, 0.05 \%\}$ & $\{-0.26 \%, 4.70 \%, 0.07 \%\}$ \\
\hline$\left(\sigma_{1}, \lambda_{1}, \tau_{3}\right)$ & $\{0.35 \%, 0.30 \%, 0.01 \%\}$ & $\{-3.82 \%, 4.80 \%, 0.72 \%\}$ \\
\hline$\left(\sigma_{1}, \lambda_{2}, \tau_{1}\right)$ & $\{-0.03 \%, 0.11 \%, 0.02 \%\}$ & $\{1.54 \%, 1.69 \%, 1.20 \%\}$ \\
\hline$\left(\sigma_{1}, \lambda_{2}, \tau_{2}\right)$ & $\{0.28 \%, 0.24 \%, 0.24 \%\}$ & $\{-1.12 \%, 4.25 \%, 0.04 \%\}$ \\
\hline$\left(\sigma_{1}, \lambda_{2}, \tau_{3}\right)$ & $\{6.57 \%, 0.09 \%, 0.41 \%\}$ & $\{-1.83 \%, 4.86 \%, 0.54 \%\}$ \\
\hline$\left(\sigma_{1}, \lambda_{3}, \tau_{1}\right)$ & $\{-0.03 \%, 0.24 \%, 0.07 \%\}$ & $\{1.29 \%, 1.43 \%, 1.08 \%\}$ \\
\hline$\left(\sigma_{1}, \lambda_{3}, \tau_{2}\right)$ & $\{0.28 \%, 0.26 \%, 0.10 \%\}$ & $\{-0.64 \%, 3.44 \%, 0.60 \%\}$ \\
\hline$\left(\sigma_{1}, \lambda_{3}, \tau_{3}\right)$ & $\{-0.88 \%, 0.27 \%, 0.17 \%\}$ & $\{-3.57 \%, 4.93 \%, 0.19 \%\}$ \\
\hline$\left(\sigma_{2}, \lambda_{1}, \tau_{1}\right)$ & $\{0.58 \%, 0.06 \%, 0.19 \%\}$ & $\{1.32 \%, 1.75 \%, 0.39 \%\}$ \\
\hline$\left(\sigma_{2}, \lambda_{1}, \tau_{2}\right)$ & $\{-0.50 \%, 0.01 \%, 0.10 \%\}$ & $\{-1.47 \%, 4.61 \%, 1.35 \%\}$ \\
\hline$\left(\sigma_{2}, \lambda_{1}, \tau_{3}\right)$ & $\{0.35 \%, 0.11 \%, 0.04 \%\}$ & $\{-4.59 \%, 6.76 \%, 1.74 \%\}$ \\
\hline$\left(\sigma_{2}, \lambda_{2}, \tau_{1}\right)$ & $\{-0.20 \%, 0.03 \%, 0.09 \%\}$ & $\{1.02 \%, 1.05 \%, 0.36 \%\}$ \\
\hline$\left(\sigma_{2}, \lambda_{2}, \tau_{2}\right)$ & $\{-0.50 \%, 0.08 \%, 0.15 \%\}$ & $\{-2.39 \%, 4.27 \%, 0.96 \%\}$ \\
\hline$\left(\sigma_{2}, \lambda_{2}, \tau_{3}\right)$ & $\{-0.96 \%, 0.63 \%, 0.06 \%\}$ & $\{-5.14 \%, 6.34 \%, 1.44 \%\}$ \\
\hline$\left(\sigma_{2}, \lambda_{3}, \tau_{1}\right)$ & $\{1.36 \%, 0.12 \%, 0.11 \%\}$ & $\{0.74 \%, 0.88 \%, 0.40 \%\}$ \\
\hline$\left(\sigma_{2}, \lambda_{3}, \tau_{2}\right)$ & $\{0.28 \%, 0.12 \%, 0.16 \%\}$ & $\{-1.94 \%, 3.65 \%, 1.17 \%\}$ \\
\hline$\left(\sigma_{2}, \lambda_{3}, \tau_{3}\right)$ & $\{-0.18 \%, 0.64 \%, 0.05 \%\}$ & $\{-5.45 \%, 6.52 \%, 1.50 \%\}$ \\
\hline$\left(\sigma_{3}, \lambda_{1}, \tau_{1}\right)$ & $\{-0.20 \%, 0.01 \%, 0.10 \%\}$ & $\{0.29 \%,-0.55 \%, 0.38 \%\}$ \\
\hline$\left(\sigma_{3}, \lambda_{1}, \tau_{2}\right)$ & $\{3.72 \%, 0.24 \%, 0.33 \%\}$ & $\{-4.30 \%, 3.18 \%, 2.73 \%\}$ \\
\hline$\left(\sigma_{3}, \lambda_{1}, \tau_{3}\right)$ & $\{1.48 \%, 0.25 \%, 0.20 \%\}$ & $\{-6.65 \%, 7.13 \%, 3.93 \%\}$ \\
\hline$\left(\sigma_{3}, \lambda_{2}, \tau_{1}\right)$ & $\{-0.20 \%, 0.35 \%, 0.21 \%\}$ & $\{-1.32 \%,-0.26 \%, 0.20 \%\}$ \\
\hline$\left(\sigma_{3}, \lambda_{2}, \tau_{2}\right)$ & $\{-0.50 \%, 0.14 \%, 0.16 \%\}$ & $\{-3.92 \%, 2.45 \%, 2.45 \%\}$ \\
\hline$\left(\sigma_{3}, \lambda_{2}, \tau_{3}\right)$ & $\{-0.96 \%, 0.25 \%, 0.05 \%\}$ & $\{-4.52 \%, 6.90 \%, 2.79 \%\}$ \\
\hline$\left(\sigma_{3}, \lambda_{3}, \tau_{1}\right)$ & $\{-0.20 \%, 0.02 \%, 0.10 \%\}$ & $\{-1.61 \%, 0.06 \%, 0.43 \%\}$ \\
\hline$\left(\sigma_{3}, \lambda_{3}, \tau_{2}\right)$ & $\{0.28 \%, 0.02 \%, 0.09 \%\}$ & $\{-3.47 \%, 1.80 \%, 2.58 \%\}$ \\
\hline$\left(\sigma_{3}, \lambda_{3}, \tau_{3}\right)$ & $\{0.60 \%, 0.29 \%, 0.04 \%\}$ & $\{-7.33 \%, 6.33 \%, 1.76 \%\}$ \\
\hline
\end{tabular}


Table 14: Detailed results for the cost savings percentages $\triangle_{0}, \triangle_{1}, \triangle_{2}$ for all 27 instances of Test bed 2 and under two fitting options for the degradation process

\begin{tabular}{|c|cc|cc|cc|}
\hline \multicolumn{2}{|c|}{$\triangle_{0}$} & \multicolumn{2}{c|}{$\triangle_{1}$} & \multicolumn{2}{c|}{$\triangle_{2}$} \\
\hline$\left(\sigma_{1}, \lambda_{1}, \tau_{1}\right)$ & $35.3 \%$ & $31.4 \%$ & $31.6 \%$ & $25.9 \%$ & $5.1 \%$ & $8.8 \%$ \\
$\left(\sigma_{1}, \lambda_{1}, \tau_{2}\right)$ & $30.9 \%$ & $27.4 \%$ & $27.0 \%$ & $20.6 \%$ & $5.1 \%$ & $8.8 \%$ \\
$\left(\sigma_{1}, \lambda_{1}, \tau_{3}\right)$ & $25.0 \%$ & $24.0 \%$ & $11.6 \%$ & $16.5 \%$ & $5.1 \%$ & $8.8 \%$ \\
$\left(\sigma_{1}, \lambda_{2}, \tau_{1}\right)$ & $35.0 \%$ & $31.2 \%$ & $31.6 \%$ & $25.9 \%$ & $8.9 \%$ & $11.8 \%$ \\
$\left(\sigma_{1}, \lambda_{2}, \tau_{2}\right)$ & $30.2 \%$ & $27.1 \%$ & $27.0 \%$ & $20.6 \%$ & $8.9 \%$ & $11.8 \%$ \\
$\left(\sigma_{1}, \lambda_{2}, \tau_{3}\right)$ & $23.0 \%$ & $23.7 \%$ & $11.6 \%$ & $16.5 \%$ & $8.9 \%$ & $11.8 \%$ \\
$\left(\sigma_{1}, \lambda_{3}, \tau_{1}\right)$ & $34.7 \%$ & $31.0 \%$ & $31.6 \%$ & $25.9 \%$ & $11.7 \%$ & $14.0 \%$ \\
$\left(\sigma_{1}, \lambda_{3}, \tau_{2}\right)$ & $29.6 \%$ & $26.9 \%$ & $27.0 \%$ & $20.6 \%$ & $11.7 \%$ & $14.0 \%$ \\
$\left(\sigma_{1}, \lambda_{3}, \tau_{3}\right)$ & $23.1 \%$ & $23.6 \%$ & $11.6 \%$ & $16.5 \%$ & $11.7 \%$ & $14.0 \%$ \\
$\left(\sigma_{2}, \lambda_{1}, \tau_{1}\right)$ & $34.7 \%$ & $30.1 \%$ & $29.7 \%$ & $26.4 \%$ & $5.0 \%$ & $7.5 \%$ \\
$\left(\sigma_{2}, \lambda_{1}, \tau_{2}\right)$ & $29.0 \%$ & $26.2 \%$ & $23.0 \%$ & $20.7 \%$ & $5.0 \%$ & $7.5 \%$ \\
$\left(\sigma_{2}, \lambda_{1}, \tau_{3}\right)$ & $24.0 \%$ & $23.1 \%$ & $14.6 \%$ & $15.4 \%$ & $5.0 \%$ & $7.5 \%$ \\
$\left(\sigma_{2}, \lambda_{2}, \tau_{1}\right)$ & $34.4 \%$ & $29.9 \%$ & $29.7 \%$ & $26.4 \%$ & $8.7 \%$ & $10.7 \%$ \\
$\left(\sigma_{2}, \lambda_{2}, \tau_{2}\right)$ & $28.6 \%$ & $26.0 \%$ & $23.0 \%$ & $20.7 \%$ & $8.7 \%$ & $10.7 \%$ \\
$\left(\sigma_{2}, \lambda_{2}, \tau_{3}\right)$ & $22.7 \%$ & $23.0 \%$ & $14.6 \%$ & $15.4 \%$ & $8.7 \%$ & $10.7 \%$ \\
$\left(\sigma_{2}, \lambda_{3}, \tau_{1}\right)$ & $34.1 \%$ & $29.8 \%$ & $29.7 \%$ & $26.4 \%$ & $11.5 \%$ & $13.1 \%$ \\
$\left(\sigma_{2}, \lambda_{3}, \tau_{2}\right)$ & $28.2 \%$ & $25.9 \%$ & $23.0 \%$ & $20.7 \%$ & $11.5 \%$ & $13.1 \%$ \\
$\left(\sigma_{2}, \lambda_{3}, \tau_{3}\right)$ & $22.7 \%$ & $23.0 \%$ & $14.6 \%$ & $15.4 \%$ & $11.5 \%$ & $13.1 \%$ \\
$\left(\sigma_{3}, \lambda_{1}, \tau_{1}\right)$ & $34.3 \%$ & $29.7 \%$ & $29.5 \%$ & $27.9 \%$ & $4.8 \%$ & $6.4 \%$ \\
$\left(\sigma_{3}, \lambda_{1}, \tau_{2}\right)$ & $28.4 \%$ & $25.8 \%$ & $20.2 \%$ & $21.9 \%$ & $4.8 \%$ & $6.4 \%$ \\
$\left(\sigma_{3}, \lambda_{1}, \tau_{3}\right)$ & $23.7 \%$ & $22.9 \%$ & $16.2 \%$ & $12.2 \%$ & $4.8 \%$ & $6.4 \%$ \\
$\left(\sigma_{3}, \lambda_{2}, \tau_{1}\right)$ & $34.0 \%$ & $29.6 \%$ & $29.5 \%$ & $27.9 \%$ & $8.5 \%$ & $9.8 \%$ \\
$\left(\sigma_{3}, \lambda_{2}, \tau_{2}\right)$ & $28.1 \%$ & $25.7 \%$ & $20.2 \%$ & $21.9 \%$ & $8.5 \%$ & $9.8 \%$ \\
$\left(\sigma_{3}, \lambda_{2}, \tau_{3}\right)$ & $23.1 \%$ & $22.9 \%$ & $16.2 \%$ & $12.2 \%$ & $8.5 \%$ & $9.8 \%$ \\
$\left(\sigma_{3}, \lambda_{3}, \tau_{1}\right)$ & $33.7 \%$ & $29.5 \%$ & $29.5 \%$ & $27.9 \%$ & $11.3 \%$ & $12.4 \%$ \\
$\left(\sigma_{3}, \lambda_{3}, \tau_{2}\right)$ & $27.8 \%$ & $25.6 \%$ & $20.2 \%$ & $21.9 \%$ & $11.3 \%$ & $12.4 \%$ \\
$\left(\sigma_{3}, \lambda_{3}, \tau_{3}\right)$ & $23.0 \%$ & $23.0 \%$ & $16.2 \%$ & $12.2 \%$ & $11.3 \%$ & $12.4 \%$ \\
\hline
\end{tabular}




\begin{tabular}{|c|c|c|c|}
\hline Nr. & Year & Title & Author(s) \\
\hline 499 & 2016 & $\begin{array}{l}\text { A Condition-Based Maintenance Model for a Single } \\
\text { Component in a System with Scheduled and Unscheduled } \\
\text { Downs }\end{array}$ & $\begin{array}{l}\text { Qiushi Zhu, Hao Peng, Bas Timmermans, } \\
\text { and Geert-Jan van Houtum }\end{array}$ \\
\hline 498 & 2016 & $\begin{array}{l}\text { An age-based maintenance policy using the opportunities of } \\
\text { scheduled and unscheduled system downs }\end{array}$ & $\begin{array}{l}\text { Qiushi Zhu, Hao Peng } \\
\text { Geert-Jan van Houtum }\end{array}$ \\
\hline 497 & 2016 & $\begin{array}{l}\text { Dynamism in Inter-Organizational Service Orchestration - An } \\
\text { Analysis of the State of the Art }\end{array}$ & $\begin{array}{l}\text { Paul Grefen } \\
\text { Stefanie Rinderle-Ma }\end{array}$ \\
\hline 496 & 2016 & $\begin{array}{l}\text { Service-Dominant Business } \\
\text { Modeling in Transport Logistics }\end{array}$ & Oktay Türetken, Paul Grefen \\
\hline 495 & 2016 & Approximate Dynamic Programming by Practical Examples & $\begin{array}{l}\text { Martijn Mes } \\
\text { Arturo Perez Rivera }\end{array}$ \\
\hline 494 & 2016 & $\begin{array}{l}\text { Design of a near-optimal generalized } A B C \text { classi? } \\
\text { multi-item invention for a }\end{array}$ & $\begin{array}{l}\text { E. Van Wingerden } \\
\text { T. Tan } \\
\text { G.J. Van Houtum } \\
\end{array}$ \\
\hline 493 & 2015 & multi-item inventory control problem & $\begin{array}{l}\text { W.J.A. van Heeswijk } \\
\text { M.R.K. Mes } \\
\text { J.M.J Schutten }\end{array}$ \\
\hline 492 & 2015 & $\begin{array}{l}\text { Anticipatory Freight Selection in Intermodal } \\
\text { Long-haul Round-trips }\end{array}$ & $\begin{array}{l}\text { A.E. Pérez Rivera } \\
\text { M.R.K. Mes }\end{array}$ \\
\hline 491 & 2015 & $\begin{array}{l}\text { Base-stock policies for lost-sales models: } \\
\text { Aggregation and asymptotics }\end{array}$ & $\begin{array}{l}\text { Joachim Arts } \\
\text { Retsef Levi } \\
\text { Geert-Jan van Houtum } \\
\text { Bert Zwart }\end{array}$ \\
\hline 490 & 2015 & $\begin{array}{l}\text { The Time-Dependent Pro_table Pickup and Delivery } \\
\text { Traveling Salesman Problem with Time Windows }\end{array}$ & $\begin{array}{l}\text { Peng Sun } \\
\text { Said Dabia } \\
\text { Lucas P. Veelenturf } \\
\text { Tom Van Woensel }\end{array}$ \\
\hline 489 & 2015 & $\begin{array}{l}\text { A survey of maintenance and service logistics management: } \\
\text { Classification and research agenda from a maritime sector } \\
\text { perspective }\end{array}$ & $\begin{array}{l}\text { Ayse Sena Eruguz, Tarkan Tan, Geert-Jan } \\
\text { van Houtum }\end{array}$ \\
\hline 488 & 2015 & Structuring AHP-based maintenance policy selection & $\begin{array}{l}\text { A.J.M. Goossens, R.J.I. Basten, J.M. } \\
\text { Hummel, L.L.M. van der Wegen }\end{array}$ \\
\hline 487 & 2015 & $\begin{array}{l}\text { Pooling of critical, low-utilization resources with } \\
\text { unavailability }\end{array}$ & $\begin{array}{l}\text { Loe Schlicher, Marco Slikker, } \\
\text { Geert-Jan van Houtum }\end{array}$ \\
\hline 486 & 2015 & $\begin{array}{l}\text { Business Process Management Technology for Discrete } \\
\text { Manufacturing }\end{array}$ & Irene Vanderfeesten, Paul Grefen \\
\hline 485 & 2015 & $\begin{array}{l}\text { Towards an Architecture for Cooperative-Intelligent } \\
\text { Transport System (C-ITS) Applications in the Netherlands }\end{array}$ & $\begin{array}{l}\text { Marcel van Sambeek, Frank Ophelders, } \\
\text { Tjerk Bijlsma, Borgert van der Kluit, } \\
\text { Oktay Türetken, Rik Eshuis, Kostas } \\
\text { Traganos, Paul Grefen }\end{array}$ \\
\hline 484 & 2015 & $\begin{array}{l}\text { Reasoning About Property Preservation in Adaptive Case } \\
\text { Management }\end{array}$ & Rik Eshuis, Richard Hull, Mengfei Yi \\
\hline 483 & 2015 & $\begin{array}{l}\text { An Adaptive Large Neighborhood Search Heuristic for the } \\
\text { Pickup and Delivery Problem with Time Windows and } \\
\text { Scheduled Lines }\end{array}$ & $\begin{array}{l}\text { Veaceslav Ghilas, Emrah Demir, Tom } \\
\text { Van Woensel }\end{array}$ \\
\hline 482 & 2015 & $\begin{array}{l}\text { Inventory Dynamics in the Financial Crisis: An Empirical } \\
\text { Analysis of Firm Responsiveness and its Effect on Financial } \\
\text { Performance }\end{array}$ & $\begin{array}{l}\text { Kai Hoberg, Maximiliano Udenio, Jan } \\
\text { C. Fransoo }\end{array}$ \\
\hline 481 & 2015 & $\begin{array}{l}\text { The extended gate problem: Intermodal hub location with } \\
\text { multiple actors }\end{array}$ & $\begin{array}{l}\text { Yann Bouchery, Jan Fransoo, Marco } \\
\text { Slikker }\end{array}$ \\
\hline 480 & 2015 & $\begin{array}{l}\text { Inventory Management with Two Demand Streams: A } \\
\text { Maintenance Application }\end{array}$ & Rob J.I. Basten, Jennifer K. Ryan \\
\hline 479 & 2015 & Optimal Design of Uptime-Guarantee Contracts & Behzad Hezarkhani \\
\hline
\end{tabular}




\begin{tabular}{|c|c|c|c|}
\hline Nr. & Year & Title & Author(s) \\
\hline 478 & 2015 & $\begin{array}{l}\text { Collaborative Replenishment in the Presence of } \\
\text { Intermediaries }\end{array}$ & $\begin{array}{l}\text { Behzad Hezarkhani, Marco Slikker, Tom } \\
\text { Van Woensel }\end{array}$ \\
\hline 477 & 2015 & $\begin{array}{l}\text { Reference Architecture for Mobility-Related Services A } \\
\text { reference architecture based on GET Service and SIMPLI-CITY } \\
\text { Project architectures }\end{array}$ & $\begin{array}{l}\text { A. Husak, M. Politis, V. Shah, } \\
\text { Eshuis, P. Grefen }\end{array}$ \\
\hline 476 & 2015 & $\begin{array}{l}\text { A Multi-Item Approach to Repairable Stocking and } \\
\text { Expediting in a Fluctuating Demand Environment }\end{array}$ & Joachim Arts \\
\hline 475 & 2015 & $\begin{array}{l}\text { An Adaptive Large Neighborhood Search Heuristic for the } \\
\text { Share-a-Ride Problem }\end{array}$ & $\begin{array}{l}\text { Baoxiang Li, Dmitry Krushinsky, Tom Van } \\
\text { Woensel, Hajo A. Reijers }\end{array}$ \\
\hline 474 & 2015 & $\begin{array}{l}\text { An approximate dynamic programming approach to urban } \\
\text { freight distribution with batch arrivals }\end{array}$ & $\begin{array}{l}\text { Wouter van Heeswijk, Martijn Mes, } \\
\text { Marco Schutten }\end{array}$ \\
\hline 473 & 2015 & Dynamic Multi-period Freight Consolidation & Arturo Pérez Rivera, Martijn Mes \\
\hline 472 & 2015 & $\begin{array}{l}\text { Maintenance policy selection for ships: finding the most } \\
\text { important criteria and considerations }\end{array}$ & A.J.M. Goossens, R.J.I. Basten \\
\hline 471 & 2015 & Using Twitter to Predict Sales: A Case Study & $\begin{array}{l}\text { Remco Dijkman, Panagiotis Ipeirotis, } \\
\text { Freek Aertsen, Roy van Helden }\end{array}$ \\
\hline 470 & 2015 & The Effect of Exceptions in Business Processes & $\begin{array}{l}\text { Remco Dijkman, Geoffrey van } \\
\text { IJzendoorn, Oktay Türetken, Meint de } \\
\text { Vries }\end{array}$ \\
\hline 469 & 2015 & $\begin{array}{l}\text { Business Model Prototyping for Intelligent Transport } \\
\text { Systems. A Service-Dominant Approach }\end{array}$ & $\begin{array}{l}\text { Konstantinos Traganos, Paul Grefen, } \\
\text { Aafke den Hollander, Oktay Türetken, } \\
\text { Rik Eshuis }\end{array}$ \\
\hline 468 & 2015 & $\begin{array}{l}\text { How suitable is the RePro technique for rethinking care } \\
\text { processes? }\end{array}$ & $\begin{array}{l}\text { Rob J.B. Vanwersch, Luise Pufahl, Irene } \\
\text { Vanderfeesten, Jan Mendling, Hajo A. } \\
\text { Reijers }\end{array}$ \\
\hline 467 & 2014 & $\begin{array}{l}\text { Where to exert abatement effort for sustainable operations } \\
\text { considering supply chain interactions? }\end{array}$ & Tarkan Tan, Astrid Koomen \\
\hline 466 & 2014 & $\begin{array}{l}\text { An Exact Algorithm for the Vehicle Routing Problem with } \\
\text { Time Windows and Shifts }\end{array}$ & $\begin{array}{l}\text { Said Dabia, Stefan Ropke, Tom Van } \\
\text { Woensel }\end{array}$ \\
\hline 465 & 2014 & $\begin{array}{l}\text { The RePro technique: a new, systematic technique for } \\
\text { rethinking care processes }\end{array}$ & $\begin{array}{l}\text { Rob J.B. Vanwersch, Luise Pufahl, Irene } \\
\text { Vanderfeesten, Hajo A. Reijers }\end{array}$ \\
\hline 464 & 2014 & $\begin{array}{l}\text { Exploring maintenance policy selection using the Analytic } \\
\text { Hierarchy Process: an application for naval ships }\end{array}$ & A.J.M. Goossens, R.J.I. Basten \\
\hline 463 & 2014 & $\begin{array}{l}\text { Allocating service parts in two-echelon networks at a utility } \\
\text { company }\end{array}$ & $\begin{array}{l}\text { D. van den Berg, M.C. van der Heijden, } \\
\text { P.C. Schuur }\end{array}$ \\
\hline 462 & 2014 & Freight consolidation in networks with transshipments & $\begin{array}{l}\text { W.J.A. van Heeswijk, M.R.K. Mes, J.M.J. } \\
\text { Schutten, W.H.M. Zijm }\end{array}$ \\
\hline 461 & 2014 & A Software Architecture for a Transportation Control Tower & $\begin{array}{l}\text { Anne Baumgrass, Remco Dijkman, Paul } \\
\text { Grefen, Shaya Pourmirza, Hagen Völzer, } \\
\text { Mathias Weske }\end{array}$ \\
\hline 460 & 2014 & Small traditional retailers in emerging markets & $\begin{array}{l}\text { Youssef Boulaksil, Jan C. Fransoo, Edgar } \\
\text { E. Blanco, Sallem Koubida }\end{array}$ \\
\hline 459 & 2014 & Defining line replaceable units & J.E. Parada Puig, R.J.I. Basten \\
\hline 458 & 2014 & Inventories and the Credit Crisis: A Chicken and Egg Situation & $\begin{array}{l}\text { Maximiliano Udenio, Vishal Gaur, Jan C. } \\
\text { Fransoo }\end{array}$ \\
\hline 457 & 2014 & An Exact Approach for the Pollution-Routing Problem & $\begin{array}{l}\text { Said Dabia, Emrah Demir, Tom Van } \\
\text { Woensel }\end{array}$ \\
\hline 456 & 2014 & Fleet readiness: stocking spare parts and high-tech assets & Rob J.I. Basten, Joachim J. Arts \\
\hline 455 & 2014 & Competitive Solutions for Cooperating Logistics Providers & $\begin{array}{l}\text { Behzad Hezarkhani, Marco Slikker, Tom } \\
\text { Van Woensel }\end{array}$ \\
\hline 454 & 2014 & $\begin{array}{l}\text { Simulation Framework to Analyse Operating Room Release } \\
\text { Mechanisms }\end{array}$ & $\begin{array}{l}\text { Rimmert van der Kooij, Martijn Mes, } \\
\text { Erwin Hans }\end{array}$ \\
\hline 453 & 2014 & A Unified Race Algorithm for Offline Parameter Tuning & $\begin{array}{l}\text { Tim van Dijk, Martijn Mes, Marco } \\
\text { Schutten, Joaquim Gromicho }\end{array}$ \\
\hline 452 & 2014 & $\begin{array}{l}\text { Cost, carbon emissions and modal shift in intermodal } \\
\text { network design decisions }\end{array}$ & Yann Bouchery, Jan Fransoo \\
\hline
\end{tabular}




\begin{tabular}{|c|c|c|c|}
\hline Nr. & Year & Title & Author(s) \\
\hline 451 & 2014 & $\begin{array}{l}\text { Transportation Cost and CO2 Emissions in Location Decision } \\
\text { Models }\end{array}$ & $\begin{array}{l}\text { Josue C. Vélazquez-Martínez, Jan C. } \\
\text { Fransoo, Edgar E. Blanco, Jaime Mora- } \\
\text { Vargas }\end{array}$ \\
\hline 450 & 2014 & Tracebook: A Dynamic Checklist Support System & $\begin{array}{l}\text { Shan Nan, Pieter Van Gorp, Hendrikus } \\
\text { H.M. Korsten, Richard Vdovjak, Uzay } \\
\text { Kaymak }\end{array}$ \\
\hline 449 & 2014 & Intermodal hinterland network design with multiple actors & Yann Bouchery, J an Fransoo \\
\hline 448 & 2014 & The Share-a-Ride Problem: People and Parcels Sharing Taxis & $\begin{array}{l}\text { Baoxiang Li, Dmitry Krushinsky, Hajo } \\
\text { A. Reijers, Tom Van Woensel }\end{array}$ \\
\hline 447 & 2014 & $\begin{array}{l}\text { Stochastic inventory models for a single item at a single } \\
\text { location }\end{array}$ & $\begin{array}{l}\text { K.H. van Donselaar, R.A.C.M. } \\
\text { Broekmeulen }\end{array}$ \\
\hline 446 & 2014 & $\begin{array}{l}\text { Optimal and heuristic repairable stocking and expediting in a } \\
\text { fluctuating demand environment }\end{array}$ & $\begin{array}{l}\text { J oachim Arts, Rob Basten, Geert-J an } \\
\text { van Houtum }\end{array}$ \\
\hline 445 & 2014 & $\begin{array}{l}\text { Connecting inventory control and repair shop control: a } \\
\text { differentiated control structure for repairable spare parts }\end{array}$ & $\begin{array}{l}\text { M.A. Driessen, W.D. Rustenburg, G.J. } \\
\text { van Houtum, V.C.S. Wiers }\end{array}$ \\
\hline 444 & 2014 & $\begin{array}{l}\text { A survey on design and usage of Software Reference } \\
\text { Architectures }\end{array}$ & $\begin{array}{l}\text { Samuil Angelov, Jos Trienekens, Rob } \\
\text { Kusters }\end{array}$ \\
\hline 443 & 2014 & $\begin{array}{l}\text { Extending and Adapting the Architecture Tradeoff Analysis } \\
\text { Method for the Evaluation of Software Reference } \\
\text { Architectures }\end{array}$ & $\begin{array}{l}\text { Samuil Angelov, Jos J.M. Trienekens, } \\
\text { Paul Grefen }\end{array}$ \\
\hline 442 & 2014 & $\begin{array}{l}\text { A multimodal network flow problem with product quality } \\
\text { preservation, transshipment, and asset management }\end{array}$ & $\begin{array}{l}\text { Maryam SteadieSeifi, Nico Dellaert, } \\
\text { Tom Van Woensel }\end{array}$ \\
\hline 441 & 2013 & $\begin{array}{l}\text { Integrating passenger and freight transportation: Model } \\
\text { formulation and insights }\end{array}$ & $\begin{array}{l}\text { Veaceslav Ghilas, Emrah Demir, Tom } \\
\text { Van Woensel }\end{array}$ \\
\hline 440 & 2013 & The Price of Payment Delay & $\begin{array}{l}\text { K. van der Vliet, M.J. Reindorp, J.C. } \\
\text { Fransoo }\end{array}$ \\
\hline 439 & 2013 & $\begin{array}{l}\text { On Characterization of the Core of Lane Covering Games via } \\
\text { Dual Solutions }\end{array}$ & $\begin{array}{l}\text { Behzad Hezarkhani, Marco Slikker, Tom } \\
\text { van Woensel }\end{array}$ \\
\hline 438 & 2013 & $\begin{array}{l}\text { Destocking, the Bullwhip Effect, and the Credit Crisis: } \\
\text { Empirical Modeling of Supply Chain Dynamics }\end{array}$ & $\begin{array}{l}\text { Maximiliano Udenio, Jan C. Fransoo, } \\
\text { Robert Peels }\end{array}$ \\
\hline 437 & 2013 & $\begin{array}{l}\text { Methodological support for business process redesign in } \\
\text { healthcare: a systematic literature review }\end{array}$ & $\begin{array}{l}\text { Rob J.B. Vanwersch, Khurram Shahzad, } \\
\text { I rene Vanderfeesten, Kris Vanhaecht, } \\
\text { Paul Grefen, Liliane Pintelon, Jan } \\
\text { Mendling, Geofridus G. van Merode, } \\
\text { Haio A. Reiiers }\end{array}$ \\
\hline 436 & 2013 & $\begin{array}{l}\text { Dynamics and equilibria under incremental horizontal } \\
\text { differentiation on the Salop circle }\end{array}$ & $\begin{array}{l}\text { B. Vermeulen, J.A. La Poutré, A.G. de } \\
\text { Kok }\end{array}$ \\
\hline 435 & 2013 & $\begin{array}{l}\text { Analyzing Conformance to Clinical Protocols Involving } \\
\text { Advanced Synchronizations }\end{array}$ & $\begin{array}{l}\text { Hui Yan, Pieter Van Gorp, Uzay } \\
\text { Kaymak, Xudong Lu, Richard Vdovjak, } \\
\text { Hendriks H.M. Korsten, Huilong Duan }\end{array}$ \\
\hline 434 & 2013 & $\begin{array}{l}\text { Models for Ambulance Planning on the Strategic and the } \\
\text { Tactical Level }\end{array}$ & $\begin{array}{l}\text { J. Theresia van Essen, J ohann L. } \\
\text { Hurink, Stefan Nickel, Melanie Reuter }\end{array}$ \\
\hline 433 & 2013 & $\begin{array}{l}\text { Mode Allocation and Scheduling of Inland Container } \\
\text { Transportation: A Case-Study in the Netherlands }\end{array}$ & $\begin{array}{l}\text { Stefano Fazi, Tom Van Woensel, Jan C. } \\
\text { Fransoo }\end{array}$ \\
\hline 432 & 2013 & $\begin{array}{l}\text { Socially responsible transportation and lot sizing: Insights } \\
\text { from multiobjective optimization }\end{array}$ & $\begin{array}{l}\text { Yann Bouchery, Asma Ghaffari, Zied } \\
\text { Jemai, J an Fransoo }\end{array}$ \\
\hline 431 & 2013 & Inventory routing for dynamic waste collection & $\begin{array}{l}\text { Martijn Mes, Marco Schutten, Arturo } \\
\text { Pérez Rivera }\end{array}$ \\
\hline 430 & 2013 & $\begin{array}{l}\text { Simulation and Logistics Optimization of an Integrated } \\
\text { Emergency Post }\end{array}$ & $\begin{array}{l}\text { N.J. Borgman, M.R.K. Mes, I.M.H. } \\
\text { Vliegen, E.W. Hans }\end{array}$ \\
\hline 429 & 2013 & Last Time Buy and Repair Decisions for Spare Parts & $\begin{array}{l}\text { S. Behfard, M.C. van der Heijden, A. Al } \\
\text { Hanbali, W.H.M. Zijm }\end{array}$ \\
\hline 428 & 2013 & $\begin{array}{l}\text { A Review of Recent Research on Green Road Freight } \\
\text { Transportation }\end{array}$ & $\begin{array}{l}\text { Emrah Demir, Tolga Bektas, Gilbert } \\
\text { Laporte }\end{array}$ \\
\hline 427 & 2013 & Typology of Repair Shops for Maintenance Spare Parts & $\begin{array}{l}\text { M.A. Driessen, V.C.S. Wiers, G.J. van } \\
\text { Houtum, W.D. Rustenburg }\end{array}$ \\
\hline 426 & 2013 & $\begin{array}{l}\text { A value network development model and implications for } \\
\text { innovation and production network management }\end{array}$ & B. Vermeulen, A.G. de Kok \\
\hline 425 & 2013 & $\begin{array}{l}\text { Single Vehicle Routing with Stochastic Demands: } \\
\text { Approximate Dynamic Programming }\end{array}$ & $\begin{array}{l}\text { C. Zhang, N.P. Dellaert, L. Zhao, T. } \\
\text { Van Woensel, D. Sever }\end{array}$ \\
\hline
\end{tabular}




\begin{tabular}{|c|c|c|c|}
\hline Nr. & Year & Title & Author(s) \\
\hline 424 & 2013 & $\begin{array}{l}\text { Influence of Spillback Effect on Dynamic Shortest Path } \\
\text { Problems with Travel-Time-Dependent Network Disruptions }\end{array}$ & $\begin{array}{l}\text { Derya Sever, Nico Dellaert, Tom Van } \\
\text { Woensel, Ton de Kok }\end{array}$ \\
\hline 423 & 2013 & $\begin{array}{l}\text { Dynamic Shortest Path Problem with Travel-Time-Dependent } \\
\text { Stochastic Disruptions: Hybrid Approximate Dynamic } \\
\text { Programming Algorithms with a Clustering Approach }\end{array}$ & $\begin{array}{l}\text { Derya Sever, Lei Zhao, Nico Dellaert, } \\
\text { Tom Van Woensel, Ton de Kok }\end{array}$ \\
\hline 422 & 2013 & System-oriented inventory models for spare parts & R.J.I. Basten, G.J. van Houtum \\
\hline 421 & 2013 & $\begin{array}{l}\text { Lost Sales Inventory Models with Batch Ordering and } \\
\text { Handling Costs }\end{array}$ & $\begin{array}{l}\text { T. Van Woensel, N. Erkip, A. Curseu, J.C. } \\
\text { Fransoo }\end{array}$ \\
\hline 420 & 2013 & Response speed and the bullwhip & $\begin{array}{l}\text { Maximiliano Udenio, Jan C. Fransoo, } \\
\text { Eleni Vatamidou, Nico Dellaert }\end{array}$ \\
\hline 419 & 2013 & Anticipatory Routing of Police Helicopters & $\begin{array}{l}\text { Rick van Urk, Martijn R.K. Mes, Erwin W. } \\
\text { Hans }\end{array}$ \\
\hline 418 & 2013 & Supply Chain Finance: research challenges ahead & $\begin{array}{l}\text { Kasper van der Vliet, Matthew J. } \\
\text { Reindorp, Jan C. Fransoo }\end{array}$ \\
\hline 417 & 2013 & $\begin{array}{l}\text { Improving the Performance of Sorter Systems by Scheduling } \\
\text { Inbound Containers }\end{array}$ & S.W.A. Haneyah, J.M.J. Schutten, K. Fikse \\
\hline 416 & 2013 & $\begin{array}{l}\text { Regional logistics land allocation policies: Stimulating spatial } \\
\text { concentration of logistics firms }\end{array}$ & $\begin{array}{l}\text { Frank P. van den Heuvel, Peter W. de } \\
\text { Langen, Karel H. van Donselaar, Jan C. } \\
\text { Fransoo }\end{array}$ \\
\hline 415 & 2013 & The development of measures of process harmonization & $\begin{array}{l}\text { Heidi L. Romero, Remco M. Dijkman, } \\
\text { Paul W.P.J. Grefen, Arjan van Weele }\end{array}$ \\
\hline 414 & 2013 & $\begin{array}{l}\text { BASE/X. Business Agility through Cross-Organizational Service } \\
\text { Engineering. The Business and Service Design Approach } \\
\text { developed in the CoProFind Project }\end{array}$ & $\begin{array}{l}\text { Paul Grefen, Egon Lüftenegger, Eric van } \\
\text { der Linden, Caren Weisleder }\end{array}$ \\
\hline 413 & 2013 & $\begin{array}{l}\text { The Time-Dependent Vehicle Routing Problem with Soft Time } \\
\text { Windows and Stochastic Travel Times }\end{array}$ & $\begin{array}{l}\text { Duygu Tas, Nico Dellaert, Tom van } \\
\text { Woensel, Ton de Kok }\end{array}$ \\
\hline 412 & 2013 & $\begin{array}{l}\text { Clearing the Sky - Understanding SLA Elements in Cloud } \\
\text { Computing }\end{array}$ & $\begin{array}{l}\text { Marco Comuzzi, Guus Jacobs, Paul } \\
\text { Grefen }\end{array}$ \\
\hline 411 & 2013 & $\begin{array}{l}\text { Approximations for the waiting time distribution in an } M / G / c \\
\text { priority queue }\end{array}$ & $\begin{array}{l}\text { A. Al Hanbali, E.M. Alvarez, M.C. van der } \\
\text { Heijden }\end{array}$ \\
\hline 410 & 2013 & $\begin{array}{l}\text { To co-locate or not? Location decisions and logistics } \\
\text { concentration areas }\end{array}$ & $\begin{array}{l}\text { Frank P. van den Heuvel, Karel H. van } \\
\text { Donselaar, Rob A.C.M. Broekmeulen, } \\
\text { Jan C. Fransoo, Peter W. de Langen } \\
\end{array}$ \\
\hline 409 & 2013 & The Time-Dependent Pollution-Routing Problem & $\begin{array}{l}\text { Anna Franceschetti, Dorothée Honhon, } \\
\text { Tom van Woensel, Tolga Bektas, Gilbert } \\
\text { Laporte }\end{array}$ \\
\hline 408 & 2013 & $\begin{array}{l}\text { Scheduling the scheduling task: A time management } \\
\text { perspective on scheduling }\end{array}$ & J.A. Larco, V. Wiers, J. Fransoo \\
\hline 407 & 2013 & $\begin{array}{l}\text { Clustering Clinical Departments for Wards to Achieve a } \\
\text { Prespecified Blocking Probability }\end{array}$ & $\begin{array}{l}\text { J. Theresia van Essen, Mark van } \\
\text { Houdenhoven, Johann L. Hurink }\end{array}$ \\
\hline 406 & 2013 & MyPHRMachines: Personal Health Desktops in the Cloud & Pieter Van Gorp, Marco Comuzzi \\
\hline 405 & 2013 & Maximising the Value of Supply Chain Finance & $\begin{array}{l}\text { Kasper van der Vliet, Matthew J. } \\
\text { Reindorp, Jan C. Fransoo }\end{array}$ \\
\hline 404 & 2013 & $\begin{array}{l}\text { Reaching } 50 \text { million nanostores: retail distribution in } \\
\text { emerging megacities }\end{array}$ & Edgar E. Blanco, Jan C. Fransoo \\
\hline 403 & 2013 & A Vehicle Routing Problem with Flexible Time Windows & Duygu Tas, Ola Jabali, Tom van Woensel \\
\hline 402 & 2013 & $\begin{array}{l}\text { The Service Dominant Business Model: A Service Focused } \\
\text { Conceptualization }\end{array}$ & $\begin{array}{l}\text { Egon Lüftenegger, Marco Comuzzi, Paul } \\
\text { Grefen, Caren Weisleder }\end{array}$ \\
\hline 401 & 2013 & $\begin{array}{l}\text { Relationship between freight accessibility and logistics } \\
\text { employment in US counties }\end{array}$ & $\begin{array}{l}\text { Frank P. van den Heuvel, Liliana Rivera, } \\
\text { Karel H. van Donselaar, Ad de Jong, } \\
\text { Yossi Sheffi, Peter W. de Langen, Jan C. } \\
\text { Fransoo }\end{array}$ \\
\hline 400 & 2012 & $\begin{array}{l}\text { A Condition-Based Maintenance Policy for Multi-Component } \\
\text { Systems with a High Maintenance Setup Cost }\end{array}$ & $\begin{array}{l}\text { Qiushi Zhu, Hao Peng, Geert-Jan van } \\
\text { Houtum }\end{array}$ \\
\hline
\end{tabular}




\begin{tabular}{|c|c|c|c|}
\hline Nr. & Year & Title & Author(s) \\
\hline 399 & 2012 & $\begin{array}{l}\text { A flexible iterative improvement heuristic to support creation } \\
\text { of feasible shift rosters in self-rostering }\end{array}$ & $\begin{array}{l}\text { E. van der Veen, J.L. Hurink, J.M.J. } \\
\text { Schutten, S.T. Uijland }\end{array}$ \\
\hline 398 & 2012 & $\begin{array}{l}\text { Scheduled Service Network Design with Synchronization and } \\
\text { Transshipment Constraints for Intermodal Container } \\
\text { Transportation Networks }\end{array}$ & $\begin{array}{l}\text { K. Sharypova, T.G. Crainic, T. van } \\
\text { Woensel, J.C. Fransoo }\end{array}$ \\
\hline 397 & 2012 & $\begin{array}{l}\text { Destocking, the bullwhip effect, and the credit crisis: } \\
\text { empirical modeling of supply chain dynamics }\end{array}$ & $\begin{array}{l}\text { Maximiliano Udenio, Jan C. Fransoo, } \\
\text { Robert Peels }\end{array}$ \\
\hline 396 & 2012 & Vehicle routing with restricted loading capacities & $\begin{array}{l}\text { J. Gromicho, J.J. van Hoorn, A.L. Kok, } \\
\text { J.M.J. Schutten }\end{array}$ \\
\hline 395 & 2012 & $\begin{array}{l}\text { Service differentiation through selective lateral } \\
\text { transshipments }\end{array}$ & $\begin{array}{l}\text { E.M. Alvarez, M.C. van der Heijden, } \\
\text { I.M.H. Vliegen, W.H.M. Zijm }\end{array}$ \\
\hline 394 & 2012 & $\begin{array}{l}\text { A Generalized Simulation Model of an Integrated Emergency } \\
\text { Post }\end{array}$ & Martijn Mes, Manon Bruens \\
\hline 393 & 2012 & $\begin{array}{l}\text { Business Process Technology and the Cloud: defining a } \\
\text { Business Process Cloud Platform }\end{array}$ & Vassil Stoitsev, Paul Grefen \\
\hline 392 & 2012 & $\begin{array}{l}\text { Vehicle Routing with Soft Time Windows and Stochastic } \\
\text { Travel Times: A Column Generation and Branch-and-Price } \\
\text { Solution Approach }\end{array}$ & $\begin{array}{l}\text { D. Tas, M. Gendreau, N. Dellaert, T. van } \\
\text { Woensel, A.G. de Kok }\end{array}$ \\
\hline 391 & 2012 & Improve OR-Schedule to Reduce Number of Required Beds & $\begin{array}{l}\text { J. Theresia van Essen, Joël M. Bosch, } \\
\text { Erwin W. Hans, Mark van Houdenhoven, } \\
\text { Johann L. Hurink }\end{array}$ \\
\hline 390 & 2012 & $\begin{array}{l}\text { How does development lead time affect performance over } \\
\text { the ramp-up lifecycle? Evidence from the consumer } \\
\text { electronics industry }\end{array}$ & $\begin{array}{l}\text { Andreas Pufall, Jan C. Fransoo, Ad de } \\
\text { Jong, A.G. (Ton) de Kok }\end{array}$ \\
\hline 389 & 2012 & The Impact of Product Complexity on Ramp-Up Performance & $\begin{array}{l}\text { Andreas Pufall, Jan C. Fransoo, Ad de } \\
\text { Jong, A.G. (Ton) de Kok }\end{array}$ \\
\hline 388 & 2012 & $\begin{array}{l}\text { Co-location synergies: specialized versus diverse logistics } \\
\text { concentration areas }\end{array}$ & $\begin{array}{l}\text { Frank P. van den Heuvel, Peter W. de } \\
\text { Langen, Karel H. van Donselaar, Jan C. } \\
\text { Fransoo }\end{array}$ \\
\hline 387 & 2012 & $\begin{array}{l}\text { Proximity matters: Synergies through co-location of logistics } \\
\text { establishments }\end{array}$ & $\begin{array}{l}\text { Frank P. van den Heuvel, Peter W. de } \\
\text { Langen, Karel H. van Donselaar, Jan C. } \\
\text { Fransoo }\end{array}$ \\
\hline 386 & 2012 & $\begin{array}{l}\text { Spatial concentration and location dynamics in logistics: the } \\
\text { case of a Dutch province }\end{array}$ & $\begin{array}{l}\text { Frank P. van den Heuvel, Peter W. de } \\
\text { Langen, Karel H. van Donselaar, Jan C. } \\
\text { Fransoo }\end{array}$ \\
\hline 385 & 2012 & FNet: An Index for Advanced Business Process Querying & $\begin{array}{l}\text { Zhiqiang Yan, Remco Dijkman, Paul } \\
\text { Grefen }\end{array}$ \\
\hline 384 & 2012 & Defining Various Pathway Terms & W.R. Dalinghaus, P.M.E. Van Gorp \\
\hline 383 & 2012 & $\begin{array}{l}\text { The Service Dominant Strategy Canvas: Defining and } \\
\text { Visualizing a Service Dominant Strategy through the } \\
\text { Traditional Strategic Lens }\end{array}$ & $\begin{array}{l}\text { Egon Lüftenegger, Paul Grefen, Caren } \\
\text { Weisleder }\end{array}$ \\
\hline 382 & 2012 & $\begin{array}{l}\text { A Stochastic Variable Size Bin Packing Problem with Time } \\
\text { Constraints }\end{array}$ & $\begin{array}{l}\text { Stefano Fazi, Tom van Woensel, Jan C. } \\
\text { Fransoo }\end{array}$ \\
\hline 381 & 2012 & $\begin{array}{l}\text { Coordination and Analysis of Barge Container Hinterland } \\
\text { Networks }\end{array}$ & $\begin{array}{l}\text { K. Sharypova, T. van Woensel, J.C. } \\
\text { Fransoo }\end{array}$ \\
\hline 380 & 2012 & $\begin{array}{l}\text { Proximity matters: Synergies through co-location of logistics } \\
\text { establishments }\end{array}$ & $\begin{array}{l}\text { Frank P. van den Heuvel, Peter W. de } \\
\text { Langen, Karel H. van Donselaar, Jan C. } \\
\text { Fransoo }\end{array}$ \\
\hline 379 & 2012 & $\begin{array}{l}\text { A literature review in process harmonization: a conceptual } \\
\text { framework }\end{array}$ & $\begin{array}{l}\text { Heidi Romero, Remco Dijkman, Paul } \\
\text { Grefen, Arjan van Weele }\end{array}$ \\
\hline 378 & 2012 & $\begin{array}{l}\text { A Generic Material Flow Control Model for Two Different } \\
\text { Industries }\end{array}$ & $\begin{array}{l}\text { S.W.A. Haneyah, J.M.J. Schutten, P.C. } \\
\text { Schuur, W.H.M. Zijm }\end{array}$ \\
\hline 377 & 2012 & $\begin{array}{l}\text { Dynamic demand fulfillment in spare parts networks with } \\
\text { multiple customer classes }\end{array}$ & $\begin{array}{l}\text { H.G.H. Tiemessen, M. Fleischmann, G.J. } \\
\text { van Houtum, J.A.E.E. van Nunen, E. } \\
\text { Pratsini }\end{array}$ \\
\hline 376 & 2012 & Paper has been replaced by wp 417 & K. Fikse, S.W.A. Haneyah, J.M.J. Schutten \\
\hline
\end{tabular}




\begin{tabular}{|c|c|c|c|}
\hline Nr. & Year & Title & Author(s) \\
\hline 375 & 2012 & $\begin{array}{l}\text { Strategies for dynamic appointment making by container } \\
\text { terminals }\end{array}$ & Albert Douma, Martijn Mes \\
\hline 374 & 2012 & $\begin{array}{l}\text { MyPHRMachines: Lifelong Personal Health Records in the } \\
\text { Cloud }\end{array}$ & Pieter van Gorp, Marco Comuzzi \\
\hline 373 & 2012 & $\begin{array}{l}\text { Service differentiation in spare parts supply through } \\
\text { dedicated stocks }\end{array}$ & $\begin{array}{l}\text { E.M. Alvarez, M.C. van der Heijden, } \\
\text { W.H.M. Zijm }\end{array}$ \\
\hline 372 & 2012 & Spare parts inventory pooling: how to share the benefits? & Frank Karsten, Rob Basten \\
\hline 371 & 2012 & Condition based spare parts supply & $\begin{array}{l}\text { X. Lin, R.J.I. Basten, A.A. Kranenburg, } \\
\text { G.J. van Houtum }\end{array}$ \\
\hline 370 & 2012 & $\begin{array}{l}\text { Using Simulation to Assess the Opportunities of Dynamic } \\
\text { Waste Collection }\end{array}$ & Martijn Mes \\
\hline 369 & 2012 & Aggregate overhaul and supply chain planning for rotables & J. Arts, S.D. Flapper, K. Vernooij \\
\hline 368 & 2012 & Operating Room Rescheduling & $\begin{array}{l}\text { J.T. van Essen, J.L. Hurink, W. Hartholt, } \\
\text { B.J. van den Akker }\end{array}$ \\
\hline 367 & 2011 & $\begin{array}{l}\text { Switching Transport Modes to Meet Voluntary Carbon } \\
\text { Emission Targets }\end{array}$ & $\begin{array}{l}\text { Kristel M.R. Hoen, Tarkan Tan, Jan C. } \\
\text { Fransoo, Geert-Jan van Houtum }\end{array}$ \\
\hline 366 & 2011 & $\begin{array}{l}\text { On two-echelon inventory systems with Poisson demand and } \\
\text { lost sales }\end{array}$ & Elisa Alvarez, Matthieu van der Heijden \\
\hline 365 & 2011 & Minimizing the Waiting Time for Emergency Surgery & $\begin{array}{l}\text { J.T. van Essen, E.W. Hans, J.L. Hurink, A. } \\
\text { Oversberg }\end{array}$ \\
\hline 364 & 2012 & $\begin{array}{l}\text { Vehicle Routing Problem with Stochastic Travel Times } \\
\text { Including Soft Time Windows and Service Costs }\end{array}$ & $\begin{array}{l}\text { Duygu Tas, Nico Dellaert, Tom van } \\
\text { Woensel, Ton de Kok }\end{array}$ \\
\hline 363 & 2011 & $\begin{array}{l}\text { A New Approximate Evaluation Method for Two-Echelon } \\
\text { Inventory Systems with Emergency Shipments }\end{array}$ & $\begin{array}{l}\text { Erhun Özkan, Geert-Jan van Houtum, } \\
\text { Yasemin Serin }\end{array}$ \\
\hline 362 & 2011 & $\begin{array}{l}\text { Approximating Multi-Objective Time-Dependent } \\
\text { Optimization Problems }\end{array}$ & $\begin{array}{l}\text { Said Dabia, El-Ghazali Talbi, Tom Van } \\
\text { Woensel, Ton de Kok }\end{array}$ \\
\hline 361 & 2011 & $\begin{array}{l}\text { Branch and Cut and Price for the Time Dependent Vehicle } \\
\text { Routing Problem with Time Windows }\end{array}$ & $\begin{array}{l}\text { Said Dabia, Stefan Röpke, Tom Van } \\
\text { Woensel, Ton de Kok }\end{array}$ \\
\hline 360 & 2011 & $\begin{array}{l}\text { Analysis of an Assemble-to-Order System with Different } \\
\text { Review Periods }\end{array}$ & $\begin{array}{l}\text { A.G. Karaarslan, G.P. Kiesmüller, A.G. de } \\
\text { Kok }\end{array}$ \\
\hline 359 & 2011 & $\begin{array}{l}\text { Interval Availability Analysis of a Two-Echelon, Multi-Item } \\
\text { System }\end{array}$ & $\begin{array}{l}\text { Ahmad Al Hanbali, Matthieu van der } \\
\text { Heijden }\end{array}$ \\
\hline 358 & 2011 & Carbon-Optimal and Carbon-Neutral Supply Chains & $\begin{array}{l}\text { Felipe Caro, Charles J. Corbett, Tarkan } \\
\text { Tan, Rob Zuidwijk }\end{array}$ \\
\hline 357 & 2011 & $\begin{array}{l}\text { Generic Planning and Control of Automated Material } \\
\text { Handling Systems: Practical Requirements Versus Existing } \\
\text { Theory }\end{array}$ & $\begin{array}{l}\text { Sameh Haneyah, Henk Zijm, Marco } \\
\text { Schutten, Peter Schuur }\end{array}$ \\
\hline 356 & 2011 & Last time buy decisions for products sold under warranty & $\begin{array}{l}\text { Matthieu van der Heijden, Bermawi } \\
\text { Iskandar }\end{array}$ \\
\hline 355 & 2011 & $\begin{array}{l}\text { Spatial concentration and location dynamics in logistics: the } \\
\text { case of a Dutch province }\end{array}$ & $\begin{array}{l}\text { Frank P. van den Heuvel, Peter W. de } \\
\text { Langen, Karel H. van Donselaar, Jan C. } \\
\text { Fransoo }\end{array}$ \\
\hline 354 & 2011 & Identification of Employment Concentration Areas & $\begin{array}{l}\text { Frank P. van den Heuvel, Peter W. de } \\
\text { Langen, Karel H. van Donselaar, Jan C. } \\
\text { Fransoo }\end{array}$ \\
\hline 353 & 2011 & $\begin{array}{l}\text { BPMN 2.0 Execution Semantics Formalized as Graph Rewrite } \\
\text { Rules: extended version }\end{array}$ & Pieter van Gorp, Remco Dijkman \\
\hline 352 & 2011 & $\begin{array}{l}\text { Resource pooling and cost allocation among independent } \\
\text { service providers }\end{array}$ & $\begin{array}{l}\text { Frank Karsten, Marco Slikker, Geert-Jan } \\
\text { van Houtum }\end{array}$ \\
\hline 351 & 2011 & A Framework for Business Innovation Directions & E. Lüftenegger, S. Angelov, P. Grefen \\
\hline 350 & 2011 & $\begin{array}{l}\text { The Road to a Business Process Architecture: An Overview of } \\
\text { Approaches and their Use }\end{array}$ & $\begin{array}{l}\text { Remco Dijkman, Irene Vanderfeesten, } \\
\text { Hajo A. Reijers }\end{array}$ \\
\hline 349 & 2011 & $\begin{array}{l}\text { Effect of carbon emission regulations on transport mode } \\
\text { selection under stochastic demand }\end{array}$ & $\begin{array}{l}\text { K.M.R. Hoen, T. Tan, J.C. Fransoo, G.J. } \\
\text { van Houtum }\end{array}$ \\
\hline 348 & 2011 & $\begin{array}{l}\text { An improved MIP-based combinatorial approach for a multi- } \\
\text { skill workforce scheduling problem }\end{array}$ & Murat Firat, Cor Hurkens \\
\hline
\end{tabular}




\begin{tabular}{|c|c|c|c|}
\hline Nr. & Year & Title & Author(s) \\
\hline 347 & 2011 & $\begin{array}{l}\text { An approximate approach for the joint problem of level of } \\
\text { repair analysis and spare parts stocking }\end{array}$ & $\begin{array}{l}\text { R.J.I. Basten, M.C. van der Heijden, } \\
\text { J.M.J. Schutten }\end{array}$ \\
\hline 346 & 2011 & $\begin{array}{l}\text { Joint optimization of level of repair analysis and spare parts } \\
\text { stocks }\end{array}$ & $\begin{array}{l}\text { R.J.I. Basten, M.C. van der Heijden, } \\
\text { J.M.J. Schutten }\end{array}$ \\
\hline 345 & 2011 & Inventory control with manufacturing lead time flexibility & Ton G. de Kok \\
\hline 344 & 2011 & $\begin{array}{l}\text { Analysis of resource pooling games via a new extension of } \\
\text { the Erlang loss function }\end{array}$ & $\begin{array}{l}\text { Frank Karsten, Marco Slikker, Geert-Jan } \\
\text { van Houtum }\end{array}$ \\
\hline 343 & 2011 & Vehicle refueling with limited resources & $\begin{array}{l}\text { Murat Firat, C.A.J. Hurkens, Gerhard J. } \\
\text { Woeginger }\end{array}$ \\
\hline 342 & 2011 & $\begin{array}{l}\text { Optimal Inventory Policies with Non-stationary Supply } \\
\text { Disruptions and Advance Supply Information }\end{array}$ & Bilge Atasoy, Refik Güllü, Tarkan Tan \\
\hline 341 & 2011 & $\begin{array}{l}\text { Redundancy Optimization for Critical Components in High- } \\
\text { Availability Capital Goods }\end{array}$ & $\begin{array}{l}\text { Kurtulus Baris Öner, Alan Scheller-Wolf, } \\
\text { Geert-Jan van Houtum }\end{array}$ \\
\hline 340 & 2011 & $\begin{array}{l}\text { Making Decision Process Knowledge Explicit Using the } \\
\text { Product Data Model }\end{array}$ & $\begin{array}{l}\text { Razvan Petrusel, Irene Vanderfeesten, } \\
\text { Cristina Claudia Dolean, Daniel Mican } \\
\end{array}$ \\
\hline 339 & 2010 & $\begin{array}{l}\text { Analysis of a two-echelon inventory system with two supply } \\
\text { modes }\end{array}$ & Joachim Arts, Gudrun Kiesmüller \\
\hline 338 & 2010 & $\begin{array}{l}\text { Analysis of the dial-a-ride problem of Hunsaker and } \\
\text { Savelsbergh }\end{array}$ & Murat Firat, Gerhard J. Woeginger \\
\hline 335 & 2010 & Attaining stability in multi-skill workforce scheduling & Murat Firat, Cor Hurkens \\
\hline 334 & 2010 & Flexible Heuristics Miner (FHM) & A.J.M.M. Weijters, J.T.S. Ribeiro \\
\hline 333 & 2010 & $\begin{array}{l}\text { An exact approach for relating recovering surgical patient } \\
\text { workload to the master surgical schedule }\end{array}$ & $\begin{array}{l}\text { P.T. Vanberkel, R.J. Boucherie, E.W. } \\
\text { Hans, J.L. Hurink, W.A.M. van Lent, W.H. } \\
\text { van Harten }\end{array}$ \\
\hline 332 & 2010 & Efficiency evaluation for pooling resources in health care & $\begin{array}{l}\text { Peter T. Vanberkel, Richard J. Boucherie, } \\
\text { Erwin W. Hans, Johann L. Hurink, Nelly } \\
\text { Litvak }\end{array}$ \\
\hline 331 & 2010 & $\begin{array}{l}\text { The Effect of Workload Constraints in Mathematical } \\
\text { Programming Models for Production Planning }\end{array}$ & M.M. Jansen, A.G. de Kok, I.J.B.F. Adan \\
\hline 330 & 2010 & $\begin{array}{l}\text { Using pipeline information in a multi-echelon spare parts } \\
\text { inventory system }\end{array}$ & $\begin{array}{l}\text { Christian Howard, Ingrid Reijnen, Johan } \\
\text { Marklund, Tarkan Tan }\end{array}$ \\
\hline 329 & 2010 & $\begin{array}{l}\text { Reducing costs of repairable spare parts supply systems via } \\
\text { dynamic scheduling }\end{array}$ & H.G.H. Tiemessen, G.J. van Houtum \\
\hline 328 & 2010 & $\begin{array}{l}\text { Identification of Employment Concentration and } \\
\text { Specialization Areas: Theory and Application }\end{array}$ & $\begin{array}{l}\text { Frank P. van den Heuvel, Peter W. de } \\
\text { Langen, Karel H. van Donselaar, Jan C. } \\
\text { Fransoo }\end{array}$ \\
\hline 327 & 2010 & A combinatorial approach to multi-skill workforce scheduling & M. Firat, C. Hurkens \\
\hline 326 & 2010 & Stability in multi-skill workforce scheduling & M. Firat, C. Hurkens, A. Laugier \\
\hline 325 & 2010 & $\begin{array}{l}\text { Maintenance spare parts planning and control: A framework } \\
\text { for control and agenda for future research }\end{array}$ & $\begin{array}{l}\text { M.A. Driessen, J.J. Arts, G.J. van } \\
\text { Houtum, W.D. Rustenburg, B. Huisman }\end{array}$ \\
\hline 324 & 2010 & $\begin{array}{l}\text { Near-optimal heuristics to set base stock levels in a two- } \\
\text { echelon distribution network }\end{array}$ & R.J.I. Basten, G.J. van Houtum \\
\hline 323 & 2010 & $\begin{array}{l}\text { Inventory reduction in spare part networks by selective } \\
\text { throughput time reduction }\end{array}$ & $\begin{array}{l}\text { M.C. van der Heijden, E.M. Alvarez, } \\
\text { J.M.J. Schutten }\end{array}$ \\
\hline 322 & 2010 & $\begin{array}{l}\text { The selective use of emergency shipments for service- } \\
\text { contract differentiation }\end{array}$ & $\begin{array}{l}\text { E.M. Alvarez, M.C. van der Heijden, } \\
\text { W.H.M. Zijm }\end{array}$ \\
\hline 321 & 2010 & $\begin{array}{l}\text { Heuristics for Multi-Item Two-Echelon Spare Parts Inventory } \\
\text { Control Problem with Batch Ordering in the Central } \\
\text { Warehouse }\end{array}$ & $\begin{array}{l}\text { Engin Topan, Z. Pelin Bayindir, Tarkan } \\
\text { Tan }\end{array}$ \\
\hline 320 & 2010 & $\begin{array}{l}\text { Preventing or escaping the suppression mechanism: } \\
\text { intervention conditions }\end{array}$ & $\begin{array}{l}\text { Bob Walrave, Kim E. van Oorschot, A. } \\
\text { Georges L. Romme }\end{array}$ \\
\hline 319 & 2010 & $\begin{array}{l}\text { Hospital admission planning to optimize major resources } \\
\text { utilization under uncertainty }\end{array}$ & Nico Dellaert, Jully Jeunet \\
\hline 318 & 2010 & Minimal Protocol Adaptors for Interacting Services & R. Seguel, R. Eshuis, P. Grefen \\
\hline 317 & 2010 & $\begin{array}{l}\text { Teaching Retail Operations in Business and Engineering } \\
\text { Schools }\end{array}$ & $\begin{array}{l}\text { Tom Van Woensel, Marshall L. Fisher, } \\
\text { Jan C. Fransoo }\end{array}$ \\
\hline
\end{tabular}




\begin{tabular}{|c|c|c|c|}
\hline Nr. & Year & Title & Author(s) \\
\hline 316 & 2010 & $\begin{array}{l}\text { Design for Availability: Creating Value for Manufacturers and } \\
\text { Customers }\end{array}$ & $\begin{array}{l}\text { Lydie P.M. Smets, Geert-Jan van } \\
\text { Houtum, Fred Langerak }\end{array}$ \\
\hline 315 & 2010 & $\begin{array}{l}\text { Transforming Process Models: executable rewrite rules } \\
\text { versus a formalized Java program }\end{array}$ & Pieter van Gorp, Rik Eshuis \\
\hline 314 & 2010 & Working paper 314 is no longer available & ---- \\
\hline 313 & 2010 & $\begin{array}{l}\text { A Dynamic Programming Approach to Multi-Objective Time- } \\
\text { Dependent Capacitated Single Vehicle Routing Problems with } \\
\text { Time Windows }\end{array}$ & S. Dabia, T. van Woensel, A.G. de Kok \\
\hline 312 & 2010 & $\begin{array}{l}\text { Tales of a So(u)rcerer: Optimal Sourcing Decisions Under } \\
\text { Alternative Capacitated Suppliers and General Cost } \\
\text { Structures }\end{array}$ & Osman Alp, Tarkan Tan \\
\hline 311 & 2010 & $\begin{array}{l}\text { In-store replenishment procedures for perishable inventory } \\
\text { in a retail environment with handling costs and storage } \\
\text { constraints }\end{array}$ & R.A.C.M. Broekmeulen, C.H.M. Bakx \\
\hline 310 & 2010 & $\begin{array}{l}\text { The state of the art of innovation-driven business models in } \\
\text { the financial services industry }\end{array}$ & $\begin{array}{l}\text { E. Lüftenegger, S. Angelov, E. van der } \\
\text { Linden, P. Grefen }\end{array}$ \\
\hline 309 & 2010 & $\begin{array}{l}\text { Design of Complex Architectures Using a Three Dimension } \\
\text { Approach: the CrossWork Case }\end{array}$ & R. Seguel, P. Grefen, R. Eshuis \\
\hline 308 & 2010 & $\begin{array}{l}\text { Effect of carbon emission regulations on transport mode } \\
\text { selection in supply chains }\end{array}$ & $\begin{array}{l}\text { K.M.R. Hoen, T. Tan, J.C. Fransoo, G.J. } \\
\text { van Houtum }\end{array}$ \\
\hline 307 & 2010 & $\begin{array}{l}\text { Interaction between intelligent agent strategies for real-time } \\
\text { transportation planning }\end{array}$ & $\begin{array}{l}\text { Martijn Mes, Matthieu van der Heijden, } \\
\text { Peter Schuur }\end{array}$ \\
\hline 306 & 2010 & Internal Slackening Scoring Methods & $\begin{array}{l}\text { Marco Slikker, Peter Borm, René van } \\
\text { den Brink }\end{array}$ \\
\hline 305 & 2010 & $\begin{array}{l}\text { Vehicle Routing with Traffic Congestion and Drivers' Driving } \\
\text { and Working Rules }\end{array}$ & $\begin{array}{l}\text { A.L. Kok, E.W. Hans, J.M.J. Schutten, } \\
\text { W.H.M. Zijm }\end{array}$ \\
\hline 304 & 2010 & Practical extensions to the level of repair analysis & $\begin{array}{l}\text { R.J.I. Basten, M.C. van der Heijden, } \\
\text { J.M.J. Schutten }\end{array}$ \\
\hline 303 & 2010 & $\begin{array}{l}\text { Ocean Container Transport: An Underestimated and Critical } \\
\text { Link in Global Supply Chain Performance }\end{array}$ & Jan C. Fransoo, Chung-Yee Lee \\
\hline 302 & 2010 & $\begin{array}{l}\text { Capacity reservation and utilization for a manufacturer with } \\
\text { uncertain capacity and demand }\end{array}$ & Y. Boulaksil; J.C. Fransoo; T. Tan \\
\hline 300 & 2009 & Spare parts inventory pooling games & $\begin{array}{l}\text { F.J.P. Karsten; M. Slikker; G.J. van } \\
\text { Houtum }\end{array}$ \\
\hline 299 & 2009 & $\begin{array}{l}\text { Capacity flexibility allocation in an outsourced supply chain } \\
\text { with reservation }\end{array}$ & Y. Boulaksil, M. Grunow, J.C. Fransoo \\
\hline 298 & 2010 & $\begin{array}{l}\text { An optimal approach for the joint problem of level of repair } \\
\text { analysis and spare parts stocking }\end{array}$ & $\begin{array}{l}\text { R.J.I. Basten, M.C. van der Heijden, } \\
\text { J.M.J. Schutten }\end{array}$ \\
\hline 297 & 2009 & $\begin{array}{l}\text { Responding to the Lehman Wave: Sales Forecasting and } \\
\text { Supply Management during the Credit Crisis }\end{array}$ & $\begin{array}{l}\text { Robert Peels, Maximiliano Udenio, Jan } \\
\text { C. Fransoo, Marcel Wolfs, Tom Hendrikx }\end{array}$ \\
\hline 296 & 2009 & $\begin{array}{l}\text { An exact approach for relating recovering surgical patient } \\
\text { workload to the master surgical schedule }\end{array}$ & $\begin{array}{l}\text { Peter T. Vanberkel, Richard J. Boucherie, } \\
\text { Erwin W. Hans, Johann L. Hurink, } \\
\text { Wineke A.M. van Lent, Wim H. van } \\
\text { Harten }\end{array}$ \\
\hline 295 & 2009 & $\begin{array}{l}\text { An iterative method for the simultaneous optimization of } \\
\text { repair decisions and spare parts stocks }\end{array}$ & $\begin{array}{l}\text { R.J.I. Basten, M.C. van der Heijden, } \\
\text { J.M.J. Schutten }\end{array}$ \\
\hline 294 & 2009 & Fujaba hits the Wall(-e) & $\begin{array}{l}\text { Pieter van Gorp, Ruben Jubeh, Bernhard } \\
\text { Grusie, Anne Keller }\end{array}$ \\
\hline 293 & 2009 & $\begin{array}{l}\text { Implementation of a Healthcare Process in Four Different } \\
\text { Workflow Systems }\end{array}$ & $\begin{array}{l}\text { R.S. Mans, W.M.P. van der Aalst, N.C. } \\
\text { Russell, P.J.M. Bakker }\end{array}$ \\
\hline 292 & 2009 & $\begin{array}{l}\text { Business Process Model Repositories - Framework and } \\
\text { Survey }\end{array}$ & $\begin{array}{l}\text { Zhiqiang Yan, Remco Dijkman, Paul } \\
\text { Grefen }\end{array}$ \\
\hline 291 & 2009 & $\begin{array}{l}\text { Efficient Optimization of the Dual-Index Policy Using Markov } \\
\text { Chains }\end{array}$ & $\begin{array}{l}\text { Joachim Arts, Marcel van Vuuren, } \\
\text { Gudrun Kiesmuller }\end{array}$ \\
\hline 290 & 2009 & Hierarchical Knowledge-Gradient for Sequential Sampling & $\begin{array}{l}\text { Martijn R.K. Mes; Warren B. Powell; } \\
\text { Peter I. Frazier }\end{array}$ \\
\hline
\end{tabular}




\begin{tabular}{|c|c|c|c|}
\hline Nr. & Year & Title & Author(s) \\
\hline 289 & 2009 & $\begin{array}{l}\text { Analyzing combined vehicle routing and break scheduling } \\
\text { from a distributed decision making perspective }\end{array}$ & $\begin{array}{l}\text { C.M. Meyer; A.L. Kok; H. Kopfer; J.M.J. } \\
\text { Schutten }\end{array}$ \\
\hline 288 & 2010 & Lead time anticipation in Supply Chain Operations Planning & $\begin{array}{l}\text { Michiel Jansen; Ton G. de Kok; Jan C. } \\
\text { Fransoo }\end{array}$ \\
\hline 287 & 2009 & Inventory Models with Lateral Transshipments: A Review & $\begin{array}{l}\text { Colin Paterson; Gudrun Kiesmuller; } \\
\text { Ruud Teunter; Kevin Glazebrook }\end{array}$ \\
\hline 286 & 2009 & Efficiency evaluation for pooling resources in health care & $\begin{array}{l}\text { P.T. Vanberkel; R.J. Boucherie; E.W. } \\
\text { Hans; J.L. Hurink; N. Litvak }\end{array}$ \\
\hline 285 & 2009 & $\begin{array}{l}\text { A Survey of Health Care Models that Encompass Multiple } \\
\text { Departments }\end{array}$ & $\begin{array}{l}\text { P.T. Vanberkel; R.J. Boucherie; E.W. } \\
\text { Hans; J.L. Hurink; N. Litvak }\end{array}$ \\
\hline 284 & 2009 & Supporting Process Control in Business Collaborations & $\begin{array}{l}\text { S. Angelov; K. Vidyasankar; J. Vonk; P. } \\
\text { Grefen }\end{array}$ \\
\hline 283 & 2009 & Inventory Control with Partial Batch Ordering & O. Alp; W.T. Huh; T. Tan \\
\hline 282 & 2009 & $\begin{array}{l}\text { Translating Safe Petri Nets to Statecharts in a Structure- } \\
\text { Preserving Way }\end{array}$ & R. Eshuis \\
\hline 281 & 2009 & The link between product data model and process model & J.J.C.L. Vogelaar; H.A. Reijers \\
\hline 280 & 2009 & $\begin{array}{l}\text { Inventory planning for spare parts networks with delivery } \\
\text { time requirements }\end{array}$ & I.C. Reijnen; T. Tan; G.J. van Houtum \\
\hline 279 & 2009 & Co-Evolution of Demand and Supply under Competition & B. Vermeulen; A.G. de Kok \\
\hline 278 & 2010 & $\begin{array}{l}\text { Toward Meso-level Product-Market Network Indices for } \\
\text { Strategic Product Selection and (Re)Design Guidelines over } \\
\text { the Product Life-Cycle }\end{array}$ & B. Vermeulen, A.G. de Kok \\
\hline 277 & 2009 & An Efficient Method to Construct Minimal Protocol Adaptors & R. Seguel, R. Eshuis, P. Grefen \\
\hline 276 & 2009 & Coordinating Supply Chains: a Bilevel Programming Approach & Ton G. de Kok, Gabriella Muratore \\
\hline 275 & 2009 & $\begin{array}{l}\text { Inventory redistribution for fashion products under demand } \\
\text { parameter update }\end{array}$ & G.P. Kiesmuller, S. Minner \\
\hline 274 & 2009 & $\begin{array}{l}\text { Comparing Markov chains: Combining aggregation and } \\
\text { precedence relations applied to sets of states }\end{array}$ & A. Busic, I.M.H. Vliegen, A. Scheller-Wolf \\
\hline 273 & 2009 & $\begin{array}{l}\text { Separate tools or tool kits: an exploratory study of engineers' } \\
\text { preferences }\end{array}$ & $\begin{array}{l}\text { I.M.H. Vliegen, P.A.M. Kleingeld, G.J. van } \\
\text { Houtum }\end{array}$ \\
\hline 272 & 2009 & $\begin{array}{l}\text { An Exact Solution Procedure for Multi-Item Two-Echelon } \\
\text { Spare Parts Inventory Control Problem with Batch Ordering }\end{array}$ & \\
\hline 271 & 2009 & $\begin{array}{l}\text { Distributed Decision Making in Combined Vehicle Routing } \\
\text { and Break Scheduling }\end{array}$ & $\begin{array}{l}\text { C.M. Meyer, H. Kopfer, A.L. Kok, M. } \\
\text { Schutten }\end{array}$ \\
\hline 270 & 2009 & $\begin{array}{l}\text { Dynamic Programming Algorithm for the Vehicle Routing } \\
\text { Problem with Time Windows and EC Social Legislation }\end{array}$ & $\begin{array}{l}\text { A.L. Kok, C.M. Meyer, H. Kopfer, J.M.J. } \\
\text { Schutten }\end{array}$ \\
\hline 269 & 2009 & Similarity of Business Process Models: Metics and Evaluation & $\begin{array}{l}\text { Remco Dijkman, Marlon Dumas, } \\
\text { Boudewijn van Dongen, Reina Kaarik, } \\
\text { Jan Mendling }\end{array}$ \\
\hline 267 & 2009 & $\begin{array}{l}\text { Vehicle routing under time-dependent travel times: the } \\
\text { impact of congestion avoidance }\end{array}$ & A.L. Kok, E.W. Hans, J.M.J. Schutten \\
\hline 266 & 2009 & $\begin{array}{l}\text { Restricted dynamic programming: a flexible framework for } \\
\text { solving realistic VRPs }\end{array}$ & $\begin{array}{l}\text { J. Gromicho; J.J. van Hoorn; A.L. Kok; } \\
\text { J.M.J. Schutten; }\end{array}$ \\
\hline
\end{tabular}

Working Papers published before 2009 see: http://beta.ieis.tue.nl 